\title{
CLOSING THE GAP: AN ASSESSMENT OF MIXED-METHOD DATA COLLECTION TECHNIQUES IN POST OCCUPANCY EVALUATION
}

\author{
By \\ Thomas Moore \\ BAH Environmental Studies \& Physical Geography \\ Queen's University, 2012
}

\author{
A Major Research Project \\ Presented to Ryerson University \\ in partial fulfillment of the requirements of \\ Master of Building Science \\ in the program of \\ Building Science \\ Toronto, Ontario, Canada, 2017 \\ (C) Thomas Moore, 2017
}




\section{Author's Declaration}

I hereby declare that I am the sole author of this MRP. This is a true copy of the MRP, including any required final revisions.

I authorize Ryerson University to lend this MRP to other institutions or individuals for the purpose of scholarly research,

I further authorize Ryerson University to reproduce this MRP by photocopying or by other means, in total or in part, at the request of other institutions or individuals for the purpose of scholarly research.

I understand that my MRP may be made electronically available to the public. 


\title{
Closing The Gap: An Assessment of Mixed-method Data Collection Techniques in Post Occupancy Evaluation
}

Thomas Moore, MBSc, 2017

Master of Building Science Ryerson University

Toronto, Ontario, Canada

\begin{abstract}
Demand for energy efficient buildings has supported an increase in predictive performance modeling. However, operation of buildings can often be different than predictive models, creating a collective performance discrepancy referred to as the "performance gap". Post Occupancy Evaluation (POE) can close this gap by evaluating performance, and contrasting operational data to design intention. This POE demonstrates an identifiable performance gap in a practical case study on one high-performance building. Findings suggest the case building is not meeting anticipated energy consumption with a higher than predicted energy use intensity (EUI). Additional findings indicate a leaky building enclosure, significant thermal bridging, unrealistic simulation assumptions, acoustic disturbances, and occupant thermal comfort satisfaction. This POE demonstrates that mixed-method data collection provides more information than singular analyses when attempting to identify a performance gap. It is demonstrated that qualitative data collection techniques explain quantitative findings in analysis, informing understanding of performance gap causation.
\end{abstract}




\section{Acknowledgments}

I would like to extend gratitude to Dr. Mark Gorgolewski for his support developing this research project. Dr. Gorgolewski is generous with his time and knowledge; he consistently works to enable students and encourages them to always perform at their best.

I would like to extend gratitude to Dr. Russell Richman for his professional contributions to this project, and as a second reader of this document.

I would like to thank Luuk Postuma and Michael Lesage of Evergreen for granting us access to the Evergreen site and sharing their intimate understanding of Building 12.

I would like to extend gratitude to Greg Labbe and Shervin Akhavi of Blue Green Consulting Group for their professional support and guidance through the air leakage evaluation and duct leakage testing.

I would like to thank German Vaisman for introducing me to Building Science while building a cabin at Whole Village.

Finally, I would like to thank Robyn for her friendship, support and love. If there is a place we belong, we should canoe there.

\section{Memorandum of Understanding}

This study was conducted by Ryerson University in collaboration with Evergreen. The impetus of this study is grounded in an ongoing relationship and mutual agreement between Evergreen and Ryerson University's Department of Architectural Science. This agreement was formalized in a Memorandum of Understanding (MOU) signed by both parties. The MOU states that a Post Occupancy Evaluation will be conducted on Building 12 at Evergreen Brickworks with results compared to design expectations. The following report is the result of this MOU. 


\section{Table of Contents}

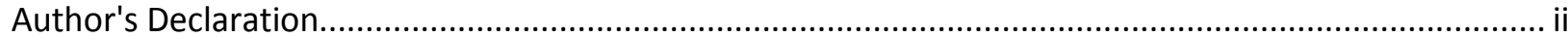

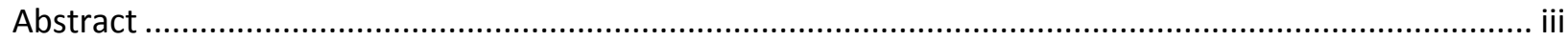

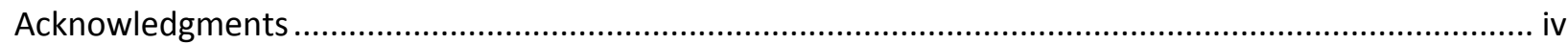

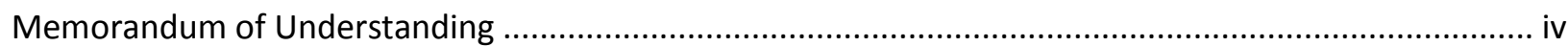

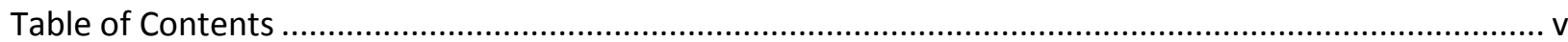

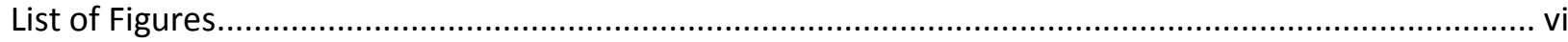

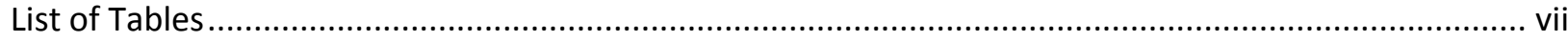

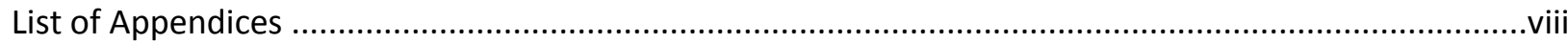

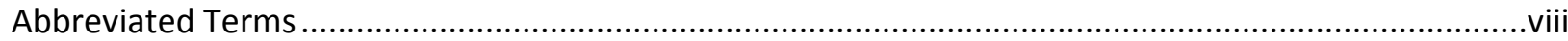

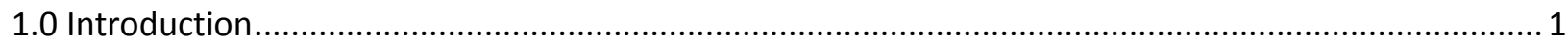

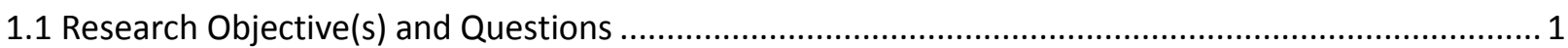

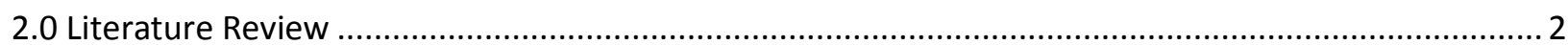

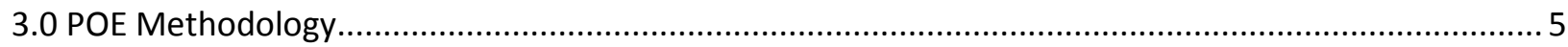

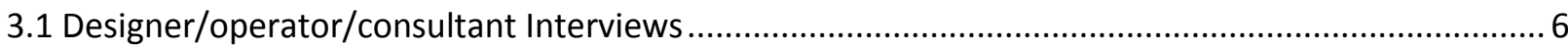

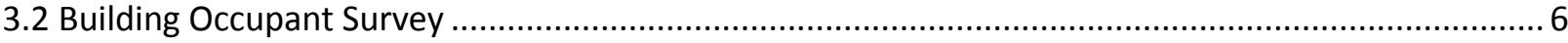

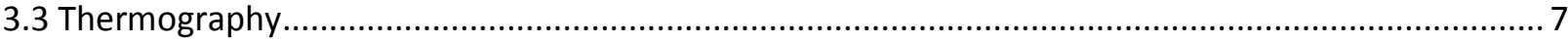

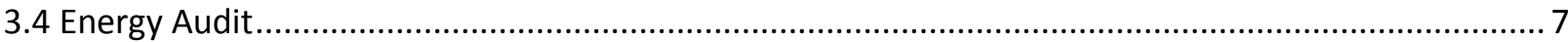

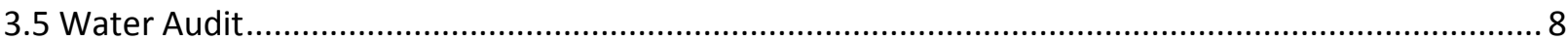

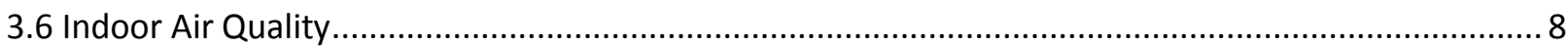

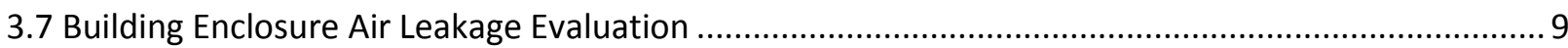

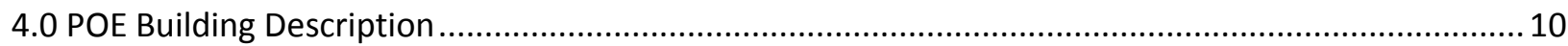

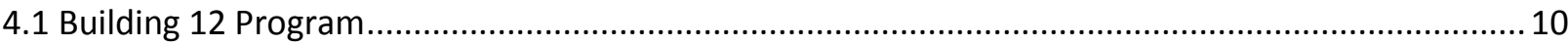

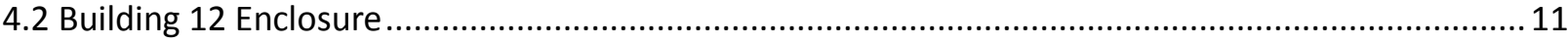

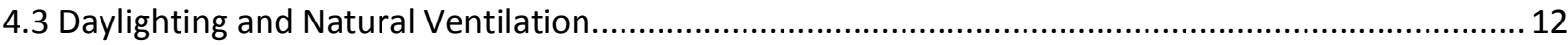

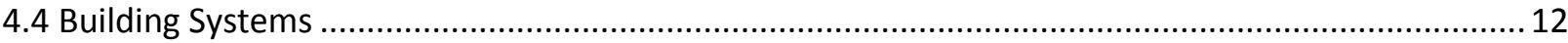

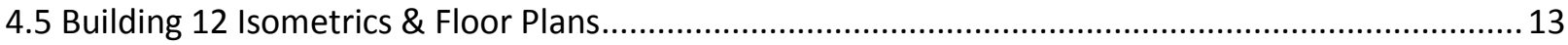

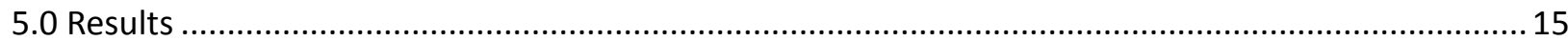

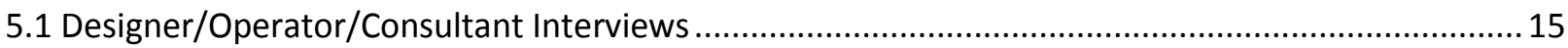

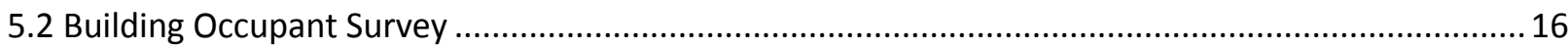

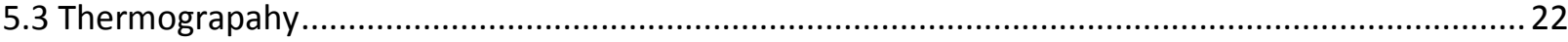

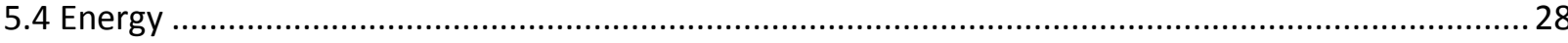

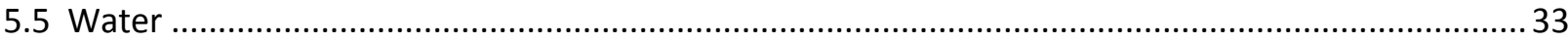


5.6 Indoor Air Quality \& Indoor Environmental Quality ................................................................ 34

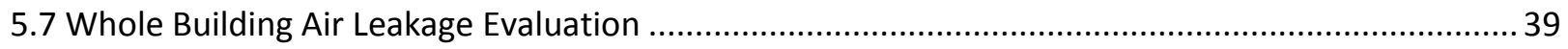

5.7.1 Test Stage 1: Whole Building Depressurization .......................................................................... 41

5.7.2 Test Stage 2: Whole Building Pressurization......................................................................... 42

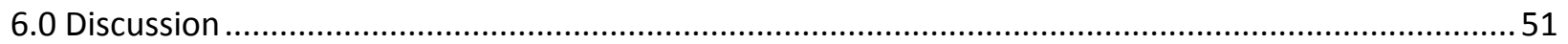

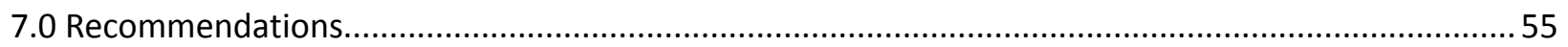

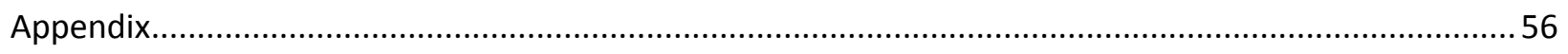

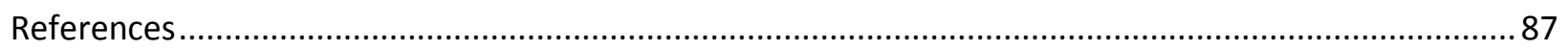

\section{List of Figures}

Figure 1: Conceptualization of the POE information feedback as per (CIBSE, 2001) .............................. 3

Figure 2: South-West and North-East Isometric Projections of Building 12. Drawing provided by Diamond

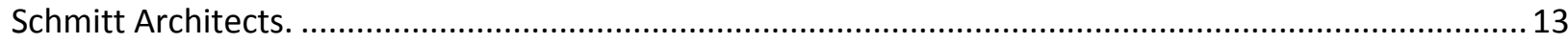

Figure 3: Building 12 floor plans ground to $6^{\text {th }}$ floor. Drawing provided by Diamond Schmitt Architects. 14

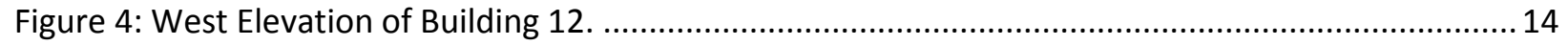

Figure 5. Investigated aspects of workplace satisfaction..................................................................... 18

Figure 6. Occupant disturbance from environmental acoustic sources. .................................................. 18

Figure 7. Occupant thermal comfort in summertime months............................................................. 19

Figure 8. Occupant satisfaction with summertime environmental air quality. ...................................... 19

Figure 10. Occupant satisfaction with summertime environmental air quality. ...................................20

Figure 11. Workspace temperature and occupant productivity.......................................................... 20

Figure 12. Occupant satisfaction with workspace temperature.......................................................... 21

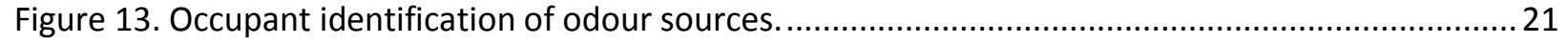

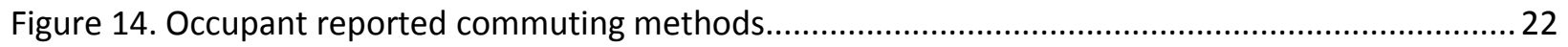

Figure 15. Thermographic images of point thermal bridging through the shading system. .................... 23

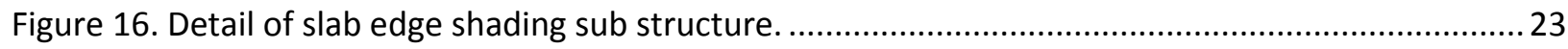

Figure 17. Thermographic images of point and linear thermal bridging in elevation details................... 24

Figure 18. Thermographic images of point thermal bridging on East elevation.....................................2 24

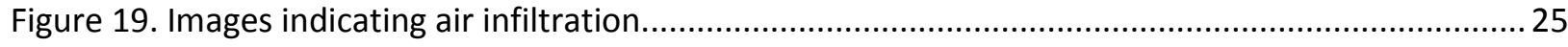

Figure 20. Thermographic images of window, door and openings and window to wall joints. ............... 26

Figure 21. Thermographic images of increased temperature in the rooftop damper houses. ................ 27

Figure 22. Internal and external spot measurements indicating, ambient temperature outside.............27

Figure 23. Thermographic images of various roof penetrations with thermal anomalies. ......................28 
Figure 24. Predicted energy consumption by end use. 29

Figure 25. Predicted energy consumption compared with actual energy consumption by annum........... 32

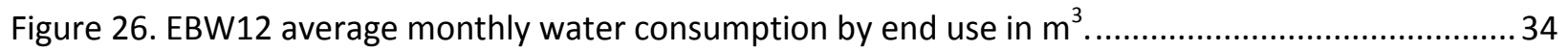

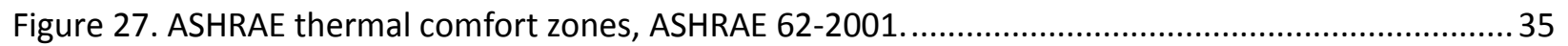

Figure 28. (a) 20-minute $\mathrm{CO}$ average at 6 locations, (b) 20-minute $\mathrm{CO}_{2}$ average at six locations. ............ 36

Figure 29. (a) 20-minute VOC average at six locations, (b) 20-minute temperature \& relative humidity at

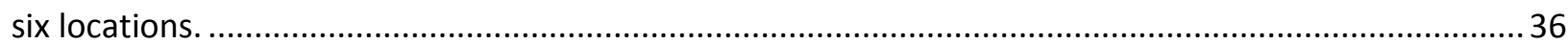

Figure 30. 10-day indoor air quality data collection, Evergreen Office. .................................................. 37

Figure $31 . \mathrm{CO}_{2}, \mathrm{~T}^{\circ} \mathrm{C}$, \% RH collected over 5 hour event period. .......................................................... 38

Figure 32. VOC (PPB) and dust $\left(\mathrm{mg} / \mathrm{m}^{3}\right)$ collected over 5 -hour event period........................................ 38

Figure 33: Simulated indoor air conditions, output from WUFI ${ }^{\circledR}$ Plus................................................. 39

Figure 34. Summary of calculated results from pressurization test. ......................................................... 41

Figure 35. Summary of calculated results from depressurization test. ..................................................... 42

Figure 36. Comparative Air Leakage Rates, EBW12 versus industry standards................................... 43

Figure 37. Linear regression of averaged data from Table 11; trendline indicating air flow rate at ambient

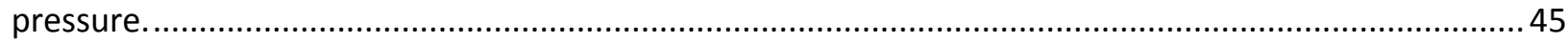

Figure 39. Images of deteriorated exterior brick indicating areas of potential air leakage...................... 48

Figure 36.Images of deteriorated exterior brick indicating areas of potential air leakage....................... 49

Figure 40. Images of interior brick indicating areas of potential air leakage.........................................50

Figure 41. Conceptual understanding of the EBW12 operational performance. ....................................53

Figure 42. Conceptual understanding of POE framework used in this study, with the interalationship between Data Collection (DC) techniques. Stakeholder interviews (DC 1), building occupant survey (DC 2), energy audit (DC 3), whole building air leakage evaluation and duct leakage to outside testing (DC 4), Infrared thermography (DC 5), IAQ (DC 6), and water audit (DC 7) .................................................. 54

\section{List of Tables}

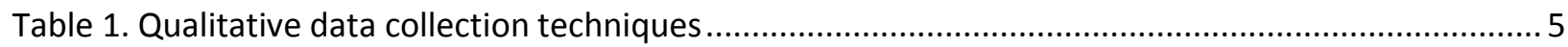

Table 2. Quantitative data collection techniques ...................................................................... 5

Table 3. EBW12 critical building dimensions taken from architectural drawings, various building metrics in Table 3 have been used to calculate the normalized results in this study.......................................... 11

Table 4. Building Occupant Survey Results Summary. ......................................................................... 17

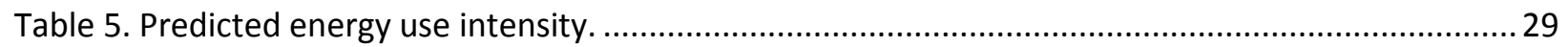

Table 6. Summarized annual natural gas and electricity consumption. ................................................ 31 
Table 7. Water use intensity $\mathrm{m}^{3} / \mathrm{m}^{2} /$ year.

Table 8. Summary of test results indicating the number of litres of air moving through each square meter of the building enclosure every second at pressure. ................................................................ 40

Table $9(a, b)$. Summary of calculated results from pressurization test. .................................................... 41

Table $10(a, b)$. Summary of calculated results from depressurization test. ........................................... 42

Table 11. Summary of test results indicating the sum of all cracks, holes, etc., into one equivalent sized opening in square meters.

Table 12. Results of the solar chimney pressurization test, indicating the amount of air moving through the mechanical dampering system in the solar chimneys.

Table 13. Summary of test results indicating the number of litres of air moving through one solar chimney roof dampering system with a surface area of $5.94 \mathrm{~m}^{2}$; data normalized to surface area $\mathrm{L} / \mathrm{s} / \mathrm{m}^{2}$.

\section{List of Appendices}

Appendix A: Building Enclosure Air Leakage Results......................................................................... 56

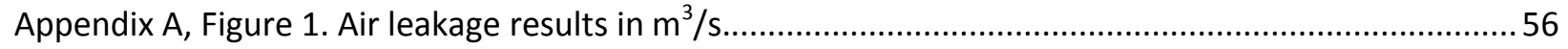

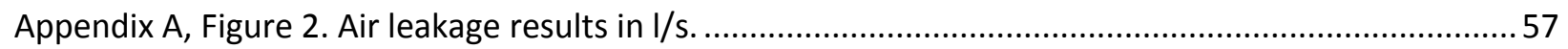

Appendix A, Table 1. Commonly used alternative metrics. Results calculated from test stage $1 \& 2$......58

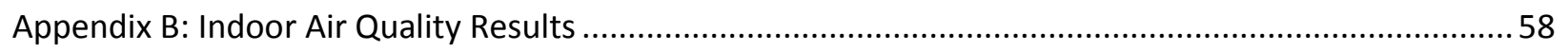

Appendix B, Figure 2. Indoor Air Quality Spot measurement results taken from the BMO Atrium. ........59

Appendix B, Figure 3. Indoor Air Quality Spot measurement results taken from the $2^{\text {nd }}$ floor................59

Appendix Figure 6. Indoor Air Quality Spot measurement results taken from the $3^{\text {rd }}$ floor Evergreen

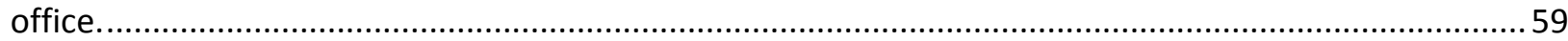

Appendix B, Figure 4. Indoor Air Quality Spot measurement results taken from the $4^{\text {th }}$ floor corridor. .. 60

Appendix B, Figure 5. Indoor Air Quality spot measurement results taken from the $5^{\text {th }}$ floor corridor....60

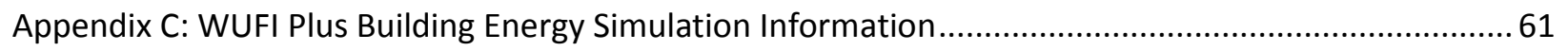

Appendix C, Figure 1. Toronto Climate File used in WUFI Plus dynamic modeling ................................61

Appendix C, Figure 2. Shading substructure thermal bridge geometry with monitoring positions

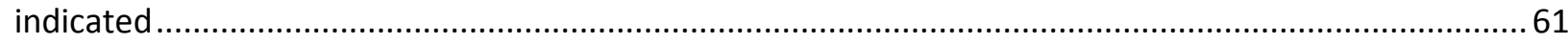

Appendix C, Figure 3. EBW12 3-dimensional input geometry for WUFI Passive....................................62

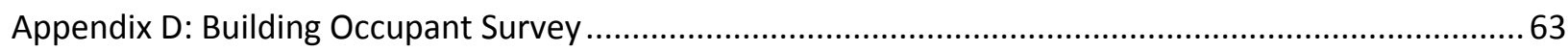

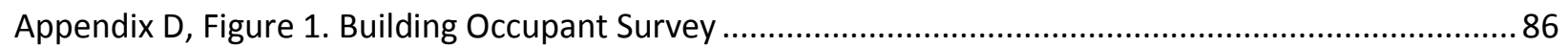

\section{Abbreviated Terms}

BPE: Building Performance Evaluation 
BOMA: Building Owners and Managers Association

CIBSE: Chartered Institute of Building Service Engineers (CIBSE),

CMU: Concrete Masonry Unit

EBW12: Evergreen Brickworks Building 12

EUI: Energy Use Intensity

IAQ: Indoor Air Quality

IEQ: Indoor Environmental Quality

KPI: Key Performance Indicators

LEED: Leadership in Energy and Environmental Design

PROBE: Post Occupancy Review of Buildings and their Engineering

POE: Post Occupancy Evaluation

XPS: Extruded Polystyrene Insulation

DHW: Domestic Hot Water 


\subsection{Introduction}

Recognition that the anthropogenic release of carbon and greenhouse gases directly impacts the global climate has presented the need for emissions reductions. The built environment, contributing approximately $30 \%$ to global annual carbon emissions and $40 \%$ to global energy consumption, has been identified as an area for immediate energy and resource efficient design solutions. Increased demand for energy and resource efficient buildings has supported a trend for predictive performance modeling, while operational as-built performance is often dissimilar. Collective performance discrepancies between design intention and operational performance is often referred to as the "performance gap." The performance Gap has several causes which can lead building operation away from its original performance and environmental goals. POE offers the opportunity to close this gap by evaluating and comparing operational performance to design intention, and supply designers with feedback for the future. POE attempts to address four overarching questions (Presier \& Vischer, 2005): what is the operational performance of the building? is the building performing as originally intended? is there a possibility for improving operational performance? how can the design of future buildings be improved through information feedback? In this study the current operational performance of Evergreen Brickworks Building 12 (EBW12) is examined using various data collection techniques with results analyzed and compared to the design intention. This paper attempts to determine the performance gap and the interrelationship between mixed-method data collection techniques as a case study. EBW12 was selected as the study building for this POE as it is the showcase building of the Evergreen Brickworks site. EBW12 was designed as a LEED Platinum building and serves multiple functions for a large and mixed occupancy; additionally, EBW12 serves the adjacent Building 14 in function as well as utility provision.

\subsection{Research Objective(s) and Questions}

The primary research objective of this study is to quantify and qualify the performance gap, or collective difference between design intention, predicted performance, and current operational performance in the study building using a variety of mixed-method data collection techniques. Key Performance Indicators (KPIs) acquired from mixed-method data collection will be used to determine the operational

performance of the selected building. These KPI are to be benchmarked against design intention to assess the performance gap. The secondary research objective is to assess the interconnection of each data collection technique employed in the POE, suggesting a practical approach for the contextual understanding of the performance gap using EBW12 as a case study example. To address these study objectives and the identified research gap, two research questions are put forth. 
The research questions for this study are the following:

1) What is the current operational performance of the study building and is there an identifiable performance gap?

2) What is the interconnection between data collection techniques and how can they be used in combination to assess building performance?

\subsection{Literature Review}

POE is a subset procedure of Building Performance Evaluation (BPE) used during the building's operational and occupied life to assess various aspects of performance. POE has emerged from within the BPE academic stream as an area of research that evaluates multiple aspects of building performance, suggesting a path forward for improvement through information loops. KPI are produced through POE that describe various aspects of building performance such as, energy consumption, water consumption, air leakage, indoor air quality, indoor environmental quality, occupant satisfaction, acoustic satisfaction, etc. KPI can be used effectively to make comparisons of predicted performance and design targets, as well as to other buildings (Preiser \& Vischer, 2005). Kesik (2015) states that, KPI in POE are analogous to vital signs used in medicine to assess static state and future health of patients.

POE is used to establish various building performance metrics, with the overall intention of evaluating performance and developing a positive feedback of information to design teams, constructors, owners, and other stakeholders. However, the performance evaluation metrics and data collection techniques used in POE frameworks are inconsistent and variable depending on the resources available, individual researchers, and the context of the building. Furthermore, there appears to be a tendency in POE to focus on one quantitative performance metric without qualitative background, this is shown by the increasing number of singular studies on energy performance, predictive modelling, indoor air quality, indoor environmental quality, and occupancy behaviour. The collection of POE studies assessed in this literature review indicates a trend towards more detailed singular studies of building performance, for improved simulation techniques. This research is effective for examining one aspect of building performance at greater detail and improving predictive modeling, however it does not gather information on the building as a complete interrelated system, or provide comprehensive information on the performance gap.

A building can be conceptualized as a complex system designed for the purpose of creating and sustaining an indoor environment (Allen \& lano, 2004). This requires the implementation of technological solutions 
and the integration of appropriate human occupancy and operation. In practice, design, construction and building operation techniques can create substantial differences between predicted and operational performance (Newsham, 2009). This difference has been termed the performance gap, as described by Preiser and Vischer (2005). Studies quantifying singular aspects of building performance with KPI such as energy use intensity, while simultaneously benchmarking against comparative buildings, can be problematic as the selected building's design, occupancy and operation may have changed considerably since completion (Preiser \& Vischer, 2005). It follows, that qualitative and quantitative data collection needs to be adopted to produce multiple KPI to more comprehensively and accurately understand the performance gap, and fulfill the information feedback required of POE. The feedback loop required of POE is demonstrated by the Chartered Institute of Building Service Engineers (CIBSE), shown below in Figure 1 (CIBSE, 2001).

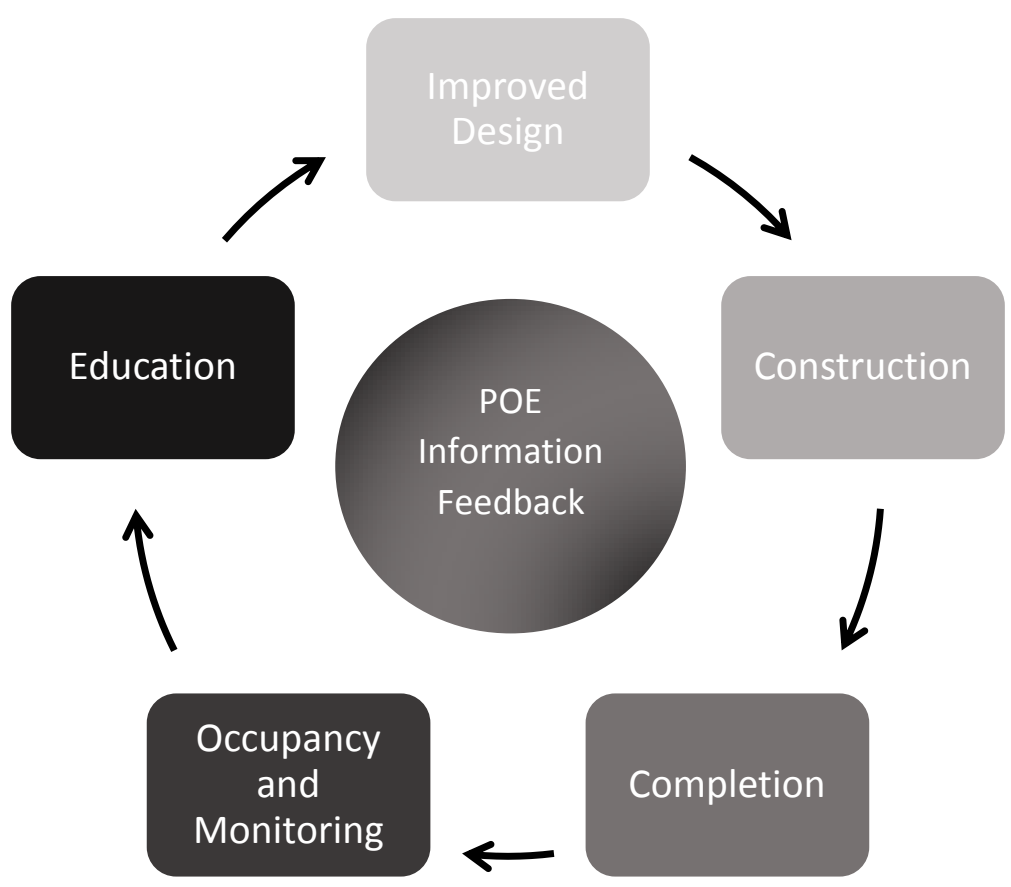

Figure 1: Conceptualization of the POE information feedback as per (CIBSE, 2001)

In addition to the trend of singular POE studies there appears to be a general consensus within the POE literature, suggesting that high performance buildings often do not operate as predicted. Several reasons are typically cited as the cause of the performance gap including, modeling inaccuracies, occupancy patterns, construction implementation, and building operation (Menezes, 2012). This trend is concerning as the construction and operation of buildings is responsible for a substantial amount of global greenhouse gas emissions. Furthermore, many high performance buildings have been presented as a solution or step towards improved human well-being, in addition to a more sustainable global emissions 
scenario (Malory-Hill, Preiser \& Watson, 2012). The Commercial Buildings Energy Consumption Survey estimates that buildings consume $40 \%$ of national primary energy in countries with mature building stocks (CBECS, 2016). This is cause for concern when studies such as PROBE: Post Occupancy Review of Buildings and their Engineering determined that actual energy consumption in the twenty-three selected buildings was up to twice as much as predicted (CIBSE, 2001). Such findings are supported by Newsham (2009), indicating that the predicted performance of USGBC designated LEED buildings are often not met in operating condition. The body of literature demonstrates that many modern buildings do not operate as designed or predicted. The Energy Star program (Energy Star, 2012a) takes the position that improving operation of buildings can provide return to owners in the form of reduced cost and increased leasing rates. As such, there may be a growing realization that POE can provide value to designers and owners. However, while energy auditing and building commissioning are becoming more common, they are still not often undertaken or mandated. Furthermore, few studies have completed comprehensive examinations of building performance that include multiple data collection techniques, performance factors, or variable indicators (Birt \& Newsham, 2009). As such, there appears to be a research gap and research need to explore comprehensive data collection techniques in POE to evaluate the performance gap in a holistic sense as a building system and design issue.

Industry groups such as the Building Owners and Managers Association (BOMA, 2014) and the U.S. Green Building Council (USGBC, 2015) envision that performance expectations for buildings and energy code compliance will be higher in the future. Additionally, there may be demand for increased or mandatory reporting for municipal building stock benchmarking. As such, moving away from predictive design and towards a commissioning structure based on evidence driven POE may be the future for high performance buildings. Comprehensive evaluation of building performance indicators will be required if this comes to fruition. Positive feedback of KPI information based on an evidence-driven POE framework would then be needed to enable designers to meet increased performance requirements, while realizing more representative inputs for predictive models (Menezes et al., 2012). Consistent use of comprehensive POEs could improve the ability to compare and contrast performance within the greater building stock; allowing benchmarking and commissioning to occur more readily, while supporting a positive feedback loop of information (Preiser \& Vischer, 2005). In order to increase the number of comprehensive POE studies, the interrelationship of data collection techniques and KPI combinations should be assessed. 


\subsection{POE Methodology}

Results from the selected study building are evaluated as a case study and compared to industry standards, while the lessons learned from undertaking mixed-method data collection on building performance are applied more generally. To fulfil the intention of POE and stimulate a positive feedback loop of information, findings from this research are to be fed back to project designers, operators, managers, owners, and consultants of the selected study building in order to improve current operation and positively influence future design processes. The methodology of the study was designed to appropriately address the research objectives and research questions by pursuing multiple data collection techniques. Similar to Gorgolewski et al. (2015), a mixed-method qualitative and quantitative research methodology was developed. Both qualitative and quantitative data collection techniques were undertaken in order to develop a summary of operational performance in the selected building. The data collection techniques pursued in this study are described in Tables 1 and 2.

\section{Qualitative data collection techniques:}

1. Designer/operator/consultant Interviews

2. Building Occupant Survey

3. Thermographic Imaging

Table 1. Qualitative data collection techniques

\section{Quantitative data collection techniques}

1. Energy Consumption Audit

2. Water Consumption Audit

3. Indoor Air Quality Testing \& IEQ Spot Measurements

4. Whole Building Air Leakage Evaluation \& Solar Chimney Duct Leakage to Outside

\section{Table 2. Quantitative data collection techniques}

This mixed-method data collection strategy was undertaken in order to provide comprehensive information on the operational performance of the study building. KPI were the result of each data collection technique. Connectivity between data collection techniques was assessed for the development of an information model, as shown in the discussion section. In consulting this model, an effective combination of data collection techniques can be developed to assess the cause of building performance deficiency. This methodology was developed to allow the results of any individual data collection technique to better inform the overarching results of a POE. In practice, and when combined, qualitative data collection techniques bolster the understanding of quantitative results to provide a more complete picture of building design intention and performance characteristics. The results of this research and the 
seven data collection techniques that were assessed are presented in the remaining body of this report. Methodologies for each data collection technique are described below.

\subsection{Designer/operator/consultant Interviews}

Individuals related to the design, implementation and operation of EBW12 were invited to participate in semi-structured 30-minute interviews. Each interview was designed with questions oriented to the project role of the interviewee. Four interview invitations were accepted and a 30-minute interview occurred with a Principal Architectural Designer, a LEED Consultant, an Energy Consultant/Modeller, and a Building Operator. The goal of these interviews was to collect qualitative information from primary sources on the intent of the original design and building performance. Information collected on the original design intention and building performance was crucial as this acted as a qualitative for intended performance; thereby, gaining a concept of the performance gap. A secondary goal was to ask for direct information on the design process, value engineering, and building operation. Specifically, questions were asked on: integrated design process, energy modelling, energy consumption, water consumption, intended indoor environmental quality, lighting strategy, acoustic design, thermal comfort goals, and occupancy scenarios. Designer/operator/consultant interviews helped to ground the quantitative results discussed in the remaining body of this report.

\subsection{Building Occupant Survey}

Using Qualtrics open-sourced software a survey was issued to all building occupants via email; 53 building occupants responded to the online survey. The survey consisted of 13 question modules on the following topics: worker description, workstations, work habits, commute, occupant health, thermal comfort, air in winter, air in summer, interior lighting quality, acoustics, odours, green design features, and overall satisfaction; a copy of this survey is shown in the appendix of this report, appendix D figure 12 . This survey was adopted originally from a study conducted by Newsham et al, 2012, later employed by Gorgolewski et al, 2015 in a POE evaluation of nine high performance buildings. The intention of the survey was to gain qualitative information on the occupants and their relationship with the study building, specifically the indoor environmental quality (IEQ) of the building. It is noted by the USGBC (2015), that buildings are created, constructed and designed for human comfort, purpose and productivity. Thereby, qualitative satisfaction and occupant interaction with the indoor environmental quality is an important building performance characteristic to be included in POE. Respondents were able to indicate their qualitative perception of the indoor environmental quality, specifically lighting, thermal comfort, acoustics, and air quality, using a 1 to 7 response scale developed by Newsham et al, 2012. In addition to the response scale survey respondents were provided comment fields for each question to 
provide additional information or clarification. Qualitative information collected from this response scale survey was used to inform the results of quantitative performance based metrics on IEQ/IAQ.

\subsection{Thermography}

Installed blower door fan units were used to create an air pressure gradient of $-75 \mathrm{~Pa}$. With a stabilized pressure gradient, a thermographic camera was used to take a series of infrared images of building intersections from the interior. The images were focused on the intersection of building components (i.e. window to wall, door to wall, wall to roof, etc). These images were taken to identify possible areas of air infiltration/exfiltration. The focus of the thermographic imaging under negative pressure was on the first floor as this portion of the enclosure is dominated by retrofitted century brick. Extensive thermographic images of the exterior were taken at ambient pressure. A thermographic survey of each building elevation was conducted in addition to a thermographic survey of the roof and all its components. Thermographic infrared images of the selected building were used to detect areas of the enclosure that may be experiencing moisture deposition, conduction, convection, or air leakage. These enclosure areas may not be readily visible, but can create or lead to building deficiencies. Identifying areas of air leakage is important for the long term energy performance of the building as the building enclosure enables space conditioning systems; while helping to maintain an appropriate indoor environmental quality, and occupant comfort range. For these reasons thermography was included as a data collection technique in this study.

\subsection{Energy Audit}

Utility bills were supplied from building management indicating monthly data on natural gas and electricity consumption for EBW12 and Building 14. This data was averaged over four years to account for anomalous weather years, and normalized conditioned building floor area or energy use intensity $\left(\mathrm{kWh} / \mathrm{m}^{2} /\right.$ year) in order to compare it to other non-residential buildings. Additionally, the results of this analysis were compared against predictive energy model data supplied by the energy modeling consultants which was prepared during the integrated design process for LEED compliance. Sub-metering does not allow distinction between the study building and the adjacent building, Building 14 . Thereby results on annual energy use intensity are divided by the combined conditioned floor area(s) of both buildings. Furthermore, the building sub-metering does not provide information to determine the enduse for operational lighting, heating, cooling, plug loads, building systems, etc. However, space conditioning systems for heating is hydronic and powered by natural gas fired boilers used to heat water for perimeter radiation, air handler heat exchangers, and domestic hot water. Space conditioning systems for cooling are also hydronic, powered by electric fans and pumps in a cooling tower. Thereby, it can be 
determined that electricity consumption would be used for interior lighting, exterior lighting, plug loads, and building system pumps/fans. As discussed, there is often a considerable difference between predictive and actual energy consumption, and thereby a potential misrepresentation of atmospheric impacts for building operation. That is why an energy audit was included as a data gathering technique in this study.

In addition to the energy audit and analysis of the design stage energy model, a whole building energy simulation was developed using the results from the qualitative and quantitative data collection. The whole building energy simulation was developed using WUFI ${ }^{\circledR}$ Plus software, allowing for dynamic modeling and extending the simulation period over one calendar year. Inputs from the qualitative interviews contributed to the development of an occupancy pattern for the model that included office use, events, and a kitchen scenario. Results of the whole building air leakage evaluation were used to calibrate the air infiltration rate for the energy model. Outputs from the single zone simulation support data collected in this POE by indicating the annual energy consumption, heat flows by component, impact of thermal bridges, occupant thermal comfort thresholds, and indoor air quality levels. Quantitative results from the whole building energy simulation are used to bolster the discussion of the performance gap evaluated in this POE.

\subsection{Water Audit}

Utility bills were supplied from building management providing data on monthly water consumption for the study building. The building sub-metering allowed the building water consumption to be separated by end use for, domestic hot water, non-potable use, potable risers, and hydronic make-up. This data was analyzed and normalized for water use intensity $\left(\mathrm{m}^{3} / \mathrm{m}^{2} /\right.$ year) in order to compare it to other nonresidential buildings; additionally, the normalized results of the water audit were compared to industry standards. IPCC (2007) states that changing climate systems have re-distributed precipitation and global water resources; thereby, making it increasingly important for buildings to consume less water for all end uses and include Water Auditing as a data collection technique in POE.

\subsection{Indoor Air Quality}

Three different data collection techniques were undertaken to evaluate the indoor air quality (IAQ) of the selected building. A series of 20-minute IAQ spot measurements were collected in each major occupied area using a $3 \mathrm{M}^{\mathrm{TM}} \mathrm{EVM}$ air quality monitor. A 20-minute spot measurement was taken in the Yonge Welcome Center, The BMO Atrium, the $2^{\text {nd }}$ floor corridor, the $3^{\text {rd }}$ floor Evergreen office, the $4^{\text {th }}$ floor corridor, and the $5^{\text {th }}$ floor corridor. Data was logged to determine baseline air quality conditions during a 
normal business day, and identify specific areas for further investigation. $\mathrm{A} \mathrm{CO}_{2}$ meter $\mathrm{CM}-0018$ data logger was set up in the reception area of the Evergreen office. This data logger collected long term information on temperature, relative humidity, and $\mathrm{CO}_{2}$. This data was collected to see daily and long term trends over one work week. Finally, the $3 \mathrm{M}^{\mathrm{TM}} \mathrm{EVM}$ apparatus was used again to trend long term IAQ data during a large 50+ person event at the Yonge Welcome Center. Data was logged to determine the relationship between event occupancy and indoor air quality parameters. The indoor air we breathe can include allergens, dander, dust, toxins, bacteria, mould, volatile organic compounds, formaldehydes, and gases from combustion (Center for Disease Control, 1991). Construction of buildings can create dust that may remain in the building long after it is occupied (USGBC, 2015) and can negatively affect the health of building occupants. The indoor air quality data gathered was analyzed for dust, gases from combustion, and volatile organic compounds.

\subsection{Building Enclosure Air Leakage Evaluation}

The building enclosure air leakage evaluation that was completed at the selected building was conducted in general accordance with ASTM E-779, the Standard Test Method for Determining Air Leakage Rate by Fan Pressurization. This is one of several common test methods used for air leakage testing (Fennell \& Haehnel, 2005). The general procedure for the Building enclosure air leakage evaluation is as follows. With the blower door apparatus installed and baseline conditions recorded, a negative and positive pressure gradient was created using the fan units. Pre-determined pressure gradients were reached incrementally according to the ASTM testing standard. The pressure gradients that were created follow this order: +/-75 $\mathrm{Pa}$, +/-70 Pa, +/-65 Pa, +/-60 Pa, +/- $55 \mathrm{~Pa}$, +/- 50Pa, +/- $45 \mathrm{~Pa},+/-40 \mathrm{~Pa},+/-35 \mathrm{~Pa}$. Once the indoor/outdoor pressure gradient stabilized, the internal/external pressure and the fan flow pressure was recorded from the fan units using Teclog Software. By measuring the variable flow pressure at the fan units and the pressure gradient, the airflow rate across the building enclosure was calculated using the surface area in Table 3. This is due to the fact that the fan unit air flow rate must be equal to the air flow being moved into/out of the building enclosure through air flow pathways.

A guarded duct leakage to outside test was performed on one of the three vertical ventilation shafts in the selected building. This test was conducted to determine the air tightness of the roof top mechanical damper and silencer housing over each ventilation shaft. Using polyethylene and tape all of the ventilation exhaust openings were sealed, with the exception of the fifth floor exhaust opening. At the fifth floor exhaust opening a flow hood was installed to measure the amount of air movement through the isolated mechanical damper. Using the blower door fan units the building was depressurized to -75 
$\mathrm{Pa},-50 \mathrm{~Pa},-25 \mathrm{~Pa}$, and pressurized to $75 \mathrm{~Pa}, 50 \mathrm{~Pa}, 25 \mathrm{~Pa}$. With the exhaust openings sealed, a pressure gradient was created while isolating the mechanical damper. It was therefore possible to determine the amount of air infiltrating under negative pressure and exfiltrating under positive pressure through the damper housing. When the pressure gradient stabilized, three data points ( $\mathrm{cfm}$ ) were gathered from the duct leakage to outside test unit, using an ACIN flowfinder MK ${ }^{\circledR}$ Balometer installed at the fifth floor exhaust opening. These data points were averaged for each respective pressure. The purpose of the whole building air leakage evaluation was to quantify the amount of air leakage through the building enclosure of the selected building, compare the airtightness rates from the air leakage evaluation to recommended industry standards, evaluate potential areas of unique and systemic air leakage in the building enclosure, and evaluate the air tightness of the buildings vertical ventilation shafts or solar chimneys. Air leakage testing was undertaken as a data collection technique as it can be closely associated to other areas of building performance such as indoor environmental quality and energy consumption.

\subsection{POE Building Description}

\subsection{Building 12 Program}

The study building used in this POE was Building 12 at Evergreen Brickwork's Centre for Green Cities, for the purpose of this study it will be referred to as "EBW12." EBW12 is located in the Don Valley in Toronto, and was awarded LEED platinum designation. EBW12 is a retrofitted, five story building utilizing the existing footprint and original ground floor walls of a former brick-pressing factory. The building is part of a larger development and a post industrial site remediation, including a major adjacent structure building 14. Building 12 has a multifunctional occupancy pattern, it includes an event space, office space, classroom(s), and a commercial kitchen/food prep area. The occupancy pattern of building 12 is variable, office spaces are regularly occupied during normal business hours while event spaces and classrooms experience intermittent but intense use by a large number of occupants. Events in EBW12 Welcome Center occur regularly throughout the year. The commercial kitchen in Building 12 services the adjacent Building 14. Building 14 is a mixed use space comprised of a commercial restaurant, retail area, and communal meeting area. Hot water used for space heating and DHW in Building 14 is supplied by the central boiler system in Building 12. Additionally, electricity for plug loads and lighting is connected to Building 12. Gas and electric sub-metering between Building 12 and Building 14 was not installed; therefore the operation of Building 14 must be included in the energy analysis of Building 12 . 


\begin{tabular}{|r|l|}
\hline \multicolumn{1}{|c|}{ EBW12 Building Archetype } & \\
\hline EBW12 Estimated Conditioned Floor Area & $4,778 \mathrm{~m}^{2}$ \\
\hline Building 14 Conditioned Floor Area & $950 \mathrm{~m}^{2}$ \\
\hline Building 12 \& 14 Conditioned Floor Area & $5,728 \mathrm{~m}^{2}$ \\
\hline EBW12 Estimated Surface Area & $4,814 \mathrm{~m}^{2}$ \\
\hline EBW12 Estimated Volume & $18,068 \mathrm{~m}^{3}$ \\
\hline EBW12 Estimated Height & $18.46 \mathrm{~m}$ \\
\hline
\end{tabular}

Table 3. EBW12 critical building dimensions taken from architectural drawings, various building metrics in Table 3 have been used to calculate the normalized results in this study.

\subsection{Building 12 Enclosure}

EBW12 includes an exterior insulation strategy with mineral wool insulation mounted outboard of a steel stud service cavity wall. The new construction portions of the building have approximately R-30 walls. The exterior insulation strategy was adopted to reduce thermal bridging, maintain interior surface temperatures, and reduce condensation potential for improved enclosure durability and occupant comfort. The window units are tripled glazed gas filled insulated glazing units with low u-value inline fiberglass frames for reduced frame thermal bridging.

The building is comprised of four stories of new construction built on top of an existing retrofitted first floor. The first floor is a combination of three types of enclosure assemblies, while the second to fifth floor is dominated by two types of enclosure assemblies. The building is described below:

- Ground Floor Slab:

$\circ$ Existing slab

- Cupolex floor system with vapor retarder

○ $50 \mathrm{~mm}$ XPS (R-10)

○ $50 \mathrm{~mm}$ self-levelling concrete over hydronic heat pipes

- Ground Floor Wall Type 1:

○ Original double whythe century brick (R-2)

- Ground Floor Wall Type 2:

- Concrete masonry unit (CMU)

- Spray applied air barrier

- $102 \mathrm{~mm}$ rigid insulation ( $\mathrm{R}-20)$

- 38mm air gap

- Brick veneer

- $\quad$ Typical $2^{\text {nd }}-5^{\text {th }}$ Floor Wall Type:

○ $16 \mathrm{~mm}$ gypsum board

- $152 \mathrm{~mm}$ steel stud 16 OC $\mathrm{w} \leq 50 \mathrm{~mm}$ spray foam insulation

- $13 \mathrm{~mm}$ ext gypsum sheathing board

- $152 \mathrm{~mm}$ steel girt system mechanically fastened to concrete slab edge 
- $102 \mathrm{~mm}$ semi rigid mineral wool ( $\mathrm{R}-16)$

- $50 \mathrm{~mm}$ semi rigid water repellent mineral wool (R-8)

- $25 \mathrm{~mm}$ galvanized steel corrugated panels

- Typical Roof Type:

- Concrete slab

- Asphalt roof barrier membrane

- Root barrier

- $200 \mathrm{~mm}$ to $250 \mathrm{~mm}$ XPS insulation (R-40 TO R-50)

- Ballast fabric

- Stone ballast

- Various surfaces

\subsection{Daylighting and Natural Ventilation}

The primary orientation of EBW12 is north to south with the majority of glazing on the west elevation. The window-to-wall ratio is approximately $23 \%$. The long north-south orientation and floorplan design includes a daylighting strategy with office and classroom space located adjacent to fenestration. Approximately $90 \%$ of the consistently occupied floor area is located within 7 metres of window units. In addition to a daylighting strategy the lighting design includes light sensors that can adjust artificial light levels in relation to daylight. The lighting system can be programmed to dim lights during specific hours of the day, reducing the annual cooling demand, peak cooling load, and electrical consumption. The majority of window units are operable allowing for natural ventilation. Building occupants are notified by building management when it is acceptable to open window units for natural ventilation. Three vertical ventilation shafts or solar chimneys are included in the design to assist natural ventilation from the occupied space.

\subsection{Building Systems}

EBW12 includes a ducted mechanical ventilation system. The buildings mechanical ventilation system includes a desiccant wheel to recovery latent energy and a glycol loop to recover sensible energy, in ventilation exhaust. One variable speed central air handling unit located on the $5^{\text {th }}$ floor provides outside air and serves the entire building. The building cooling system is intentionally undersized, relying on natural ventilation and scheduling of cooling distribution based on occupancy. One cooling tower located on the roof provides $100 \%$ of cooling for space conditioning. The building heating system is decoupled from the mechanical ventilation. Heat for space conditioning is provided by an in-floor hydronic radiant system in the ground floor concrete slab and perimeter hydronic radiators. Utilities for Building 14 are provided through building 12 and sub metering does not allow the buildings individual electric and gas consumption to be distinguished. 


\subsection{Building 12 Isometrics \& Floor Plans}
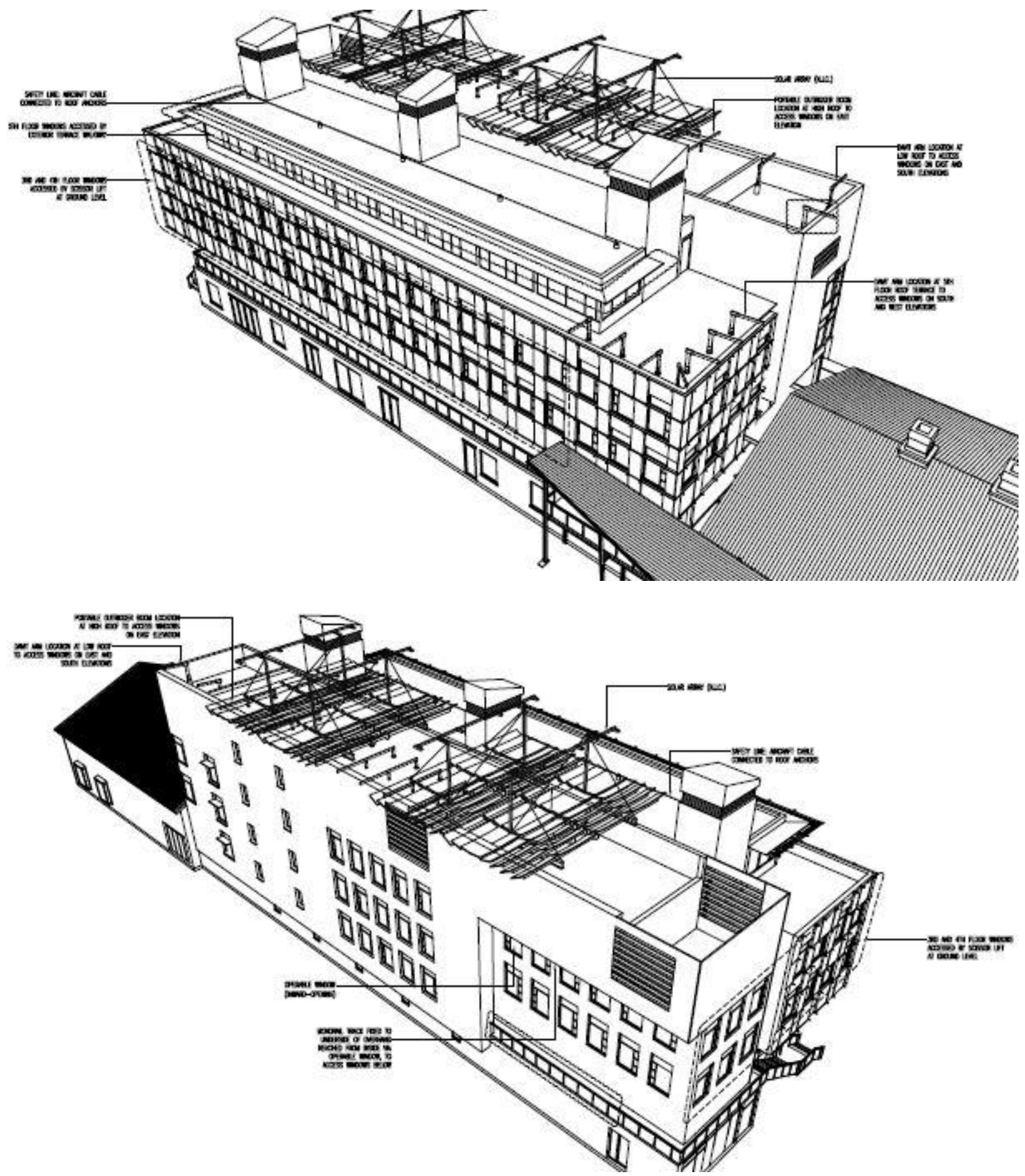

Figure 2: South-West and North-East Isometric Projections of Building 12. Drawing provided by Diamond Schmitt Architects. 

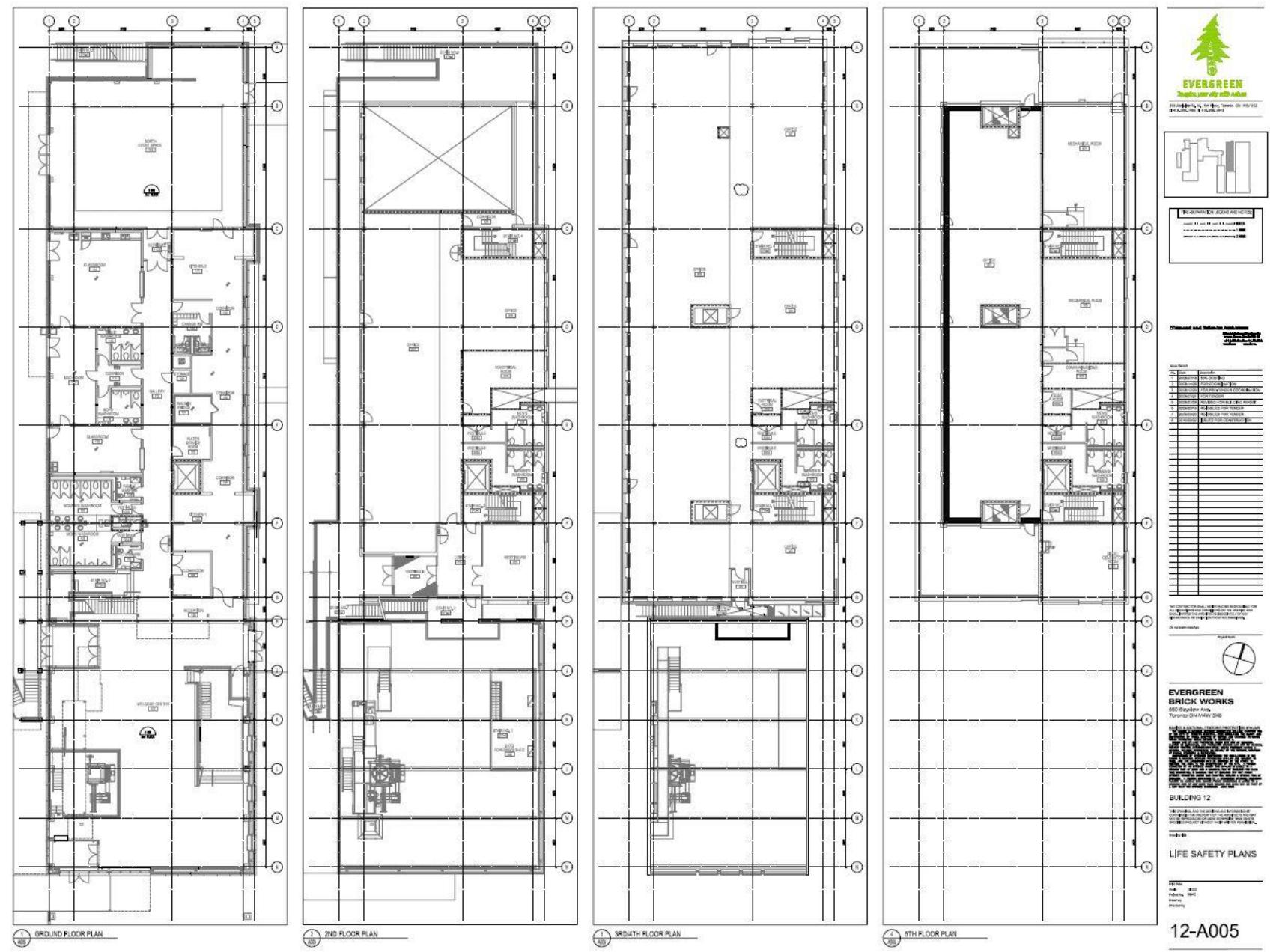

Figure 3: Building 12 floor plans ground to $6^{\text {th }}$ floor. Drawing provided by Diamond Schmitt Architects.

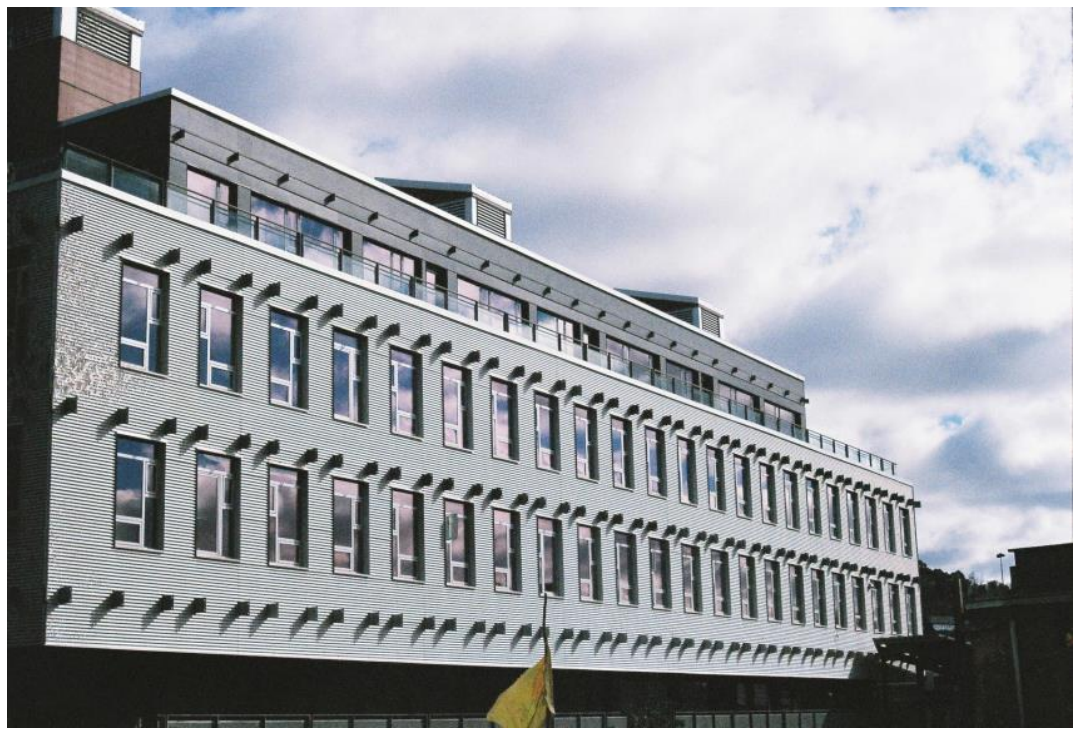

Figure 4: West Elevation of Building 12. 


\subsection{Results}

\subsection{Designer/Operator/Consultant Interviews}

The first interview was held with a principal architectural designer. In this interview it was revealed that the integrated design process (IDP) was adopted early in the project. Additionally, several aspects of the original design were value engineered. These include an operable shading system on the west elevation that was designed to restrict afternoon western sunlight in the cooling season. Furthermore, a rooftop photovoltaic system was removed from the intended design that would have offset energy consumption from interior lights, building systems, miscellaneous plug loads, etc. Finally, it was the opinion of the interviewee that EBW12 was intended as a showcase building to demonstrate the possibilities of green construction; multiple systems and technologies were combined in an exceptional way and scale for the time of construction. These include above code wall assemblies with triple pane fenestration, perimeter and slab hydronic heating, a natural ventilation strategy, a daylighting strategy, heat recovery ventilation, and high efficiency fixtures and lighting. It was noted that the interviewee believed the operational building energy consumption to be as predicted in the building energy simulation. The second interview was held with the project's LEED consultant. This interview confirmed that IDP was used from the design inception. Furthermore, the interviewee stated that LEED platinum was an important goal for this project that influenced design decisions. The interviewee stated that the most difficult credits to achieve in this retrofit project were the materials and resource credit categories, involving stringent sorting of construction waste and education of trades. LEED V1 Platinum was achieved in this project and the LEED category checklist was supplied by the consultant. In this interview it was confirmed that the building energy simulation was used in a comparative fashion to achieve the required LEED Energy and Atmosphere credits for Platinum status. Building commissioning after construction did not occur for LEED designation.

The third interview was held with the building energy consultant. In this interview it was confirmed that simulated code buildings were used as a baseline to surpass by an established margin in order to achieve perquisite credits for LEED Platinum. Input parameters for the building energy simulation were discussed. A normal office occupancy scenario was assumed in the predictive model, e.g. Monday to Friday, 9am $6 \mathrm{pm}$. As such, the modelled occupancy scenario is different than the operational occupancy of EBW12. The current occupancy of EBW 12 includes office function, educational seminars, events and food production. As such, the input parameters for the simulation are not representative of the operational occupancy. Internal gains from the kitchen processes were not included in the simulation. Summertime and shoulder season natural ventilation from operable windows and through the solar chimneys was 
included in the model that would affect the peak cooling load and annual cooling demand. The model included a photovoltaic system that would act to lower the annual energy consumption. These identifiable simulation inputs may account for the discrepancy between predicted and actual energy consumption, as paraphrased by the interviewee. Such a performance gap is not uncommon with a compliance structure such as LEED V1, based on comparative and simulated building energy consumption (Menezes, 2011). and can result in misconception about actual performance (Menezes, 2011). The final interview was held with a building operator. This interview revealed that the building's cooling systems was intentionally undersized and as such is not powerful enough to supply adequate cooling in scenarios combining peak load and peak occupancy in both the offices and event space. This could affect occupant comfort in times of peak demand. The interviewee stated that the vertical ventilation shafts or solar chimneys were in use only in the months shouldering the summer due to humidity issues. This lower use time appears to not be accounted for in the building energy simulation. Finally, it was discussed that flooding was a major issue for the site, due to its location in the Don Valley. However, it was stated that EBW12 has been resilient thus far to flooding due to foresight in the location of electrical and mechanical components, as well as durable building finishes. This resiliency was attributed to IDP by the interviewee.

\subsection{Building Occupant Survey}

A series of relevant facts are provided summarizing the results of the occupant survey, as shown in Table

4. These facts identify the number of survey respondents and the general location where the respondents are typically located. It is shown that the majority of the responses came from EBW12 occupants located on the third floor, west side. It is likely that the majority of survey respondents are from within the Evergreen organization. These facts are important to note for further interpretation of other building occupant survey results and data collection techniques.

\begin{tabular}{|l|}
\hline Building Occupant Survey Results Summary \\
\hline Number of surveys completed: 39 \\
\hline Estimated Response Rate: $40 \%$ \\
\hline Two thirds (64\%) of participants have their personal desk located on the third floor \\
\hline Nearly half (46\%) sit on the West side \\
\hline Three quarters (74\%) reside in an open plan (more than six people without partitions) workspace \\
\hline More than two thirds (68\%) have been at their current workstation for two years or less \\
\hline Nearly half (47.98\%) of time at work spent doing quiet work at their workstation \\
\hline $\begin{array}{l}\text { 95\% of respondents feel that cooling in the summer months meets their needs always or almost } \\
\text { always }\end{array}$ \\
\hline $79 \%$ of respondents feel that heating in the winter months meets their needs always or almost \\
\hline
\end{tabular}




\section{always}

$\mathbf{7 1 . 7 9 \%}$ of respondents would like to learn more about the green features of their building

\section{Table 4. Building Occupant Survey Results Summary.}

In Figure 5, aspects of workstation satisfaction were explored. Figure 5 indicates that the level of visual privacy was unsatisfactory to many respondents. The results also indicate that the respondents are least satisfied with acoustics; specifically, the level of privacy for conversations and the amount of noise from other occupants' conversations. This correlates with the results of Figure 6, indicating that speech sounds from others are a disturbing acoustic disruptions to workers. Acoustic disturbances in offices have the potential to distract workers and decrease productivity; this potential issue may be compounded depending on the interior fit out of the office and visual lines, being open plan or segmented (AIS, 2009). Open concept offices are efficient plans but are cited as potentially distracting for workers (AIS, 2009). When the building occupants were asked about acoustic quality there are several common areas of acoustic disturbance. Noise from outside was rated as the least disturbing followed closely by noise from public washrooms, noise from HVAC systems, and non-speech sounds generated by other individuals. Speech sounds generated by others was ranked as the most disturbing acoustic source, likely related to Identifying areas of acoustic disturbance, as per Figure 6, may provide direction for improving acoustic quality. Findings related to other aspects of indoor environmental quality such as lighting, temperature, glare, and aesthetics typically score from 4.9 to 5.59 indicating a high level of satisfaction. 


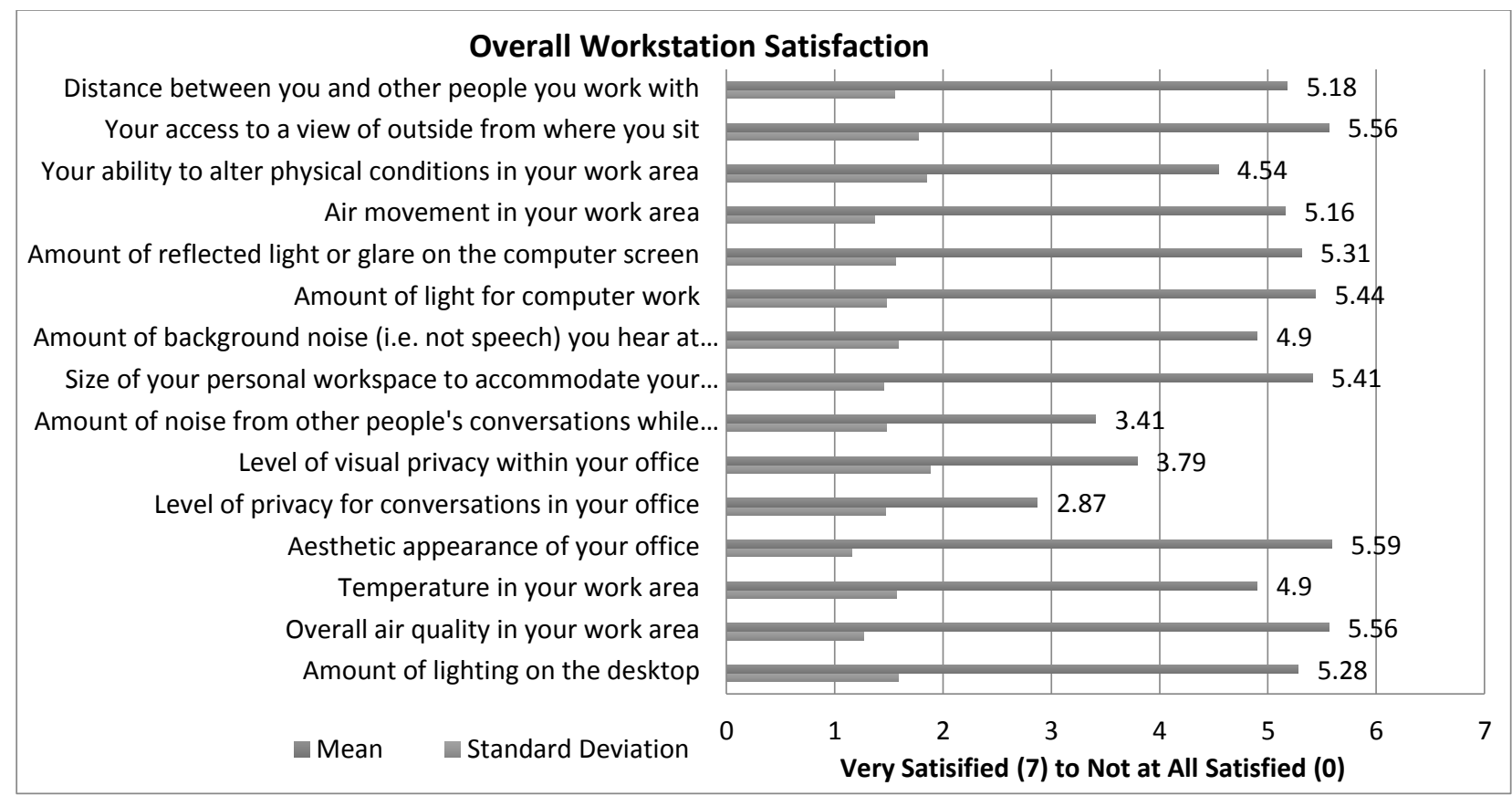

Figure 5. Investigated aspects of workplace satisfaction.

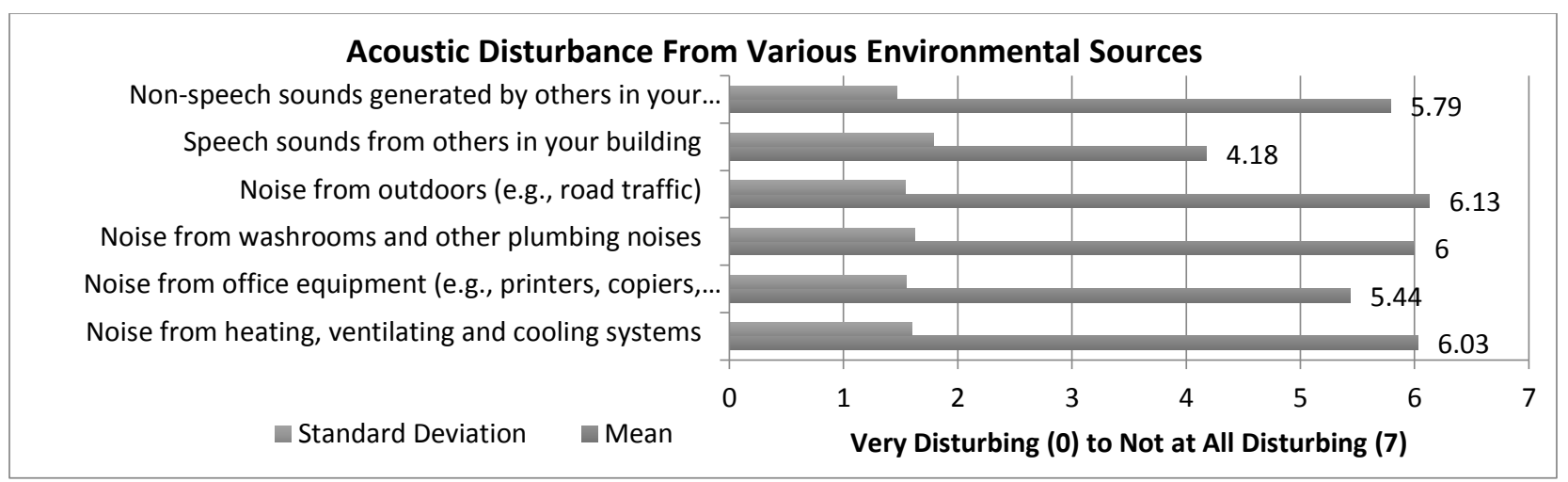

Figure 6. Occupant disturbance from environmental acoustic sources.

Thermal comfort is a dynamic component of indoor environmental quality. Satisfaction can be highly variable and dependent on factors including age, gender, clothing, season, air speed, air temperature, and relative humidity. Trying to satisfy the majority of occupants in a building with centralized space conditioning systems is challenging. Handing over controls to the occupants can be an option, but has the potential for abuse by building occupants (Deuble \& de Dear, 2012). Information on the overall thermal comfort of occupants is an important feedback to building managers and operators. Information on the satisfaction with summer and winter thermal comfort may help adjust the HVAC operating temperatures in a highly seasonal climate like Toronto. Adjustments to HVAC set points will affect the annual heating and cooling demand, and thus the energy consumption of the building. Thereby, it is important to note for building operators that the set point range is acceptable to occupants and that overheating or cooling 
is not occurring. Figures 7-12 display information on seasonal and overall occupant thermal comfort. Figure 7 indicates that $82 \%$ of respondents range between slightly cool and slightly warm in summer months; this result is positive as the building cooling system is undersized. Figure 8 and Figure 10 indicate that more building occupants are satisfied then are dissatisfied with seasonal air quality, with $13 \%-16 \%$ indicating dissatisfaction and 38\% - 46\% indicating satisfaction. Figure 9 indicates that the majority of respondents, a total of $81 \%$, are slightly cool to slightly warm in winter months. It appears that there is less satisfaction with air quality, approximately $60 \%$ satisfied, then there is with thermal comfort with approximately $80 \%$ satisfied. This could indicate that while space conditioning is appropriate the building ventilation rates may not be sufficient. Figures 11 and Figure 12 show that $41 \%$ of respondents believe their productivity is slightly interfered by workspace temperature; and, 31\% are slightly dissatisfied with general workspace temperature. The seasonal specific figures on thermal satisfaction (Figures 7-10) show a mostly neutral level of satisfaction with seasonal workplace temperature. Such findings suggest that the majority of the respondents are satisfied with the thermal comfort of the study building. These findings support the IAQ spot measurement data that fall within ASHRAE's seasonal thermal comfort zones, shown in Figure 27.

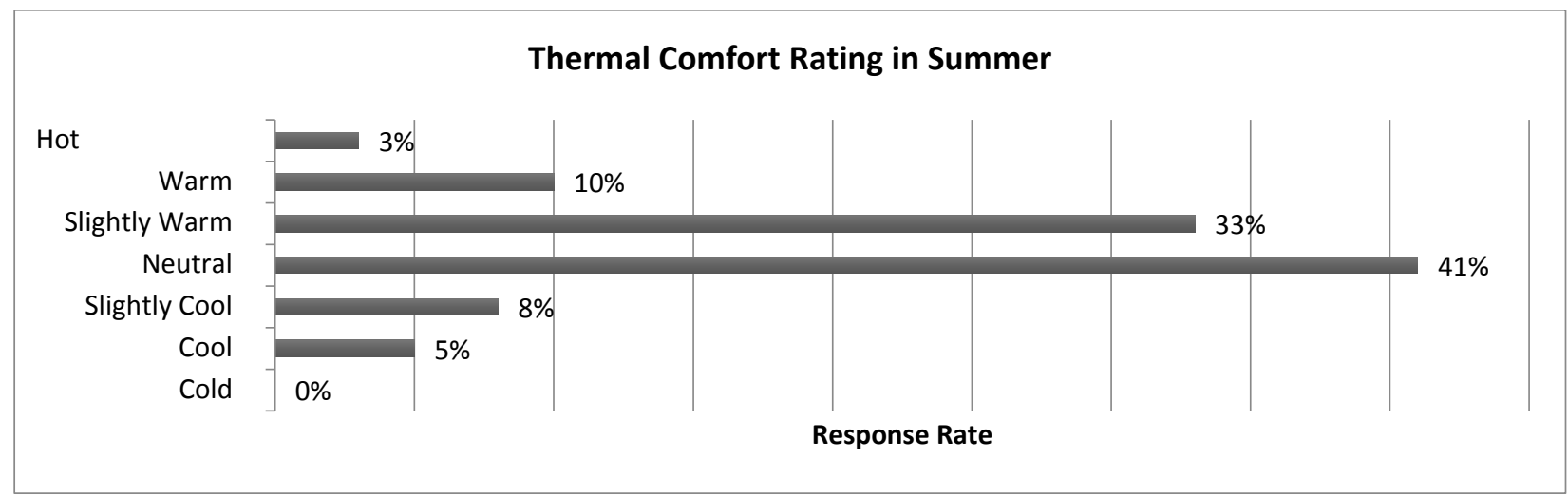

Figure 7. Occupant thermal comfort in summertime months.

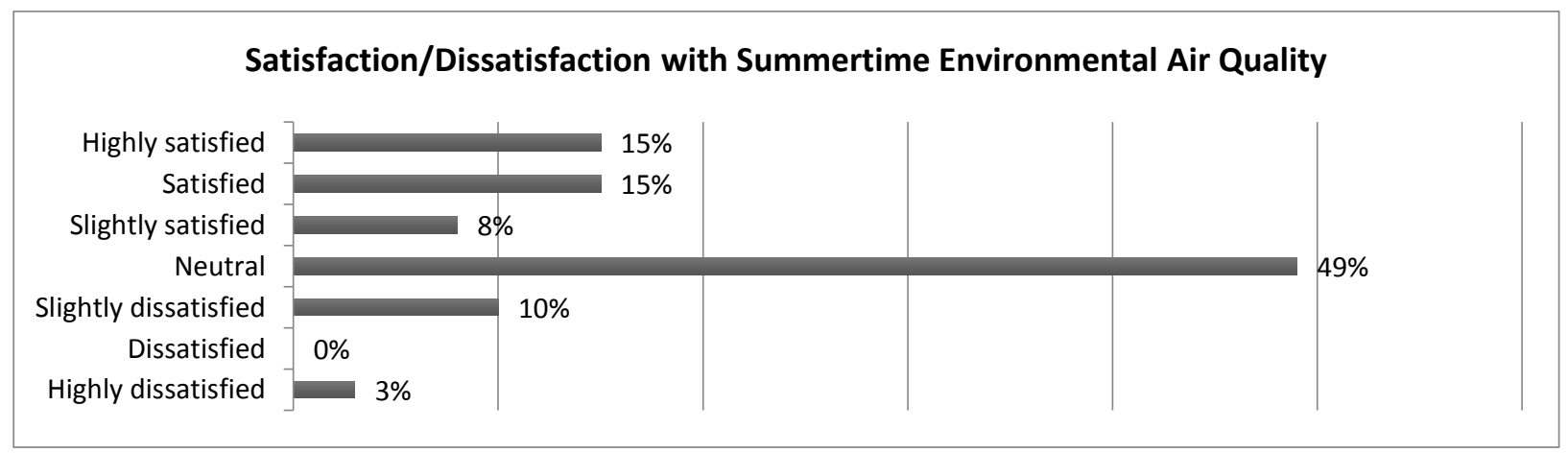

Figure 8. Occupant satisfaction with summertime environmental air quality. 


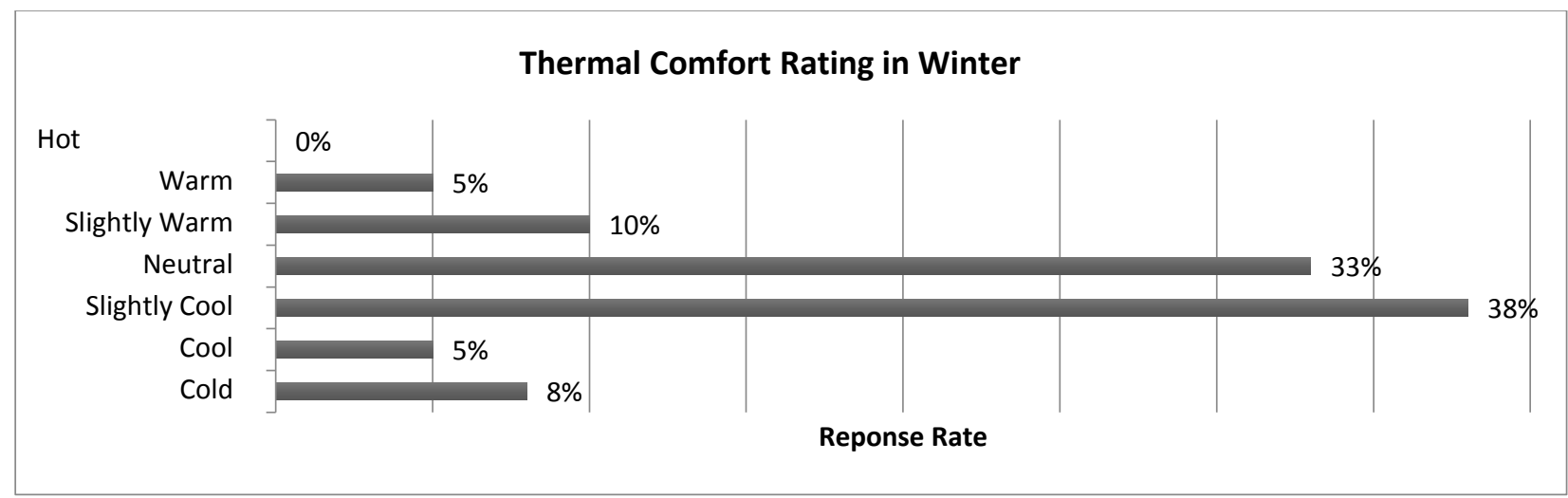

Figure 9. Occupant thermal comfort wintertime months.

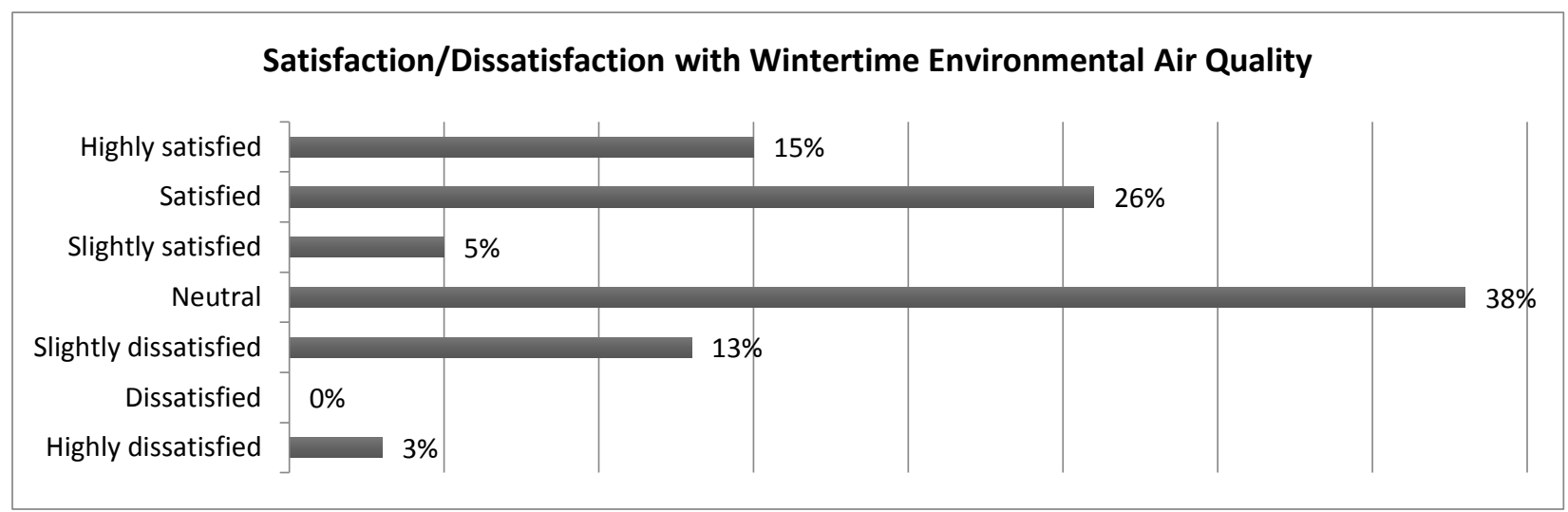

Figure 10. Occupant satisfaction with summertime environmental air quality.

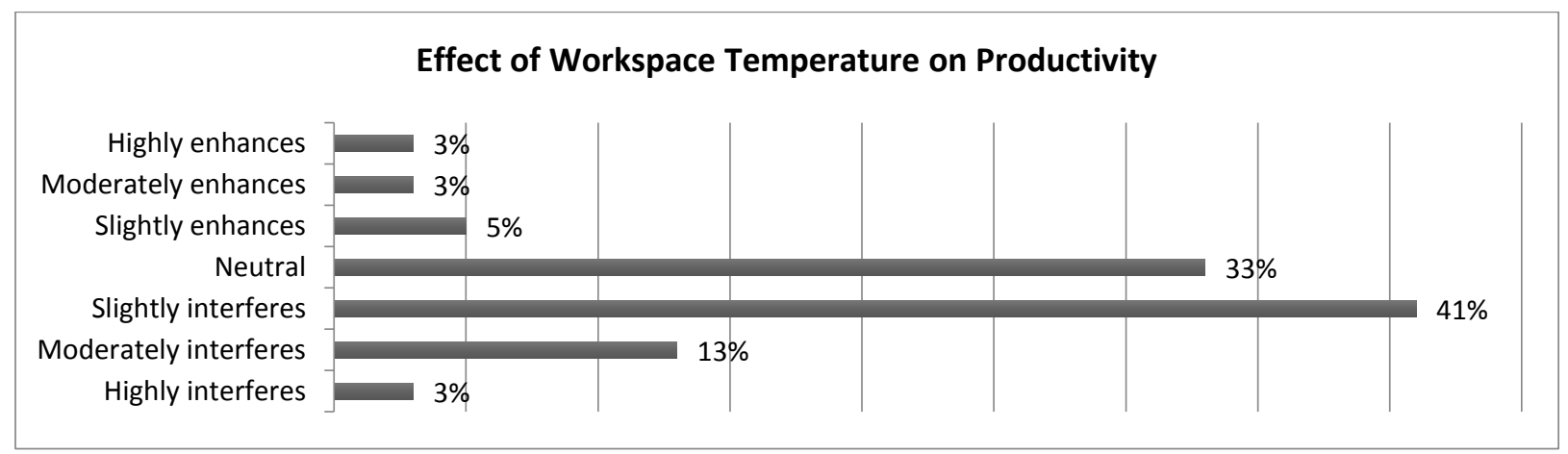

Figure 11. Workspace temperature and occupant productivity. 


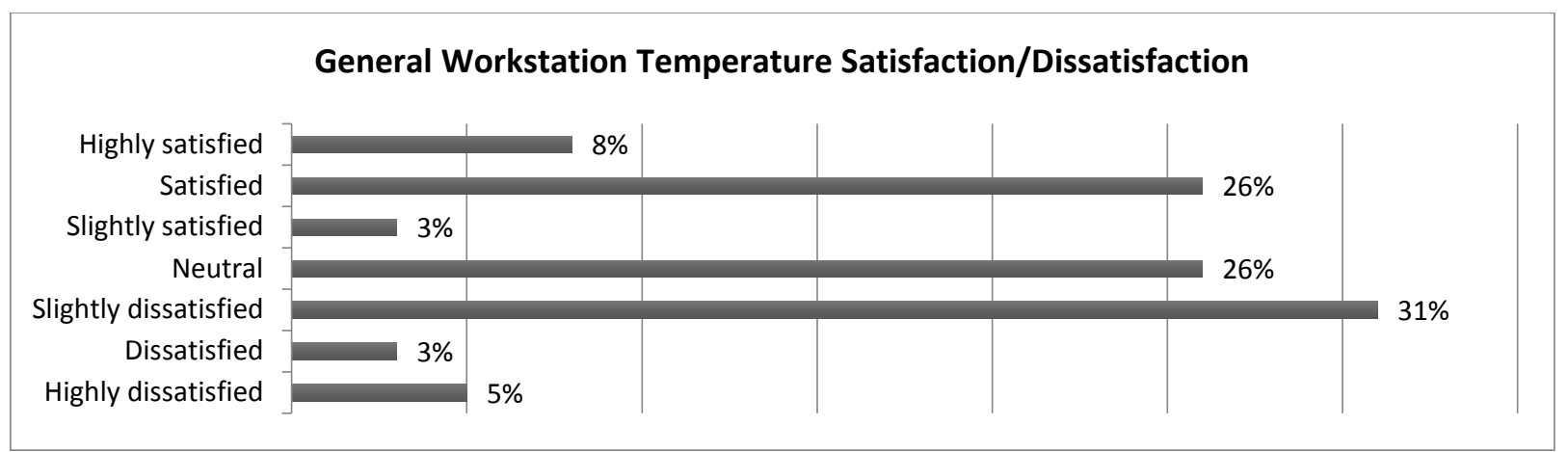

Figure 12. Occupant satisfaction with workspace temperature.

Sources of odour in the indoor environment have been previously reported to building management by occupants. Specific concerns about smoke from adjacent fires and kitchen odours were mentioned as potential issues during interviews with building management and operators. As such, specific questions were built into the building occupant survey. The results of these questions (Figure 13) show that of the respondents, $71 \%$ indicate that food odours from the restaurant kitchen are the main source of workspace odour; followed by the office kitchen(s), and outside woodsmoke. The responses from figure 13 support previous complaints made by building occupants to operations about workplace odours. Additionally, the presence of disturbing odours in the building provide further evidence that ventilation rates may not be sufficient.

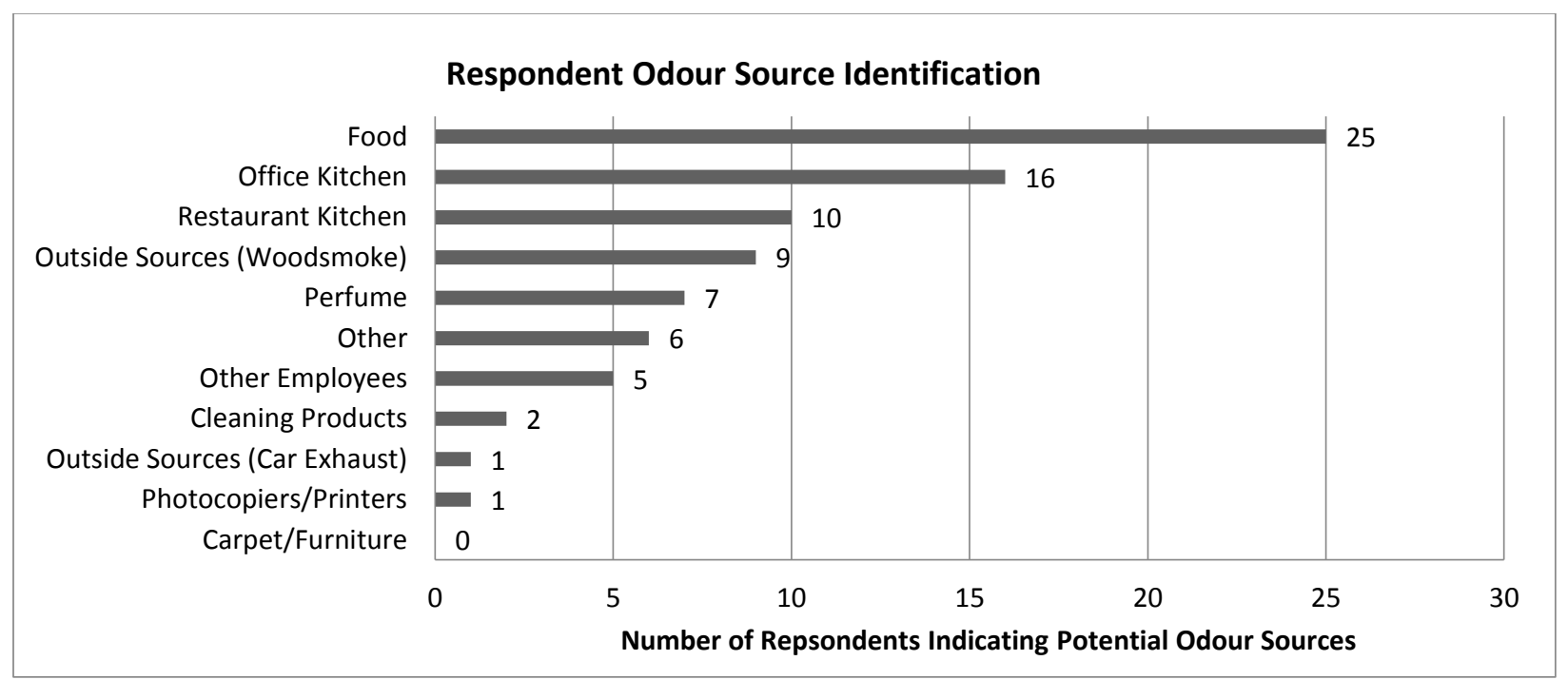

Figure 13. Occupant identification of odour sources. 


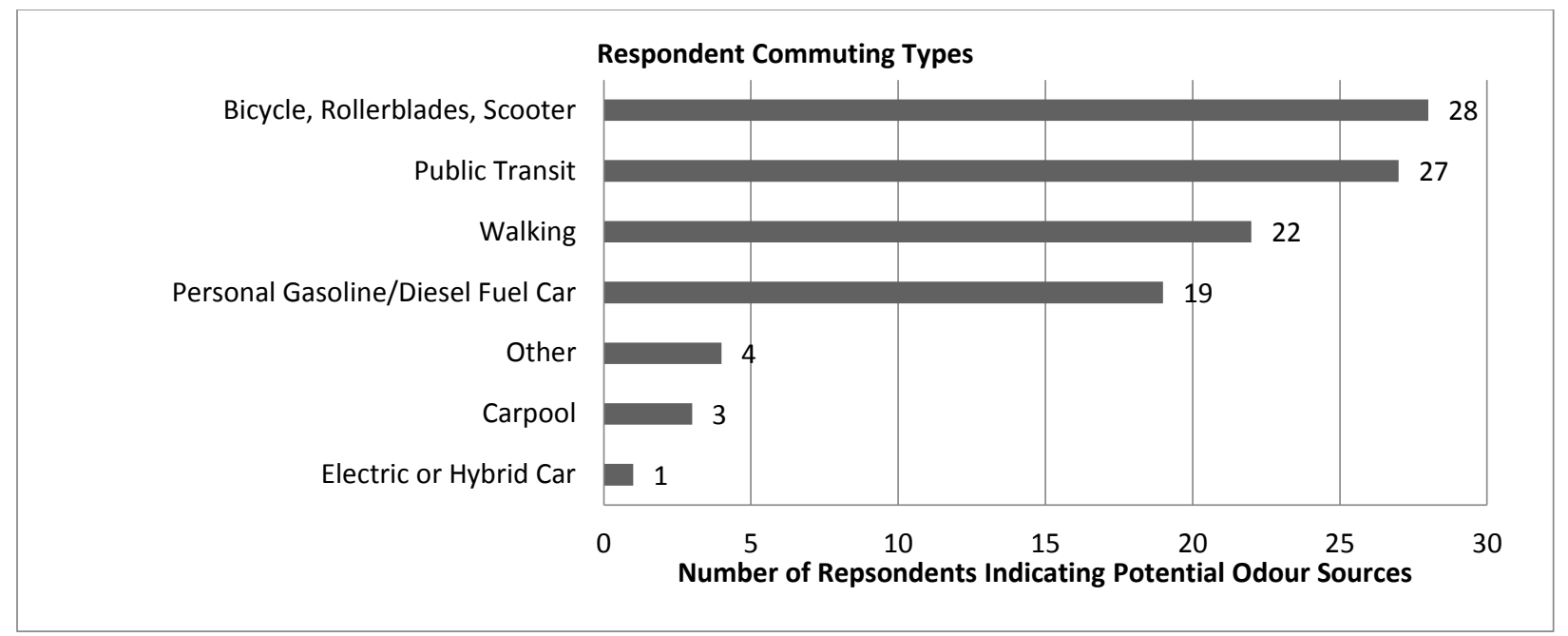

Figure 14. Occupant reported commuting methods.

As requested by Evergreen management specific questions on occupant commuting methods were built into the survey. Survey questions on commuting methods, shown in Figure 14, indicate that that the majority of respondents ride bicycles to work. This is followed closely by those who take public transit, those who walk, and finally those who drive. These results indicate that not all building occupants are driving to work; this may be attributable to the Brickworks shuttle, and EBW12's location near public transit, bike routes, and walking trails.

\subsection{Thermograpahy}

In order to ensure ideal testing conditions, all exterior thermography surveys were conducted on cold and cloudless winter nights. This was done to reduce the possibility of reflected solar radiation influencing the results. All external elevations were scanned with an FLIR thermographic imaging camera. Large areas of the building elevations were documented with the camera and were used to detect smaller areas for further investigation. Each elevation was scanned methodically starting with the West, and followed by the North, East, and South. Initial scans of the building elevations immediately revealed point thermal bridging through the steel substructure that was initially designed for the operable shading system. The operable shading system was value engineered from the project, as described during the interview data collection process. The steel fins are embedded in the edge of the concrete slab on the second, third and fourth floor, as shown in Figure 15. There are 193 support fins with an approximate surface area of $0.141 \mathrm{~m}^{2}$ each. This is an estimated surface area of $27.26 \mathrm{~m}^{2}$. This represents a comparative $.05 \%$ of the building envelope surface area, and will result in conductive thermal losses. Moreover, the steel substructure fins may be cooler than surrounding building enclosure materials at the slab edge and could 
create conditions for condensation in the building enclosure assembly. Conductive losses can be seen in the IRT images shown in Figure 15. A detail drawing of point thermal bridging is shown in Figure 16.
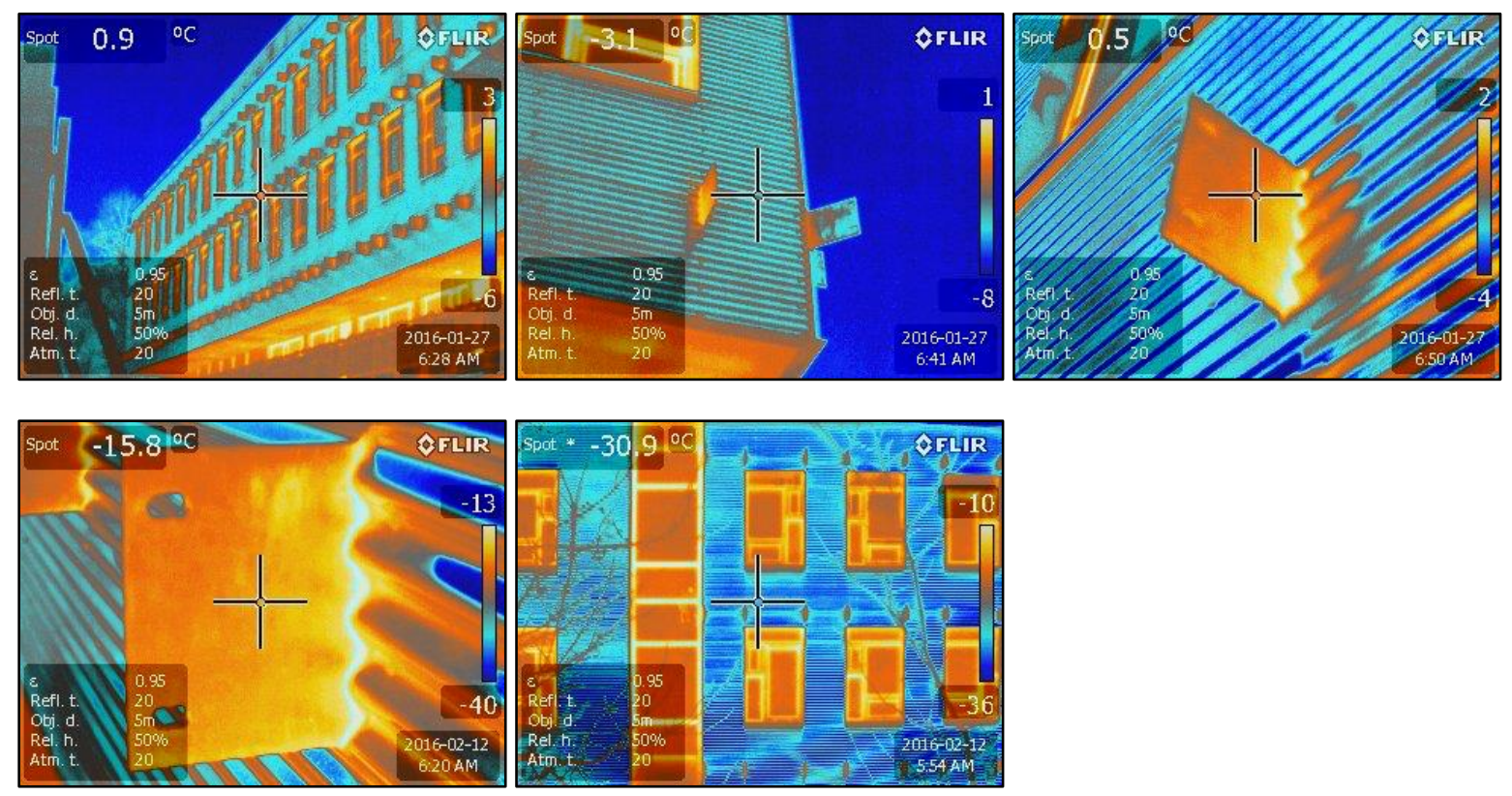

Figure 15. Thermographic images of point thermal bridging through the shading system.

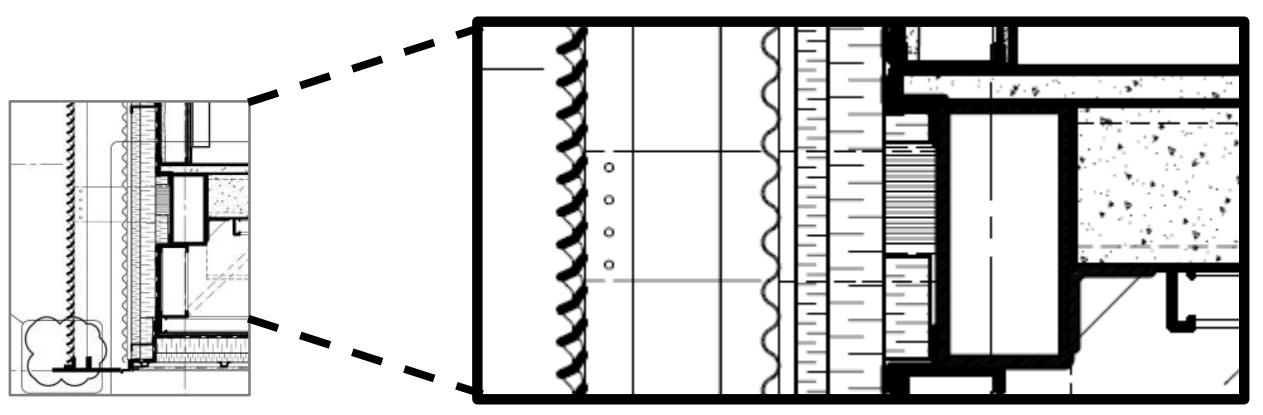

Figure 16. Detail of slab edge shading sub structure.

Both point and linear thermal bridging are occurring on the North elevation as shown in Figure 17. The thermographic images revealed that the exposed steel structure supporting the cantilevered $3^{\text {rd }}$ floor is creating a thermal bridge. Furthermore, linear thermal bridging is occurring due to this cantilever detail, at both the intersection of the ground floor roof and the second floor wall, and the intersection of the second floor wall and $3^{\text {rd }}$ floor slab. This linear thermal bridging occurs along the entire perimeter of the cantilever detail on the East, South and West elevations. Point thermal bridging is occurring on the ground floor West elevation, at the intersection of the steel structural I-beam and the masonry wall as shown in Figure 17. The thermal bridging appears to be unique on this elevation. There may be a potential opportunity to blunt this thermal bridge by insulating the last several feet of the steel I-beam. 

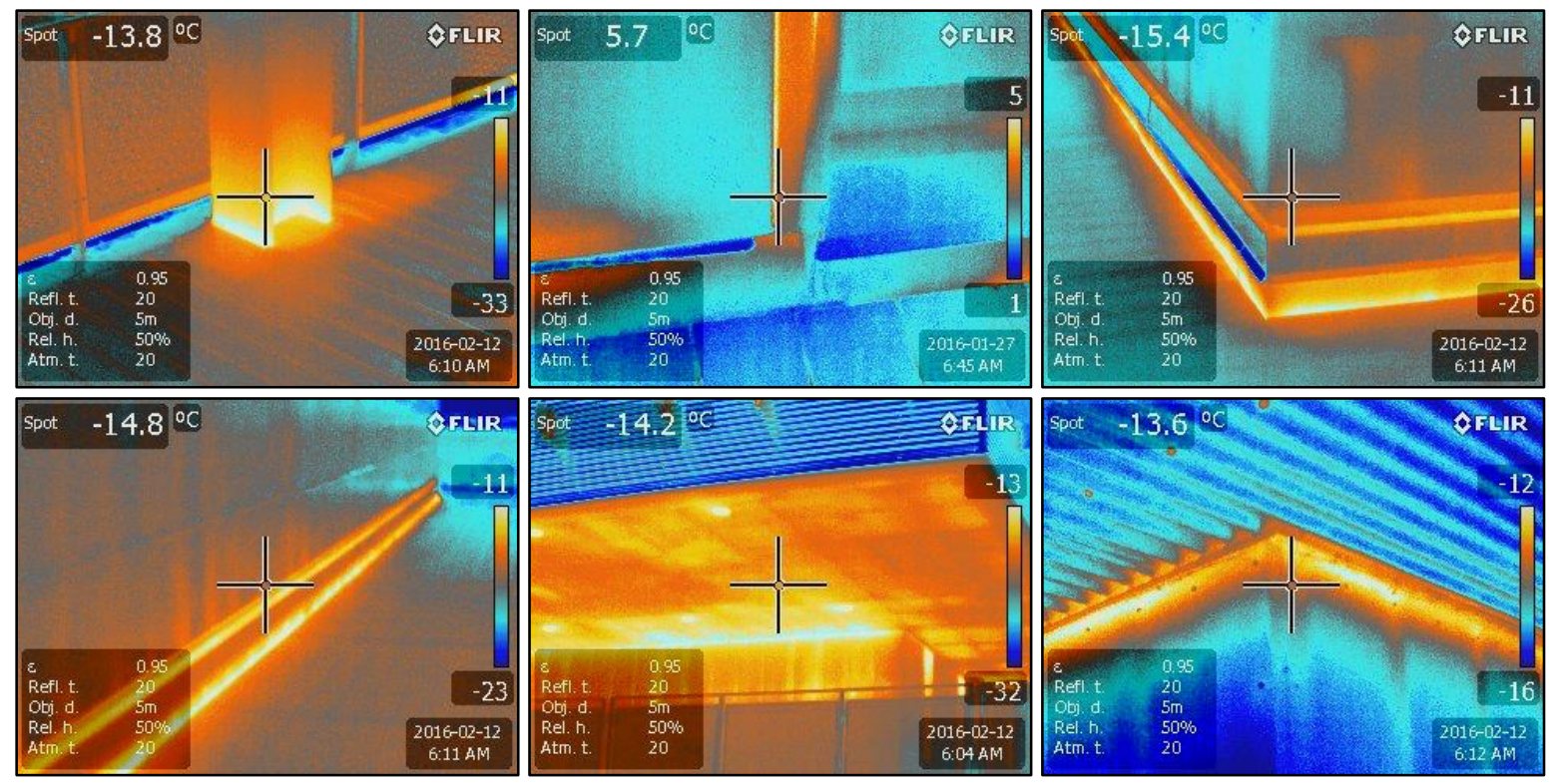

Figure 17. Thermographic images of point and linear thermal bridging in elevation details.
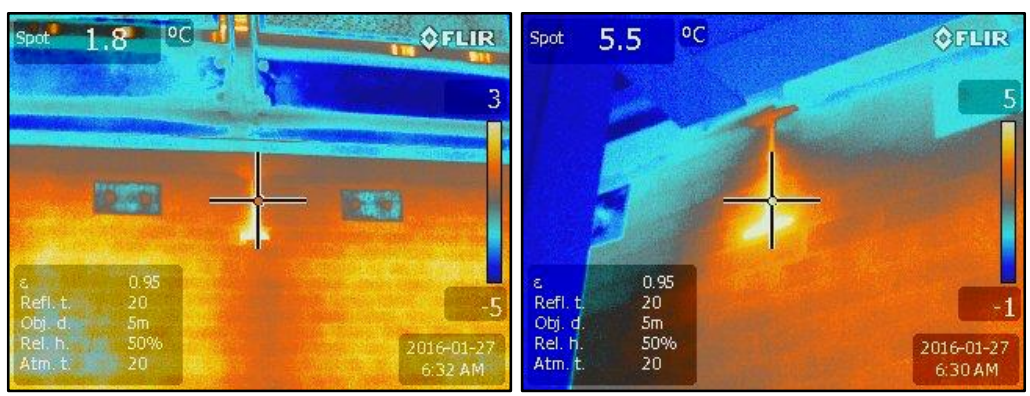

Figure 18. Thermographic images of point thermal bridging on East elevation.

Thermography was conducted on interior ground level enclosure surfaces. The thermographic images were visually analyzed for unique and systemic air leakage pathways. With a stabilized pressure differential of $-75 \mathrm{~Pa}$, a thermographic camera was used to take a series of infrared images of the building interior. The images were focused on the intersection and joints of major and minor building components (i.e. window to wall, door to wall, wall to roof). A sample of images were collected from various locations on the ground floor. However, the interior thermographic images that were collected do not show evidence of air leakage at building intersections and joints. Some minor pluming, indicating air infiltration, is visible at the base of the door openings in a selection of photos shown in Figure 19. The window openings, in Figure 19, appear to be well sealed; no visible pluming was seen at window joints when under negative pressure. Thermographic images of the roof dampers, and roof to wall intersection indicate conductive losses, but do not show uncontrolled air leakage. Minor conductive losses are visible 
in several images. Thermographic images taken of the ground floor indicate no systemic air leakage pathways, and few unique air leakage pathways at door swing openings.

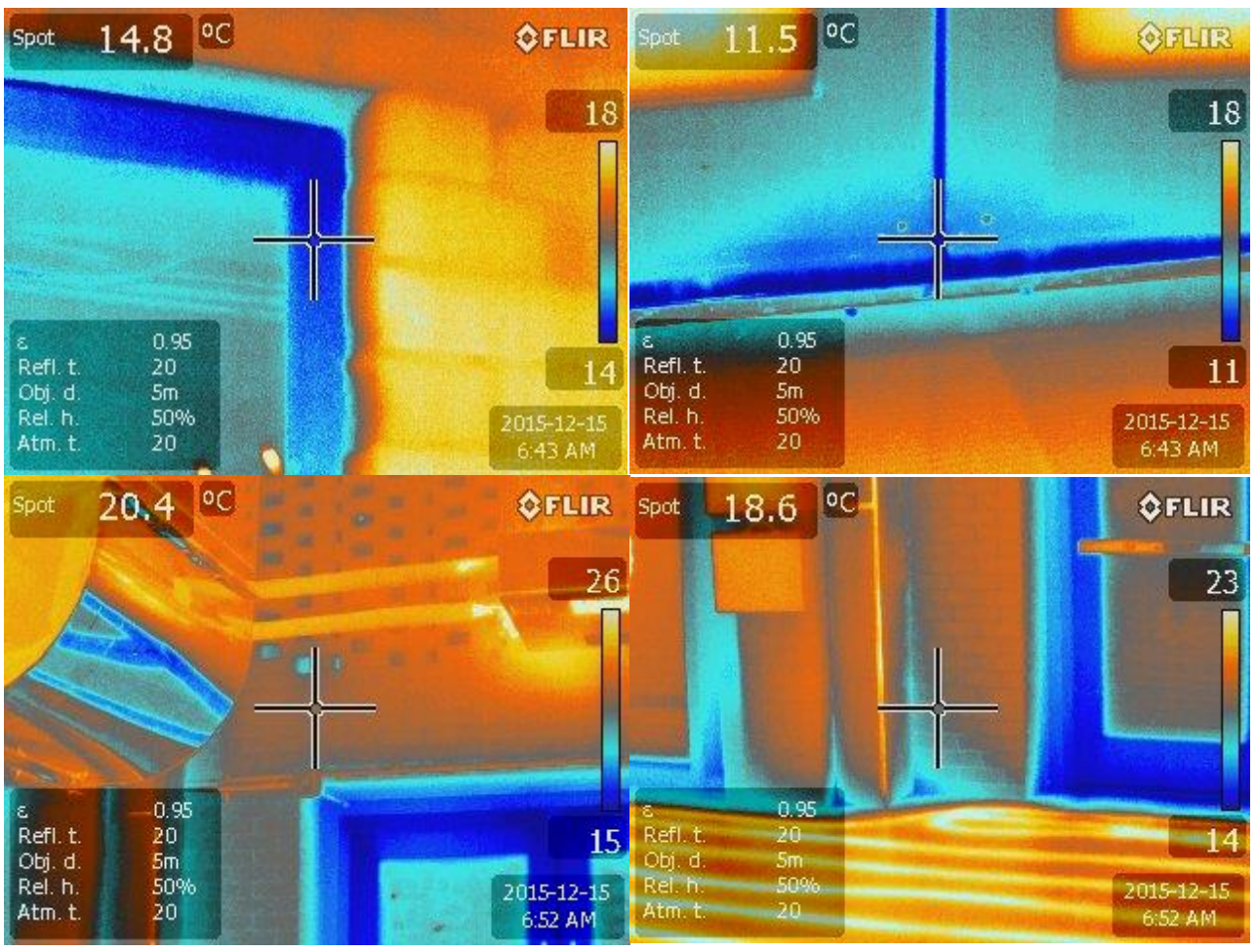

Figure 19. Images indicating air infiltration.

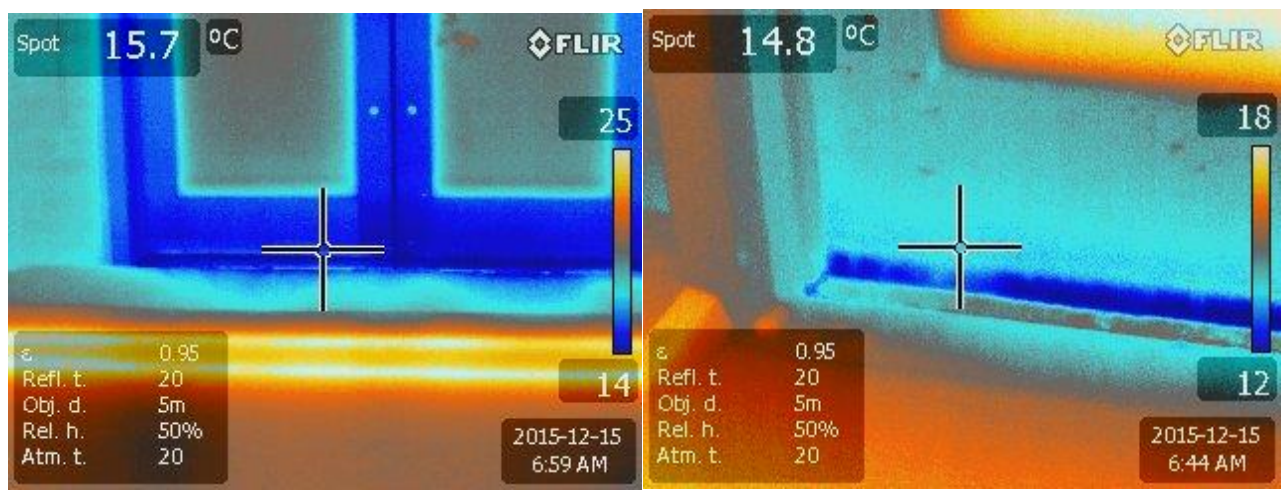




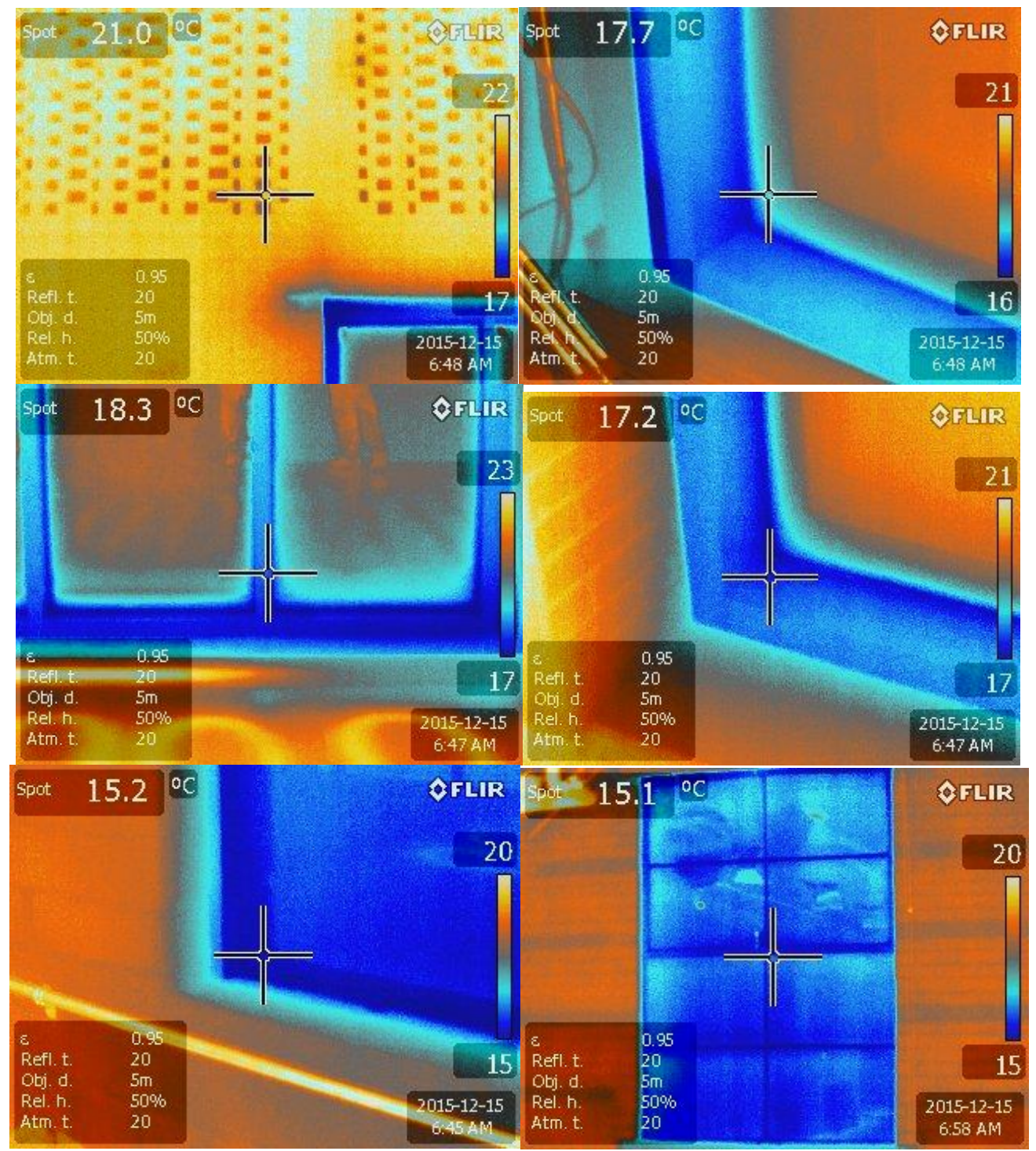

Figure 20. Thermographic images of window, door and openings and window to wall joints.

A rooftop thermographic survey was conducted with the primary goal of evaluating the performance of the damper houses and roof penetrations. It was discovered during the ground survey that damper houses were several degrees hotter than the rest of the building enclosure, as shown in Figure 21. A closer rooftop survey confirmed this. Thermographic images of the exterior and interior show a minimum temperature difference of $13.5^{\circ} \mathrm{C}$. This is supported by spot measurements taken inside the damper house and outside on the roof surface shown in Figure 22. The damper house enclosure assembly includes insulated sheathing (R-6), with exhaust dampers that open to ambient conditions. It follows that damper houses are a thermally weaker portion of the building enclosure comparatively, for both air leakage and insulation values. 

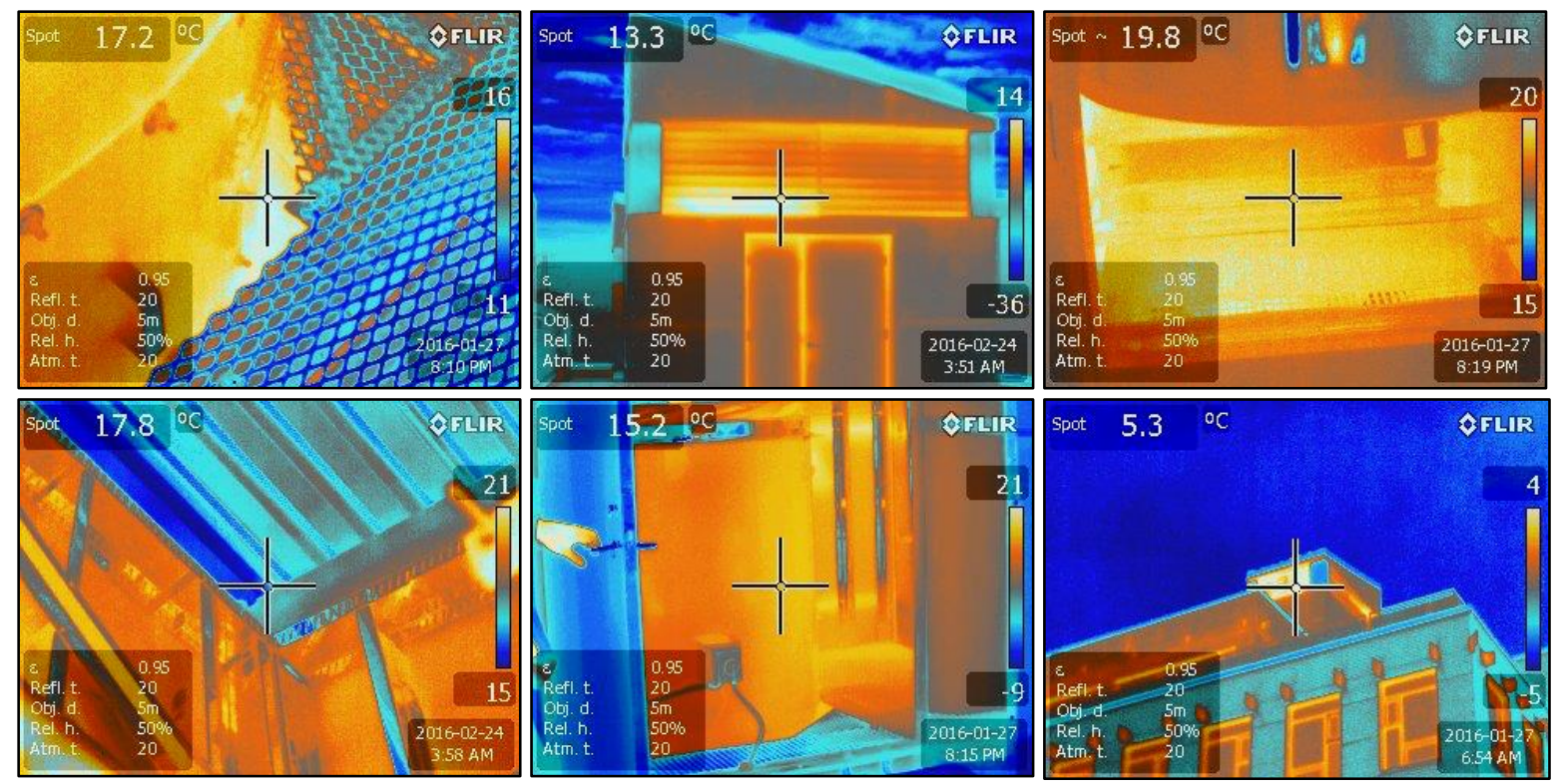

Figure 21. Thermographic images of increased temperature in the rooftop damper houses.
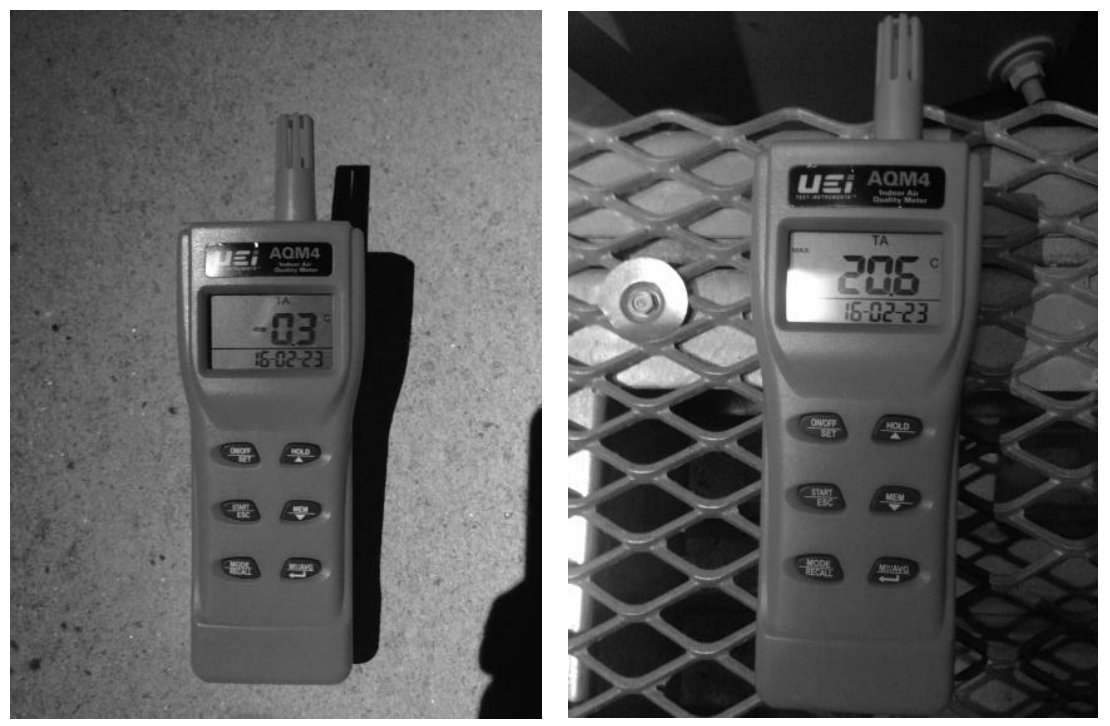

Figure 22. Internal and external spot measurements indicating, ambient temperature outside.

The rooftop thermographic survey also scanned roof penetration and parapet detail for thermal bridging and construction quality. Of the 116 photos taken during the rooftop thermographic survey the images presented in Figure 23 are most notable. These images show repetitive rooftop penetrations where conductive losses are comparatively more significant than similar details elsewhere on the roof. These roof top penetrations are anomalous when compared to the majority of roof details and penetrations. Of particular note, the image in the second row on the farthest right shows an area of the roof where there 
is a gap in insulation. This area can be compressed and is thermally unique when compared to the rest of the roof surface area images.
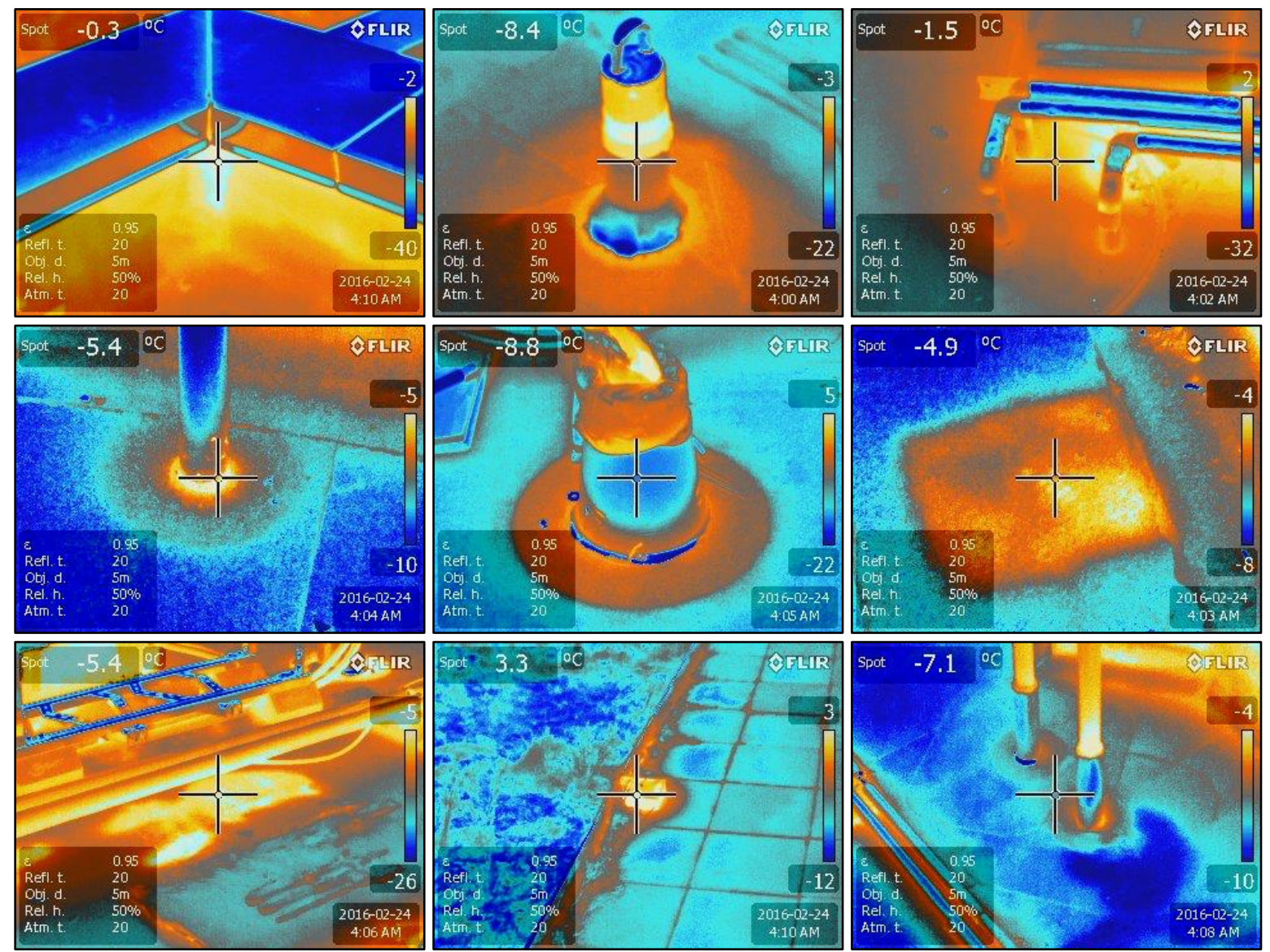

Figure 23. Thermographic images of various roof penetrations with thermal anomalies.

\subsection{Energy}

Predictive energy modelling was conducted by outside consultants during the design stage of EBW12; a building energy simulation was developed. The predicted energy end use and simulated energy use intensity was extracted from the energy model that was provided during the qualitative interview with the building energy consultant. The results of the building energy simulation are displayed in Table 5 . The building energy simulation and resulting EUI were developed with a standard weather file, variations in actual consumption will in part be due to annual weather that differs from the modeled climate file. End use consumption was determined by the simulation and is shown in Figure 24 . 


\begin{tabular}{|l|c|}
\hline & Modeled Year \\
\hline Predicted EUI $\left(\mathrm{kWh} / \mathrm{m}^{2}\right)$ & 127.83 \\
\hline Predicted EUI $\left(\mathrm{kWh} / \mathrm{ft}^{2}\right)$ & 11.88 \\
\hline
\end{tabular}

Table 5. Predicted energy use intensity.

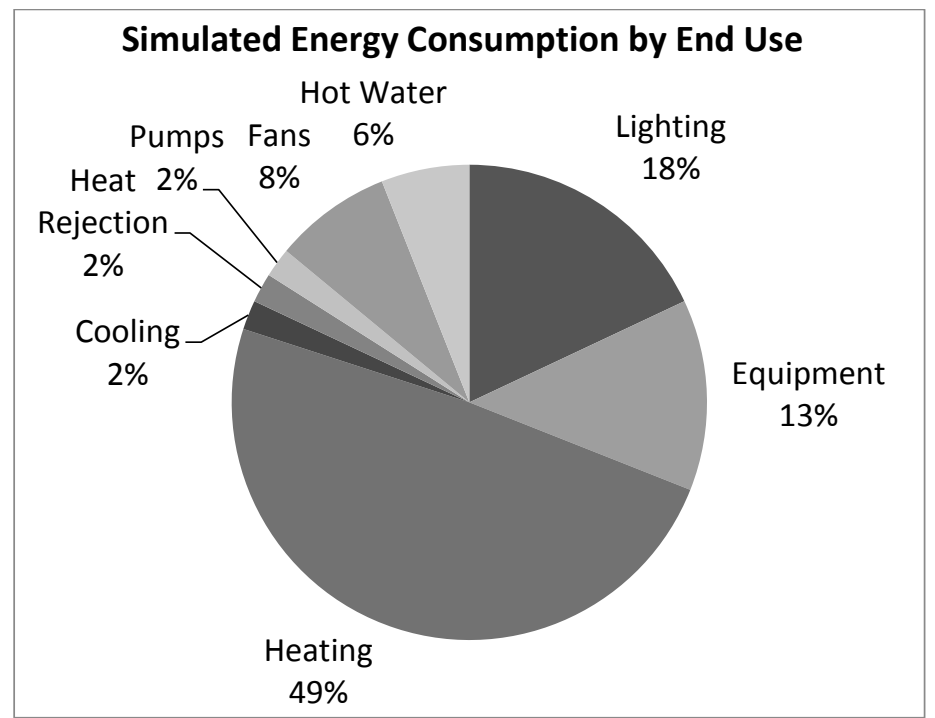

Figure 24. Predicted energy consumption by end use.

Summarized data taken from the utility bills is shown below in Table 6. This data shows the actual consumption of natural gas and electricity from 2012 to 2015. In cases where data was missing for individual months an average number was calculated based on the values for the neighbouring two months. This data is summarized in Figure 25, where predicted energy consumption is compared against actual energy consumption. Figure 25 demonstrates the significant gap between the predicted and actual performance. Menezes, Cripps, Bouchlaghem and Buswell (2012) describe that the gap between simulated and actual performance is common and can be twice as much as predicted. This is congruent with the results shown in Table 6 and Figure 25. Furthermore, energy simulations often use unrealistic baseline conditions that are designed to comply with energy codes or other third party certifications; this was confirmed in the interview process. In the case of EBW12, the energy simulation was used to obtain prerequisite credits in LEED V1 Energy and Atmosphere, prerequisite Minimum Energy Performance. Simulations designed to meet strict outside energy requirements may be forced to use non-conservative or best case modelling assumptions. However, Menezes and colleagues (2012) further describes the cause of this discrepancy is in fact due to a combination of modelling assumptions, modelling tool 
limitations, building management and controls, occupancy behaviour, and construction quality. This assessment, is consistent with the results of the qualitative interviews conducted with building energy consultants; which confirmed that idealized occupancy scenarios were used that are not representative of current operation. In addition, the original design iteration used in the predictive model included an operable shading system and rooftop photovoltaic, and excluded event occupancy and kitchen services. These factors would have increased the simulated energy consumption.

Using the energy data analyzed in Table 6, an estimation of atmospheric $\mathrm{CO}_{2}$ output was calculated. The annual carbon intensity was determined to be approximately $330,694 \mathrm{Kg} \mathrm{CO}_{2} /$ year (Table 6). This result was calculated using Environment Canada's National Inventory Report, (2011). Environment Canada (2011) states that electric power generation in Ontario is equivalent to $0.11 \mathrm{Kg} \mathrm{CO}_{2} / \mathrm{kWh}$. EBW12 consumed an annual average of 1,042,095 kWh of electricity, equivalent to $114,630 \mathrm{Kg} \mathrm{CO}_{2}$. The US Energy Information Administration states that one MMBTU of natural gas is equivalent to $53.07 \mathrm{~kg} \mathrm{CO}_{2}$. EBW12 consumed an annual average of 4,072 MMBTU of natural gas, equivalent to $216,064 \mathrm{~kg} \mathrm{CO}$. The Commercial Buildings Energy Consumption Survey indicates that the average energy use intensity of North American Office buildings is $319 \mathrm{kWh} / \mathrm{m}^{2} /$ year. Comparatively, CBECS indicates that the top $25 \%$ of office buildings has an EUI of $152 \mathrm{kWh} / \mathrm{m}^{2} /$ year and the bottom $25 \%$ of office buildings has an EUI of 684 $\mathrm{kWh} / \mathrm{m}^{2} /$ year. Statistics Canada indicates in their 2009 Survey of Commercial and Institutional Building Energy Use that the EUI of office buildings is $333 \mathrm{kWh} / \mathrm{m}^{2} /$ year (Natural Resources Canada, 2009). This means that the 4-year average EUI of $399 \mathrm{kWh} / \mathrm{m}^{2} /$ year for EBW12 is $15 \%$ higher than the anticipated EUI of a Canadian office building, $20 \%$ higher than the average CBECS office building, and falls within the third quartile of buildings included in the CBECS study (Bertoldi, Hinge, Waide, 2006).

Figure 24 indicates that $55 \%$ of energy consumption would be dedicated for space heating and DHW, while $45 \%$ of energy consumption would be directed towards space cooling, equipment, lighting, fans, pumps, and heat rejection. Examining the 4-year averages shown in Table 6, EBW12 consumed an average 1,242,829 kWh of natural gas, an average 1,042,095 kWh of electricity, for a total average energy consumption of $2,284,924 \mathrm{kWh}$. This means that natural gas consumption represents $54 \%$ of total energy consumption by end use of space heating and DHW. Electricity consumption represents $46 \%$ of total energy consumption by end use of space cooling, equipment, lighting, fans, pumps, and heat rejection. These operational end use estimates are very close to the predicted energy use consumption in the building simulation. This adherence to simulated energy consumption by end use does not indicate an 
area of end use energy that could be responsible for the higher total energy consumption and EUI over the simulation. While analyzing the energy data by end use does not appear to indicate one end use, analyzing the energy data by annum shows that the total energy consumption increased steadily over 4 years. This may be due in part to variable weather years; for example, in 2015 a relatively cold year, gas consumption rose to $58 \%$ by end use, while electricity consumption represented a relative $42 \%$ by end use.

\begin{tabular}{|c|c|c|c|c|c|}
\hline & 2012 & 2013 & 2014 & 2015 & $\begin{array}{c}4 \text { Year } \\
\text { Average }\end{array}$ \\
\hline Building $12 \& 14$ Area $\left(\mathrm{m}^{2}\right)$ & 5,728 & 5,728 & 5,728 & 5,728 & 5,728 \\
\hline Total Gas Consumption $\left(\mathrm{m}^{3}\right)$ & 105,165 & 94,021 & 118,670 & 142,451 & 115,077 \\
\hline Gas Consumption (kWh) & $1,135,782$ & $1,015,427$ & $1,281,636$ & $1,538,471$ & $1,242,829$ \\
\hline Gas Consumption (MMBTU) & 3,721 & 3,327 & 4,199 & 5,041 & 4,072 \\
\hline Gas Consumption $\left(\mathrm{KgCO}_{2}\right)$ & 197,454 & 176,531 & 222,810 & 267,461 & 216,064 \\
\hline Total Electricity Consumption (kWh) & 902,303 & $1,023,377$ & $1,145,613$ & $1,097,088$ & $1,042,095$ \\
\hline Electricity Consumption $\left(\mathrm{KgCO}_{2}\right)$ & 99,253 & 112,571 & 126,017 & 120,680 & 114,630 \\
\hline Total Energy Consumption (kWh) & $2,038,085$ & $2,038,804$ & $2,427,249$ & $2,635,559$ & $2,284,924$ \\
\hline Total Carbon Impact $\left(\mathrm{KgCO}_{2} /\right.$ year) & 296,707 & 289,102 & 348,827 & 388,141 & 330,694 \\
\hline $\mathrm{KgCO}_{2} \mathrm{eq} / \mathrm{m}^{2} /$ year & 52 & 50 & 61 & 67 & 57 \\
\hline EUI $\left(\mathrm{kWh} / \mathrm{m}^{2}\right)$ & 356 & 356 & 424 & 460 & 399 \\
\hline Predicted EUI $\left(\mathrm{kWh} / \mathrm{m}^{2}\right)$ & 128 & 128 & 128 & 128 & 128 \\
\hline
\end{tabular}

Table 6. Summarized annual natural gas and electricity consumption from utility bills, analyzed for EUI. An estimation of carbon impact based on natural gas and electricity consumption, presented in $\mathrm{KgCO}_{2}$ eq and $\mathrm{KgCO}_{2} e q / \mathrm{m}^{2}$ (EPA, 2016). 


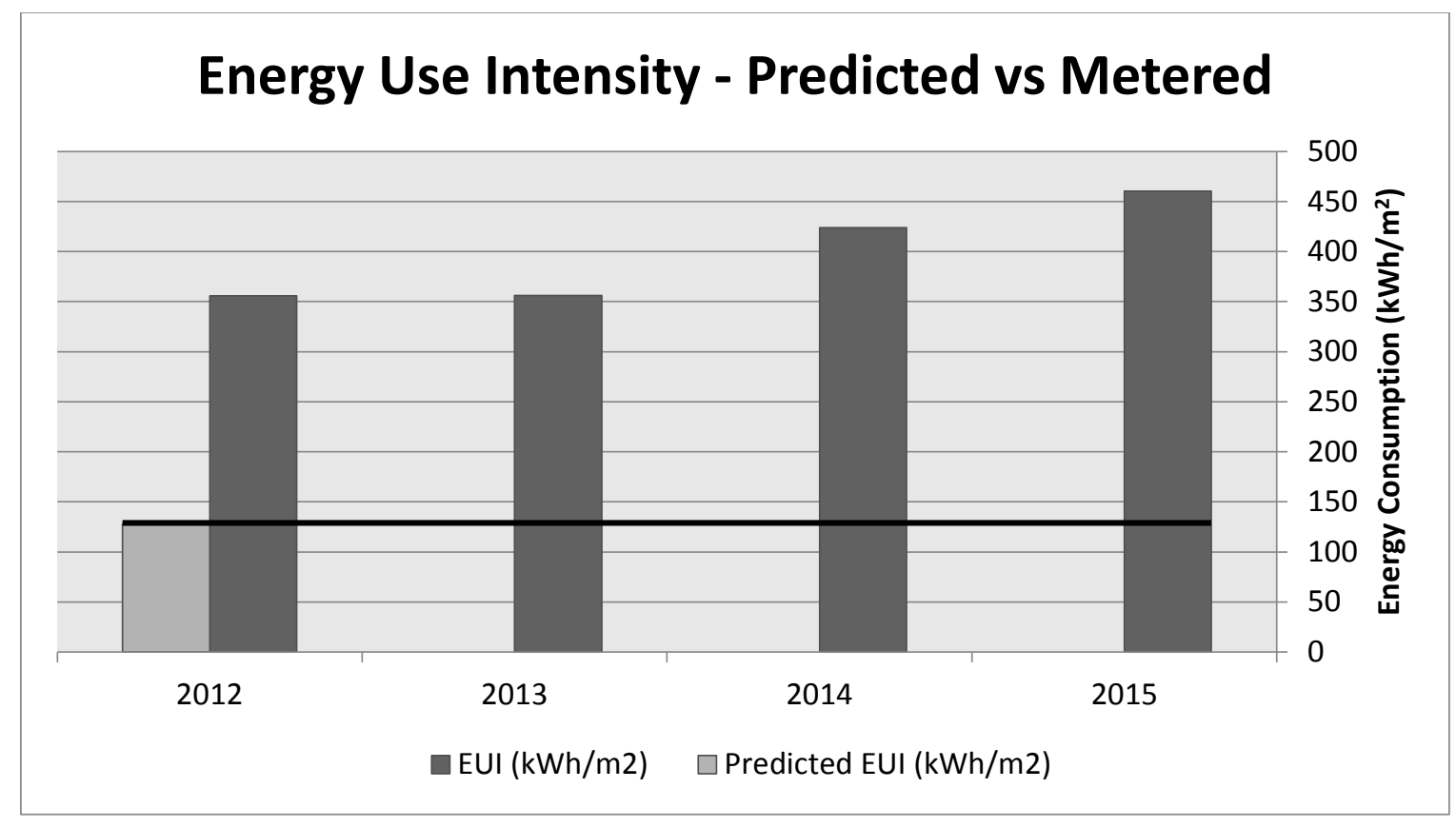

Figure 25. Predicted energy consumption compared with actual energy consumption by annum.

As a portion of the energy audit, a whole building energy simulation was developed using $\mathrm{WUFI}^{\circledR} \mathrm{Plus}$ Dynamic modeling. Climate data for the building location was downloaded through the Passive House Alliance US. PHAUS Climate Data Sets are developed using the DRY data method utilizing the software Meteonorm; climate data is produced with hourly resolution. The simulated climate file is for Toronto's International Airport (cold year), shown in appendix C Figure 9; the simulation occurred over a one year period. 3-dimensional geometry was built using the architectural drawing package and was uploaded to the modeling software as indicated by appendix C Figure 11. Envelope components types and fenestration were added to the model, referencing the architectural drawing package. Interior walls were measured using the architectural drawings and were included in the energy model as a thermal mass component. Internal loads and occupancy were estimated from information gathered in the qualitative interview process. Three occupancy scenarios were modeled simultaneously that included an open plan office, a non-residential kitchen, and conference meeting/seminar for events. Each occupancy scenario was represented in the model by number of weekly functioning hours. The office occupancy was modeled 6 days/week from 7:00 AM to 6:00 PM, the non-residential kitchen was modeled 5 days/week from 10:00 AM to 4:00 PM, the conference meeting/seminar was modeled three days per week from 10:00 AM to 4:00 PM. The natural ventilation rates were input as $0.1 \mathrm{ACH}$ average to account for the opening and closing of building doors. The mechanical ventilation rates were input at $0.3 \mathrm{ACH}$ average as per guidance by ASHRAE. The infiltration rate was added to the model from the calculated $\mathrm{ACH}$ at natural pressure in 
appendix E Table 1 at $0.13 \mathrm{ACH}$. Based on the results of the qualitative infrared data collection described previously in Figure 12, the 193 shading substructure supports were included in the energy model as a thermal bridge, as shown in appendix C Figure 10. An idealized HVAC system was included that would maintain the inner design conditions of $22^{\circ} \mathrm{C}-25^{\circ} \mathrm{C}$ and $30 \% \mathrm{RH}-65 \% \mathrm{RH}$.

The results of the revised building energy simulation predict the annual energy consumption of EBW12 to be 1,242,098 kWh/year for space conditioning. This includes heating, cooling, humidification and dehumidification for the defined occupancy scenario of EBW12 only. This is an EUI of $260 \mathrm{kWh} / \mathrm{m}^{2} /$ year to maintain the interior set point conditions established in the model. This EUI is $103 \%$ higher than the original predicted EUI of $127.8 \mathrm{kWh} / \mathrm{m}^{2} /$ year. The EUI from the revised energy model does not include energy consumption for equipment, lighting, or hot water; which accounts for $37 \%$ of total annual energy consumption based on the original prediction. If $37 \%$ is added to the revised prediction, total energy use increases to $1,701,674 \mathrm{kWh} /$ year or an EUI of $356 \mathrm{kWh} / \mathrm{m}^{2} /$ year. The whole building energy simulation is exclusive to EBW12 and does not include modeled energy consumption for Building 14 that could not previously be separated from the utility bills due to lack of sub-metering. The results of the whole building energy simulation suggest a more realistic consumption scenario for EBW12 and indicate the relative impact that building 14 has on total operational energy. The simulated EUI of 356 represents $89 \%$ of the average operational EUI at $399 \mathrm{kWh} / \mathrm{m}^{2} /$ year; in comparing these values one can speculate the potential relative impact of Building 14. Other factors that could affect the discrepancy between these values include complete calibration of the revised energy model with various weather years. Revisions of the building energy simulation are indicative of the impacts that modeling assumptions have on simulation results. This model has shown that changes to the occupancy and infiltration rate are highly impactful to the calculated energy consumption. Modeling assumptions that do not take a conservative approach can create misconception regarding operational performance and thereby lead to a performance gap.

\subsection{Water}

The EPA median findings indicate that office buildings consume approximately $0.61 \mathrm{~m}^{3} / \mathrm{m}^{2} /$ year (Energy Star, 2012b). These findings are similar to the results in this POE (Figure 26), with EBW12 consuming an average of $0.69 \mathrm{~m}^{3} / \mathrm{m}^{2} /$ year, as per Table 7. EBW12 employs low flow water saving fixtures for toilets, faucets, sinks, showers, and has waterless urinals; as such, a lower water use intensity would be anticipated. However, EBW12 includes a commercial kitchen, and café that would significantly impact the water use intensity. In addition, EBW12 hosts many large events that would also increase annual 
consumption of water. The more intensive occupancy pattern of EBW12 would explain the increased consumption of potable water. Figure 26 indicates the end-use water consumption in EBW12.

\begin{tabular}{|c|c|}
\hline Total Area Supplied $\left(\mathrm{m}^{2}\right)$ & 5728 \\
\hline Total B12 $\left(\mathrm{m}^{3}\right)$ & 3299.21 \\
\hline Water Use Intensity $\left(\mathrm{m}^{3} / \mathrm{m}^{2} /\right.$ year $)$ & 0.69 \\
\hline
\end{tabular}

Table 7. Water use intensity $\mathrm{m}^{3} / \mathrm{m}^{2} /$ year.

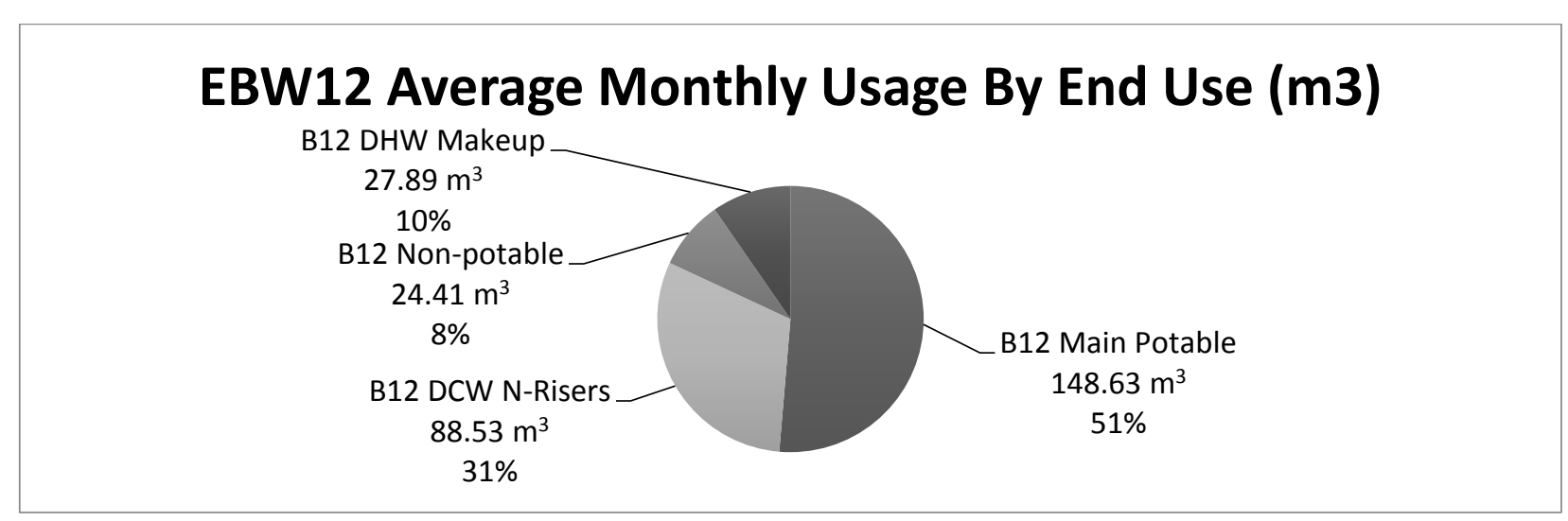

Figure 26. EBW12 average monthly water consumption by end use in $\mathrm{m}^{3}$.

\subsection{Indoor Air Quality \& Indoor Environmental Quality}

ASHRAE 55 \& 62 is the primary benchmark used to analyze thermal comfort and indoor air quality at EBW12. ASHRAE 62-2001 provided considerable guidance on the standards that should be achieved to promote occupant thermal comfort; acceptable ASHRAE comfort zones are shown below in Figure 27. The ASHRAE 55 heating and cooling season comfort zones are often cited, and commonly used as targets by building operators to provide ideal comfort to the majority of building occupants. Results from the indoor air quality analysis are compared to the ASHRAE comfort zones. 


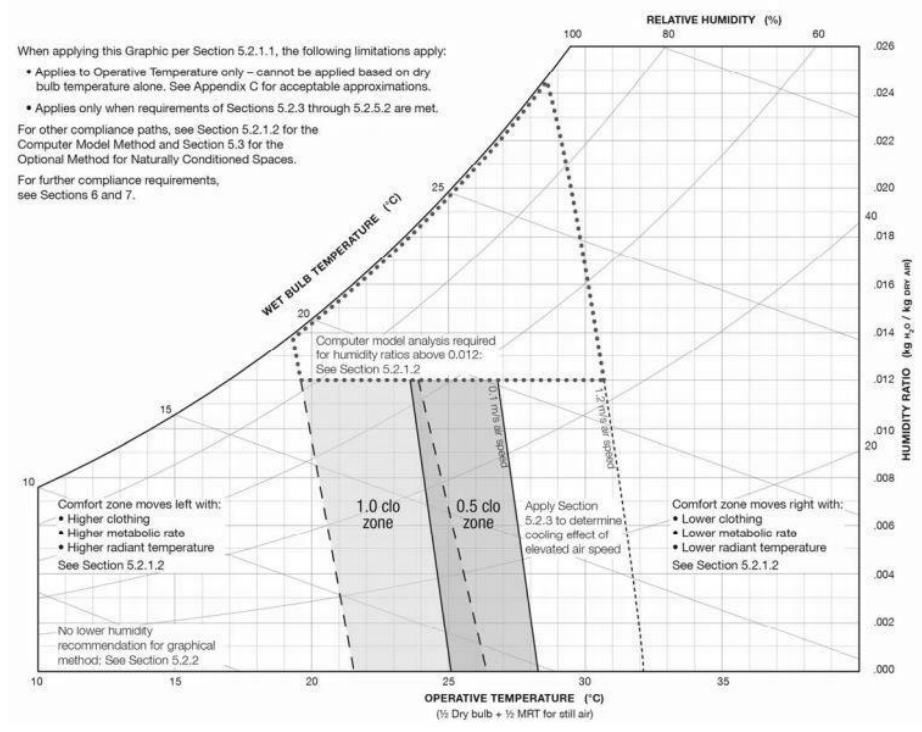

Figure 27. ASHRAE thermal comfort zones, ASHRAE 62-2001.

The following findings are the result of six individual, 20-minute air quality data collections. Data was gathered on $\mathrm{CO}, \mathrm{CO}_{2}$, VOC's, temperature and relative humidity at six different locations in EBW12. Figure 28(a,b) demonstrates that the Evergreen office has the highest average $\mathrm{CO}$ and $\mathrm{CO}_{2}$ level when compared by location, at $0.74 \mathrm{ppm}$ avg and $887.82 \mathrm{ppm}$ respectively. ASHRAE 62.1-2013 states that in sedentary offices steady-state $\mathrm{CO}_{2}$ concentrations of $700 \mathrm{ppm}$ are typical; however, $\mathrm{CO}_{2}$ concentrations up to 1000 to $1200 \mathrm{ppm}$ in office spaces are within the acceptable, safe and normal range. Furthermore, Figure 29(a) shows that the Evergreen office has the second highest average VOC level, second only to the Welcome Center, at $48.02 \mathrm{ppb}$ avg and $65.71 \mathrm{ppb}$ avg, respectively. Health Canada suggests that 40 PPB or less as the concentration target for indoor VOCs. Both World Health Organization and Health Canada suggest that the indoor concentration of VOC's should not increase beyond 100 PPB. Finally, Figure 29(b) shows that the Evergreen office has marginally higher average temperature $\left(22.7^{\circ} \mathrm{C}\right)$ and relative humidity $(42.39 \%)$. These results are not surprising as the Evergreen office is the most densely occupied space in EBW12. The high VOC levels shown in the welcome center, in Figure 29(a), are predictable as this is the main entrance and circulation area of the building. As such, the likely point source of VOC's would be building occupants entering the space from outside (World Health Organization, 2010). 


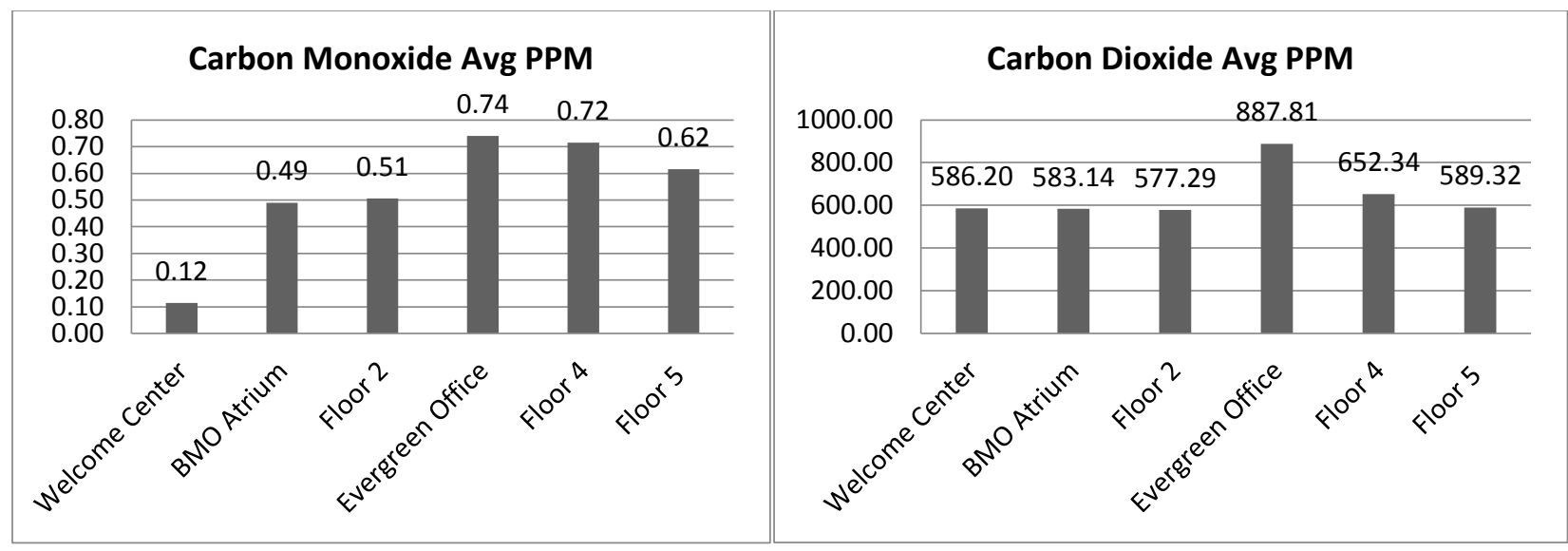

Figure 28. (a) 20-minute $\mathrm{CO}$ average at 6 locations, (b) 20-minute $\mathrm{CO}_{2}$ average at six locations.

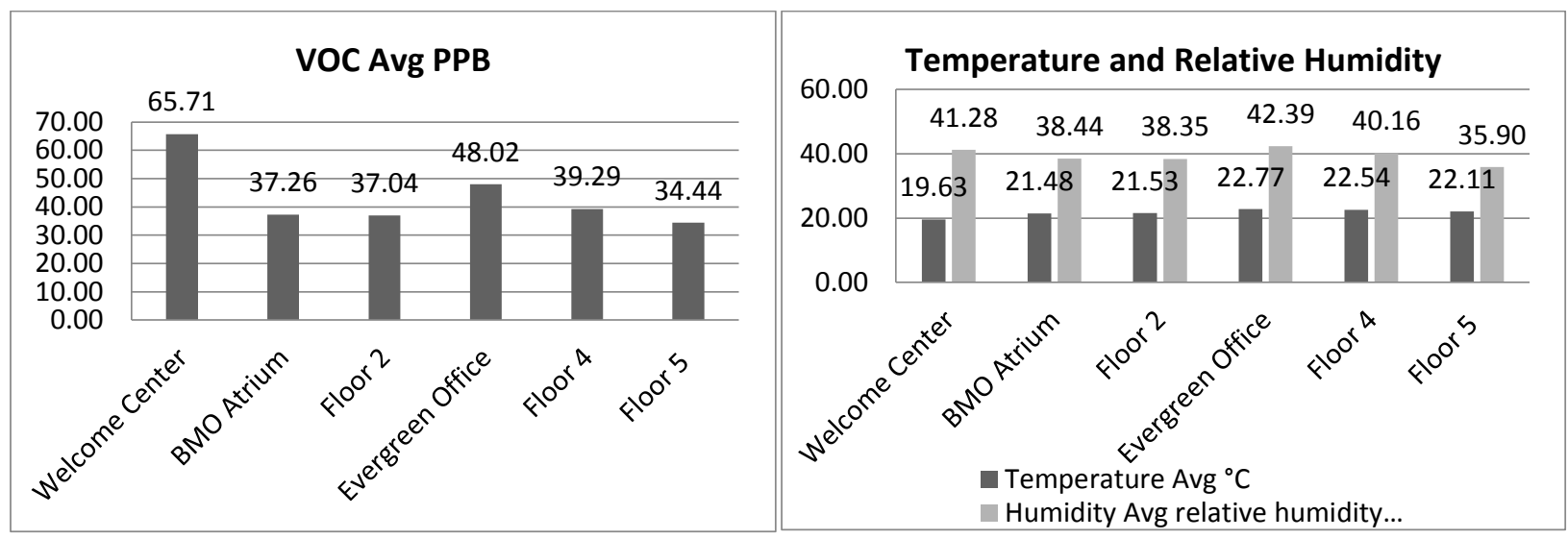

Figure 29. (a) 20-minute VOC average at six locations, (b) 20-minute temperature \& relative humidity at six locations.

The following findings are the result of a 10-day data logging collection period in the Evergreen Office. A data point for $\mathrm{CO}_{2}$, Temperature $\left(\mathrm{T}^{\circ} \mathrm{C}\right)$, and percent relative humidity $(\% \mathrm{RH})$ was collected every 15 minutes for 10 days in the reception area of the evergreen office. This focused data logging was undertaken because the Evergreen office was shown to be an area of higher average $\mathrm{CO}, \mathrm{CO}_{2}, \mathrm{~T}^{\circ} \mathrm{C}$, and $\% \mathrm{RH}$. This more thorough data gathering technique, shown in Figure 30, demonstrates the relationship between occupants $\mathrm{CO}_{2}, \mathrm{~T}^{\circ} \mathrm{C}$, and \%RH. Figure 30 shows large daily swings in $\mathrm{CO}_{2}$ and $\% \mathrm{RH}$. Thereby, it can be determined that the higher than average results shown in this area of EBW12 are more than likely attributable to occupancy patterns. The middle 5 diurnal swings in Figure 30 represent five calendar workdays (Monday to Friday). The highest $\mathrm{CO}_{2}$ level is reached on Wednesday at approximately 15:35. According to ASHRAE 62.1-2013, in sedentary offices steady-state $\mathrm{CO}_{2}$ concentrations of $700 \mathrm{ppm}$ are typical. However, $\mathrm{CO}_{2}$ concentrations up to 1000 to 1200 ppm in office spaces are within the acceptable, safe and normal range. Finally, Figure 30 indicates that relative humidity is far lower than would be 
anticipated for optimal occupant comfort. Relative humidity may be low because of data collection occurring in the winter months. These values are supported by Figure 31 that shows relative humidity fluctuating between $35 \%$ and 40\%; data presented in Figure 30 and Figure 31 was collected with two different instruments. This is congruent with results from the building occupant survey showing the majority of occupants were satisfied with thermal conditions in the winter and summer.

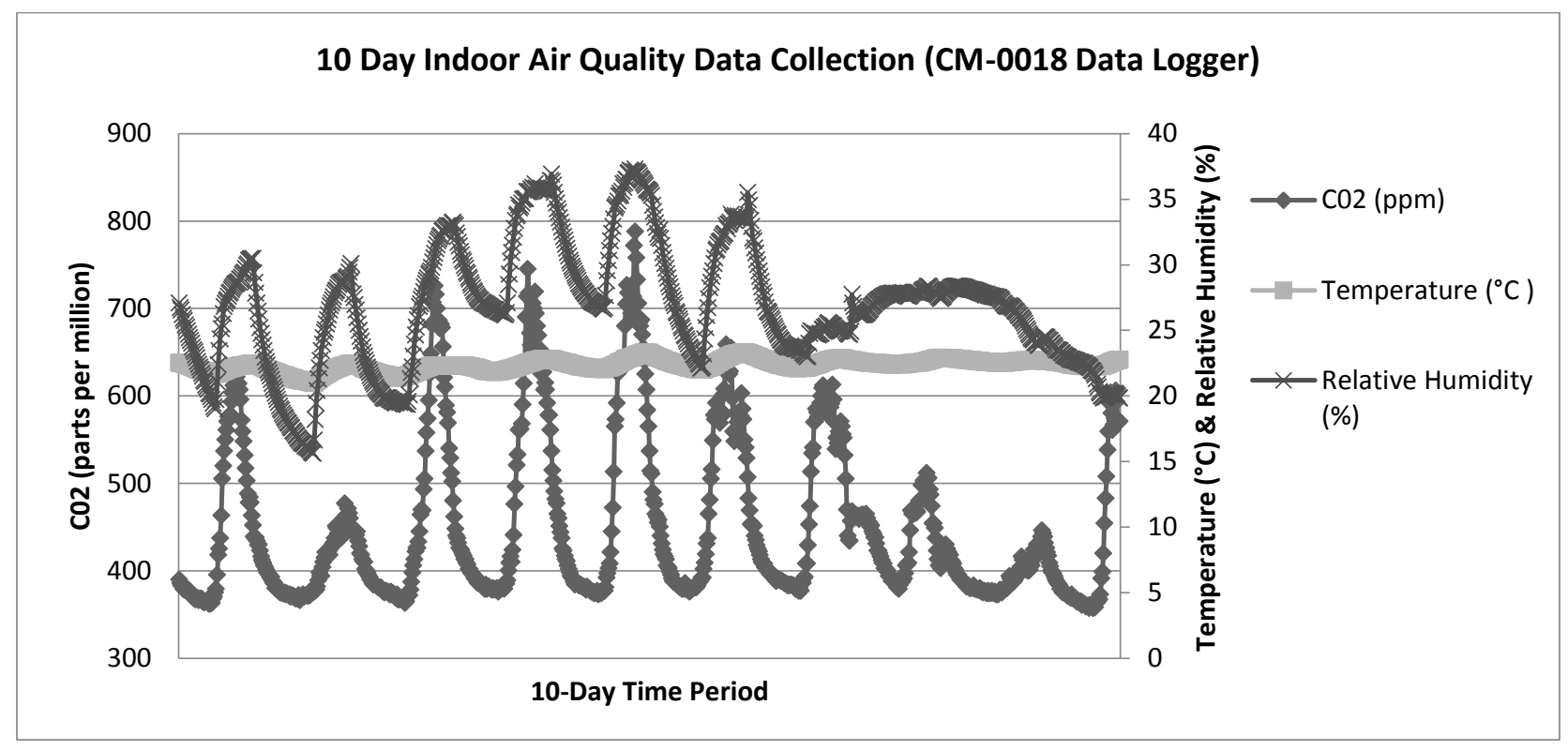

Figure 30. 10-day indoor air quality data collection, Evergreen Office.

The following findings are the result of IAQ monitoring conducted in the Welcome Center during a 50+ person event. Data logging occurred over 5 hours and collected information on $\mathrm{CO}_{2}, \mathrm{CO}, \mathrm{T}^{\circ} \mathrm{C}, \% \mathrm{RH}, \mathrm{VOC}$ avg, and dust avg. The goal of this collection was to determine the influence that occupants had on IAQ in the Welcome Center as this area is a common event space and high traffic circulation area. Figure 31 shows that $\mathrm{CO}_{2}, \mathrm{~T}^{\circ} \mathrm{C}, \% \mathrm{RH}$ all increased steadily during the event period. $\mathrm{CO}_{2}$ peaked at $780 \mathrm{ppm}$ at approximately 13:10. According to ASHRAE 62.1-2013, this falls within the safe and acceptable range of $\mathrm{CO}_{2}$ levels. Figure 32 shows a steady but moderate rise in VOC ppb over the event period. This is likely due to increased circulation of event occupants. The WHO formaldehyde guideline states that the maximum acceptable level of airborne VOC's is 100 ppb (World Health Organization, 2010); the readings taken show that the VOC levels do not exceed $45 \mathrm{ppb}$. The anomalous rise in VOC at the initiation of the recording period is likely due to instrument manipulation during set-up. 


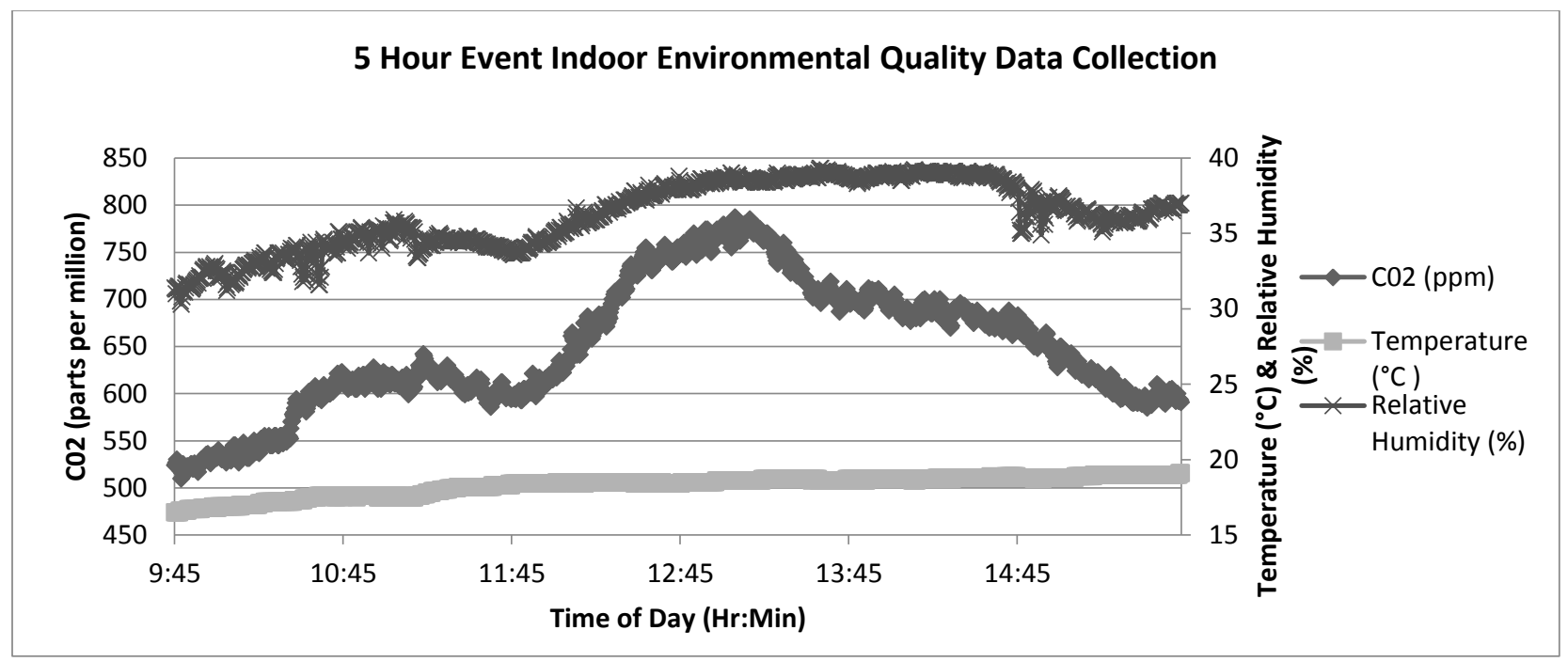

Figure 31. $\mathrm{CO}_{2}, T^{\circ} \mathrm{C}, \% \mathrm{RH}$ collected over 5 hour event period.

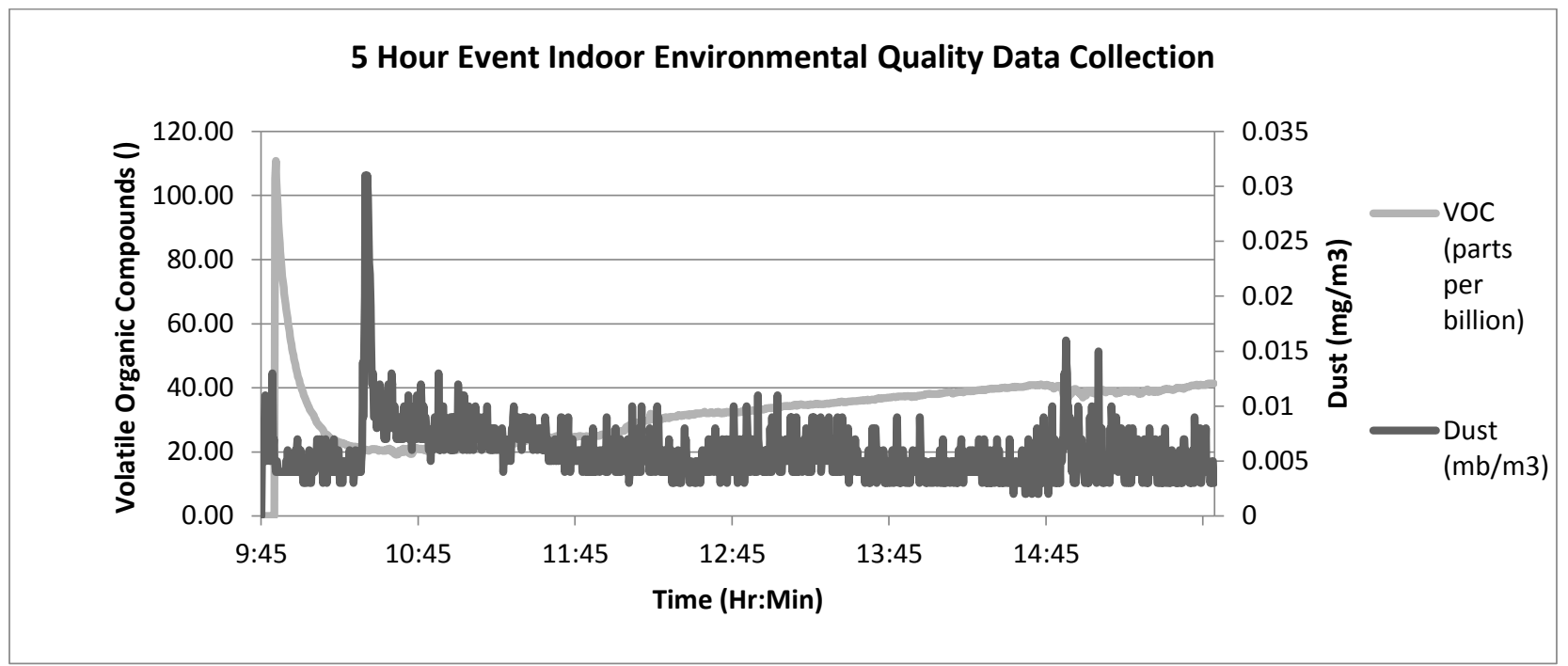

Figure 32. VOC (PPB) and dust $\left(\mathrm{mg} / \mathrm{m}^{3}\right)$ collected over 5-hour event period.

Results of the whole building energy simulation provided information on the predicted indoor environment. The simulation agrees with the results from both the indoor air quality analysis and the building occupant survey. Figure 33 indicates that the simulated thermal comfort operating threshold of EBW12 closely overlap with ASHRAE's thermal comfort zones shown in Figure 27. The predictive model showed showed that $\mathrm{CO}_{2}$ concentrations did not exceed $1029 \mathrm{ppm}$ despite modeling three overlapping occupancy scenarios; this supports the findings in Figures 28, 29 and 30, where measured $\mathrm{CO}_{2}$ levels fall below the simulated threshold. 


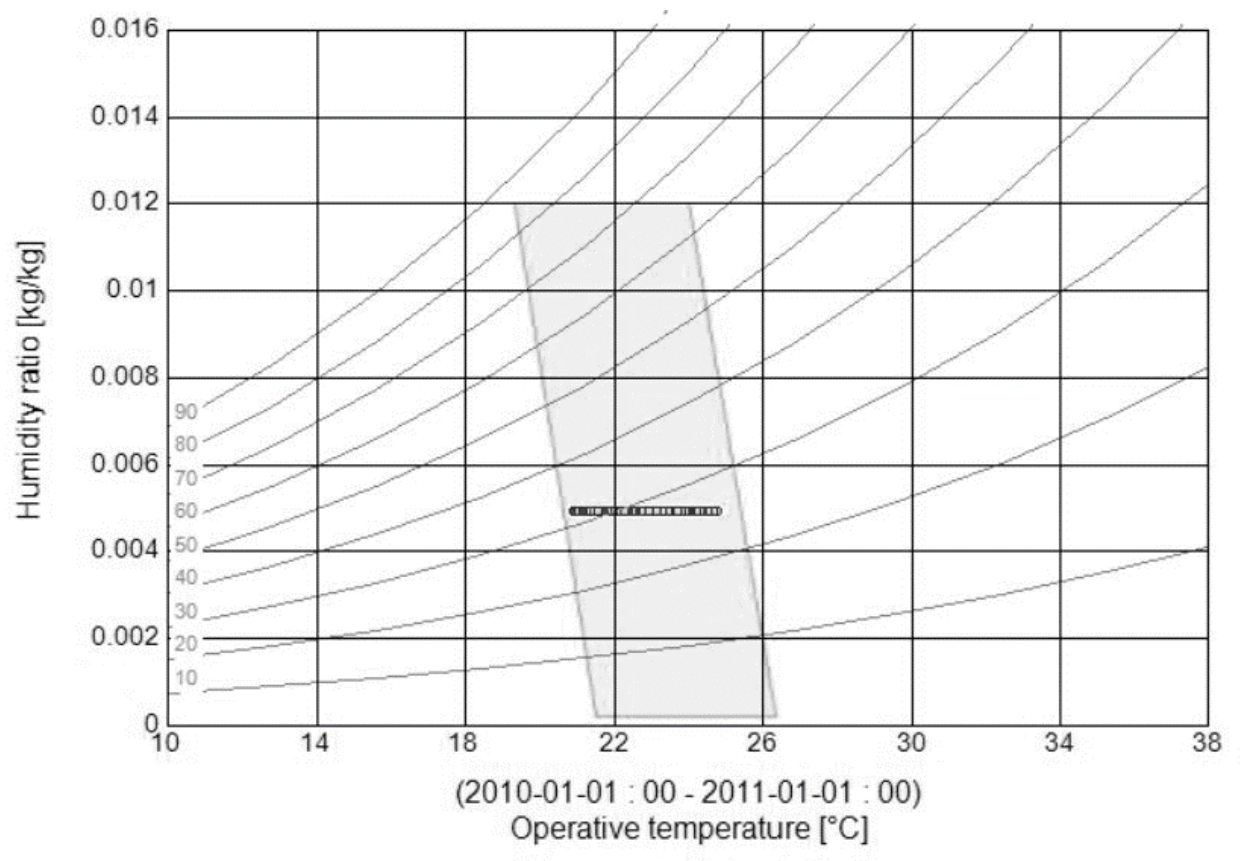

Figure 33: Simulated indoor air conditions, output from WUFI ${ }^{\circledR}$ Plus.

\subsection{Whole Building Air Leakage Evaluation}

Normalized metrics are critical for comparing and contrasting the air leakage performance of various buildings. As such, consistent normalized surface area and volume units are used in this report and are as follows. The common surface area metric for discussing results will be the Normalized Leakage Rate at 75 $\mathrm{Pa}\left(N L R_{75}\right)$. This metric normalizes the leakage rate to units of building enclosure surface area and is calculated as follows: $\mathrm{NLR}_{75}=$ total leakage rate at $75 \mathrm{~Pa}$ /enclosure area. The common volume metric for discussing results in this report will be Air Changes per Hour at $75 \mathrm{~Pa}(\mathrm{ACH} / 75)$ This metric normalizes the leakage rate to units of building volume and is calculated as follows: $\mathrm{ACH} / 75=$ total leakage rate per hour at $75 \mathrm{~Pa}$ /building volume.

The results of test stage one (depressurization) indicate an average air leakage rate of $3.44 \mathrm{~L} / \mathrm{s} / \mathrm{m}^{2}$ at a pressure gradient of $-75 \mathrm{~Pa}$ (Table $9(\mathrm{a}, \mathrm{b})$, Figure 35). In other words, 3.44 litres of air are moving through each square meter of building enclosure when a negative pressure gradient of $-75 \mathrm{~Pa}$ is created across it, as per Table 8. The results of test stage two (pressurization) indicate an average air leakage rate of 3.25 $\mathrm{L} / \mathrm{s} / \mathrm{m}^{2}$ at a pressure gradient of $75 \mathrm{~Pa}$ (Table $10(\mathrm{a}, \mathrm{b})$, Figure 35$)$. As such, 3.25 litres of air are moving through each square meter of building enclosure when a positive pressure gradient of $75 \mathrm{~Pa}$ is created across it, as per Table 8. Normalized leakage rates have also been calculated at $50 \mathrm{~Pa}, 10 \mathrm{~Pa}$ and $4 \mathrm{~Pa}$. For 
context and comparative purposes, additional units of measure and imperial results from the air leakage evaluation are shown in Appendix Table 1.

\begin{tabular}{|l|l|l|}
\hline Pressure Gradient & $\begin{array}{l}\text { Test Stage1 } \\
\text { Depressurization }\end{array}$ & $\begin{array}{l}\text { Test Stage 2 } \\
\text { Pressurization }\end{array}$ \\
\hline $4 \mathrm{~Pa}$ & $0.66 \mathrm{~L} / \mathrm{s}^{2}$ & $0.61 \mathrm{~L} / \mathrm{s} / \mathrm{m}^{2}$ \\
\hline $10 \mathrm{~Pa}$ & $1.11 \mathrm{~L} / \mathrm{s} / \mathrm{m}^{2}$ & $1.03 \mathrm{~L} / \mathrm{s} / \mathrm{m}^{2}$ \\
\hline $50 \mathrm{~Pa}$ & $2.68 \mathrm{~L} / \mathrm{s} / \mathrm{m}^{2}$ & $2.64 \mathrm{~L} / \mathrm{s} / \mathrm{m}^{2}$ \\
\hline $75 \mathrm{~Pa}$ & $3.44 \mathrm{~L} / \mathrm{s} / \mathrm{m}^{2}$ & $3.25 \mathrm{~L} / \mathrm{s} / \mathrm{m}^{2}$ \\
\hline
\end{tabular}

Table 8. Summary of test results indicating the number of litres of air moving through each square meter of the building enclosure every second at pressure. 


\subsubsection{Test Stage 1: Whole Building Depressurization}

a) Test Results

\begin{tabular}{|l|l|}
\hline $\mathrm{Pa}$ & Flow Rate $(\mathrm{I} / \mathrm{s})$ \\
\hline $\mathbf{7 5}$ & 15892.90 \\
\hline $\mathbf{7 0}$ & 15287.67 \\
\hline $\mathbf{6 5}$ & 14863.96 \\
\hline $\mathbf{6 0}$ & 13983.54 \\
\hline $\mathbf{5 5}$ & 13502.11 \\
\hline $\mathbf{5 0}$ & 12467.46 \\
\hline $\mathbf{4 5}$ & 11774.22 \\
\hline $\mathbf{4 0}$ & 10954.26 \\
\hline $\mathbf{3 5}$ & 9950.43 \\
\hline
\end{tabular}

b) Calculated Results

\begin{tabular}{|l|l|l|}
\hline $\mathbf{P a}$ & Flow Rate $(\mathrm{l} / \mathrm{s})$ & $\mathrm{NLR}_{75}\left(\mathrm{I} / \mathrm{s} / \mathrm{m}^{2}\right)$ \\
\hline $\mathbf{1 0}$ & 5336.33 & 1.11 \\
\hline $\mathbf{4}$ & 3185.68 & 0.66 \\
\hline & Leakage Area $\left(\mathrm{m}^{2}\right)$ \\
\hline EqLA 10 Pa & 2.14 \\
\hline ELA 4 Pa & 1.24 \\
\hline
\end{tabular}

Table $9(a, b)$. Summary of calculated results from pressurization test.

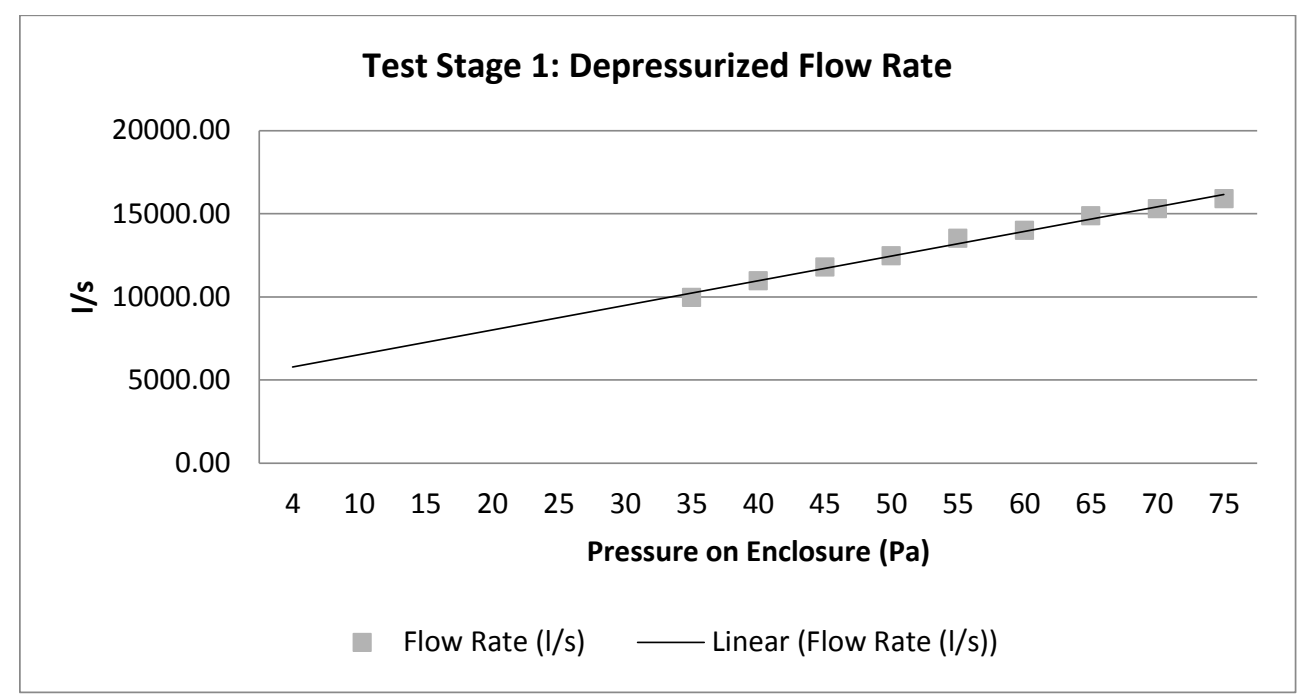

Figure 34. Summary of calculated results from pressurization test. 


\subsubsection{Test Stage 2: Whole Building Pressurization}

a)

\begin{tabular}{|l|l|}
\hline \multicolumn{2}{|l|}{ Test Results } \\
\hline $\mathrm{Pa}$ & Flow Rate $(\mathrm{I} / \mathrm{s})$ \\
\hline $\mathbf{7 5}$ & 16142.55818 \\
\hline $\mathbf{7 0}$ & 15610.29673 \\
\hline $\mathbf{6 5}$ & 14766.59767 \\
\hline $\mathbf{6 0}$ & 14494.52042 \\
\hline $\mathbf{5 5}$ & 13571.81749 \\
\hline $\mathbf{5 0}$ & 13114.59556 \\
\hline $\mathbf{4 5}$ & 12409.88479 \\
\hline $\mathbf{4 0}$ & 11543.15474 \\
\hline $\mathbf{3 5}$ & 10889.79178 \\
\hline
\end{tabular}

b) Calcualted Results

\begin{tabular}{|l|l|l|}
\hline $\mathrm{Pa}$ & Flow Rate $(\mathrm{I} / \mathrm{s})$ & $\mathrm{NLR}_{75}\left(\mathrm{l} / \mathrm{s} / \mathrm{m}^{2}\right)$ \\
\hline 10 & 4970.75 & 1.032562 \\
\hline $\mathbf{4}$ & 2951.17 & 0.613039 \\
\hline & Leakage Area $\left(\mathrm{m}^{2}\right)$ \\
\hline EqLA 10 Pa & 2 \\
\hline ELA 4 Pa & 1.15 \\
\hline
\end{tabular}

Table $10(a, b)$. Summary of calculated results from depressurization test.

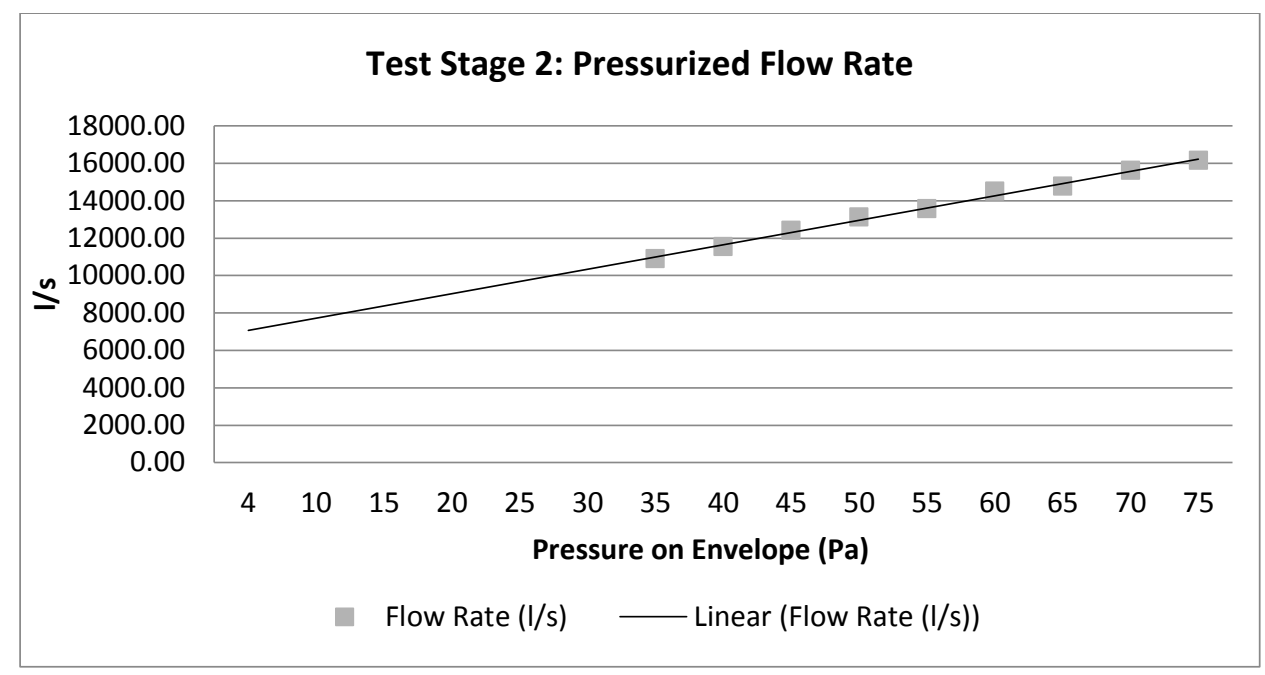

Figure 35. Summary of calculated results from depressurization test.

The results of the building enclosure air leakage evaluation were compared to NLR 75 industry standards, specifically the 2012 International Energy Conservation Code (IECC), 2009 ASHRAE Handbook of Fundamentals Ch16 Ventilation and Infiltration, 2012 US army Corps of Engineers (USACE)/2012 Air Barrier Association of America (ABAA), and the 2010 National Building Code of Canada. The results of the building enclosure air leakage evaluation indicate that the building enclosure is comparatively more leaky than the cited industry standards. This comparison indicates that the EBW12 building enclosure, NLR 75 $3.44 \mathrm{l} / \mathrm{s} / \mathrm{m}^{2}$, is more leaky than the "leaky" enclosure guideline indicated by ASHRAE 2009, NLR $3 \mathrm{l} / \mathrm{s} / \mathrm{m}^{2}$. This comparative analysis is shown graphically in Figure 36. 


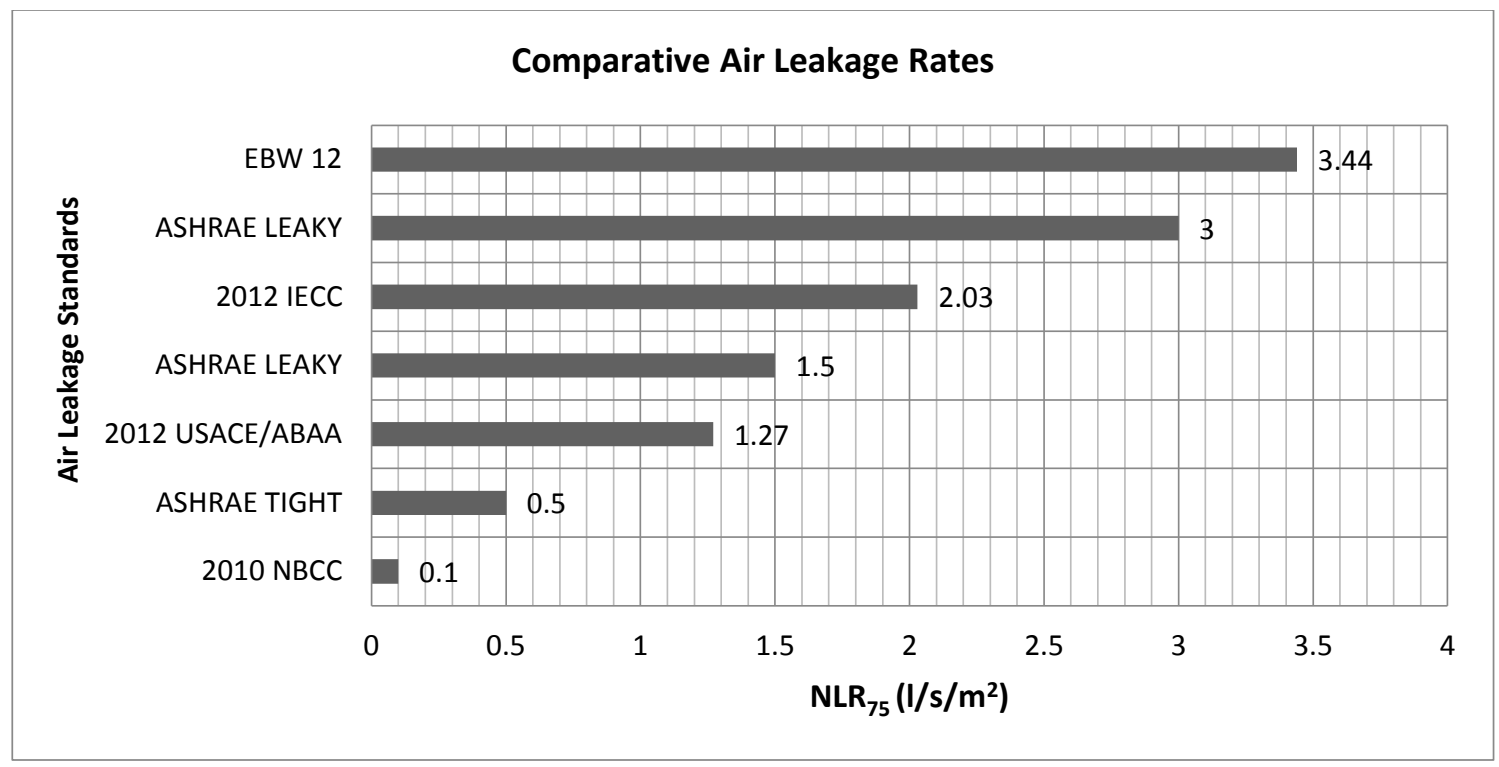

Figure 36. Comparative Air Leakage Rates, EBW12 versus industry standards.

The results of the building enclosure air leakage evaluation can be expressed in a number of different metrics. One metric to help communicate the results is equivalent or effective leakage area. Based on the building volume, surface area and recorded air flow rate through the mechanical fan units an approximation of all the building's openings, leaks and cracks can be estimated. The equivalent results indicate an approximate surface area that can be compared to the relative surface area of the building. In other words, each gap or crack in the building enclosure is combined into a single opening. This value can be conceptualized as a window that is open 24 hours per day, 365 days per year. Table 11 indicates the estimated sum of all openings in the building enclosure based on the Stage 1 and Stage 2 test results. Results in this table are shown using the American metric Effective Leakage Area (ELA at $4 \mathrm{~Pa}$ ) and the Canadian metric Equivalent Leakage Area (EqLA at $10 \mathrm{~Pa}$ ).

\begin{tabular}{|l|l|l|}
\hline Envelope Pressure & $\begin{array}{l}\text { Test Stage 1 } \\
\text { Depressurization }\end{array}$ & $\begin{array}{l}\text { Test Stage 2 } \\
\text { Pressurization }\end{array}$ \\
\hline 4 Pa (ELA) & $1.25 \mathrm{~m}^{2}$ & $1.14 \mathrm{~m}^{2}$ \\
\hline $10 \mathrm{~Pa}$ (EqLA) & $2.14 \mathrm{~m}^{2}$ & $1.99 \mathrm{~m}^{2}$ \\
\hline $\begin{array}{l}\text { EBW12 Estimated } \\
\text { Surface Area: }\end{array}$ & $4,814 \mathrm{~m}^{2}$ & $4,814 \mathrm{~m}^{2}$ \\
\hline
\end{tabular}

Table 11. Summary of test results indicating the sum of all cracks, holes, etc., into one equivalent sized opening in square meters.

The results of the duct leakage to outside test indicate that the mechanically assisted vertical ventilation shafts or "solar chimneys" are a poorly sealed component of the enclosure. As previously discussed in the 
methodology section of this report, the mechanical dampers at the roof were isolated by sealing all major openings with polyethylene and tape. The entire building was subsequently depressurized and pressurized using the fan units, with pressure holds of $75 \mathrm{~Pa}, 50 \mathrm{~Pa}$, and $25 \mathrm{~Pa}$. As all other openings were isolated, the pressure exerted on the envelope forced air through the mechanical dampers at the top of the solar chimney. The air movement through the mechanical dampers was measured at the $5^{\text {th }}$ floor corridor, using a Balometer unit on the ventilation opening. Results were recorded by the balometer at the pressure holds, and are shown in Table 12. Figure 37 is a linear regression of averaged data shown in Table 12. The linear regression analysis shown in Figure 3 extrapolates a trendline below $25 \mathrm{~Pa}$ based on the results of Table 12, and indicates how much air leakage may be occurring through the mechanical dampers at ambient or normal pressures. Figure 38 compares the flow rates of air through the envelope and the solar chimneys at $75 \mathrm{~Pa}, 50 \mathrm{~Pa}, 25 \mathrm{~Pa}, 10, \mathrm{~Pa}$, and $4 \mathrm{~Pa}$; the air flow rate has been normalized by area displaying data in $\mathrm{l} / \mathrm{s} / \mathrm{m}^{2}$. This figure indicates that when normalized by surface area $\left(\mathrm{m}^{2}\right)$ the air flow rate through the mechanical dampering system in the solar chimney is higher than the measured air flow rate through the envelope. However, the relative area of the tree mechanical damper openings (17.82 $\left.\mathrm{m}^{2}\right)$ is quite small compared to the area of the building enclosure $\left(4814.0 \mathrm{~m}^{2}\right)$. Thereby, the relative impact of the dampers to the overall air leakage of the building is limited.

\begin{tabular}{|c|c|c|}
\hline Solar Chimney Pressure Test & $\begin{array}{c}\text { Test Stage 1 } \\
\text { Depressurization }\end{array}$ & $\begin{array}{c}\text { Test Stage 2 } \\
\text { Pressurization }\end{array}$ \\
\hline $\mathbf{2 5} \mathrm{Pa}$ & $16.61 \mathrm{l} / \mathrm{s}$ & $10.0 \mathrm{I} / \mathrm{s}$ \\
\hline $\mathbf{2 5} \mathrm{Pa}$ & $19.44 \mathrm{I} / \mathrm{s}$ & 10.95 \\
\hline $\mathbf{2 5} \mathrm{Pa}$ & $16.75 \mathrm{I} / \mathrm{s}$ & $11.1 \mathrm{l} / \mathrm{s}$ \\
\hline $\mathbf{5 0} \mathrm{Pa}$ & $22.65 \mathrm{I} / \mathrm{s}$ & $20.86 \mathrm{I} / \mathrm{s}$ \\
\hline $\mathbf{5 0} \mathrm{Pa}$ & $21.71 \mathrm{l} / \mathrm{s}$ & $21.05 \mathrm{I} / \mathrm{s}$ \\
\hline $\mathbf{5 0} \mathrm{Pa}$ & $21.94 \mathrm{l} / \mathrm{s}$ & $20.05 \mathrm{I} / \mathrm{s}$ \\
\hline $\mathbf{7 5} \mathrm{Pa}$ & $28.37 \mathrm{l} / \mathrm{s}$ & $24.1 \mathrm{l} / \mathrm{s}$ \\
\hline $\mathbf{7 5} \mathrm{Pa}$ & $28.41 \mathrm{l} / \mathrm{s}$ & $24.1 \mathrm{l} / \mathrm{s}$ \\
\hline $\mathbf{7 5} \mathrm{Pa}$ & $28.78 \mathrm{I} / \mathrm{s}$ & $23.93 \mathrm{I} / \mathrm{s}$ \\
\hline
\end{tabular}

Table 12. Results of the solar chimney pressurization test, indicating the amount of air moving through the mechanical dampering system in the solar chimneys. 


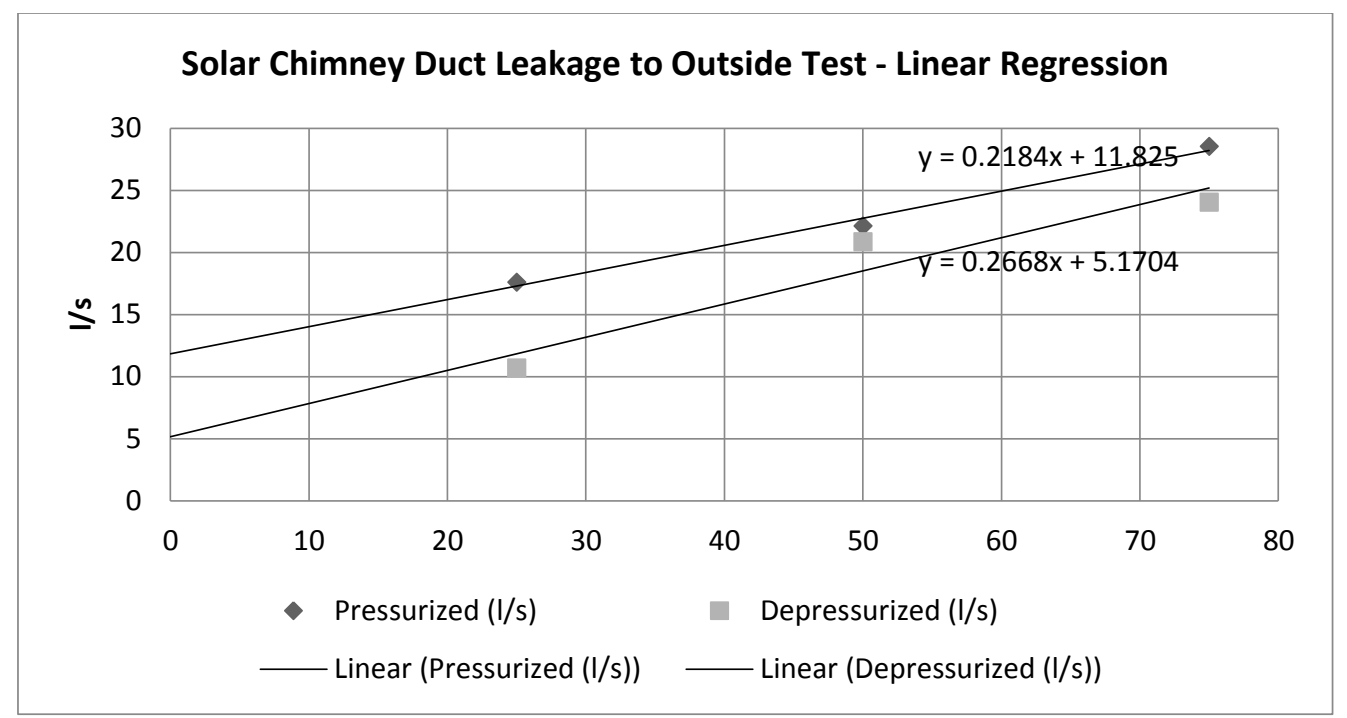

Figure 37. Linear regression of averaged data from Table 11; trendline indicating air flow rate at ambient pressure.

\begin{tabular}{|l|l|l|}
\hline $\begin{array}{l}\text { Pressure Across the } \\
\text { Enclosure }\end{array}$ & $\begin{array}{l}\text { Test Stage 1 } \\
\text { Depressurization }\end{array}$ & $\begin{array}{l}\text { Test Stage 2 } \\
\text { Pressurization }\end{array}$ \\
\hline $4 \mathrm{~Pa}$ & $1.05 \mathrm{~L} / \mathrm{s} / \mathrm{m}^{2}$ & $2.14 \mathrm{~L} / \mathrm{s} / \mathrm{m}^{2}$ \\
\hline $10 \mathrm{~Pa}$ & $1.32 \mathrm{~L} / \mathrm{s} / \mathrm{m}^{2}$ & $2.36 \mathrm{~L} / \mathrm{s} / \mathrm{m}^{2}$ \\
\hline $25 \mathrm{~Pa}$ & $1.80 \mathrm{~L} / \mathrm{s} / \mathrm{m}^{2}$ & $2.96 \mathrm{~L} / \mathrm{s} / \mathrm{m}^{2}$ \\
\hline $50 \mathrm{~Pa}$ & $3.51 \mathrm{~L} / \mathrm{s} / \mathrm{m}^{2}$ & $3.88 \mathrm{~L} / \mathrm{s} / \mathrm{m}^{2}$ \\
\hline $75 \mathrm{~Pa}$ & $4.04 \mathrm{~L} / \mathrm{s} / \mathrm{m}^{2}$ & $4.80 \mathrm{~L} / \mathrm{s} / \mathrm{m}^{2}$ \\
\hline
\end{tabular}

Table 13. Summary of test results indicating the number of litres of air moving through one solar chimney roof dampering system with a surface area of $5.94 \mathrm{~m}^{2}$; data normalized to surface area $\mathrm{L} / \mathrm{s} / \mathrm{m}^{2}$.

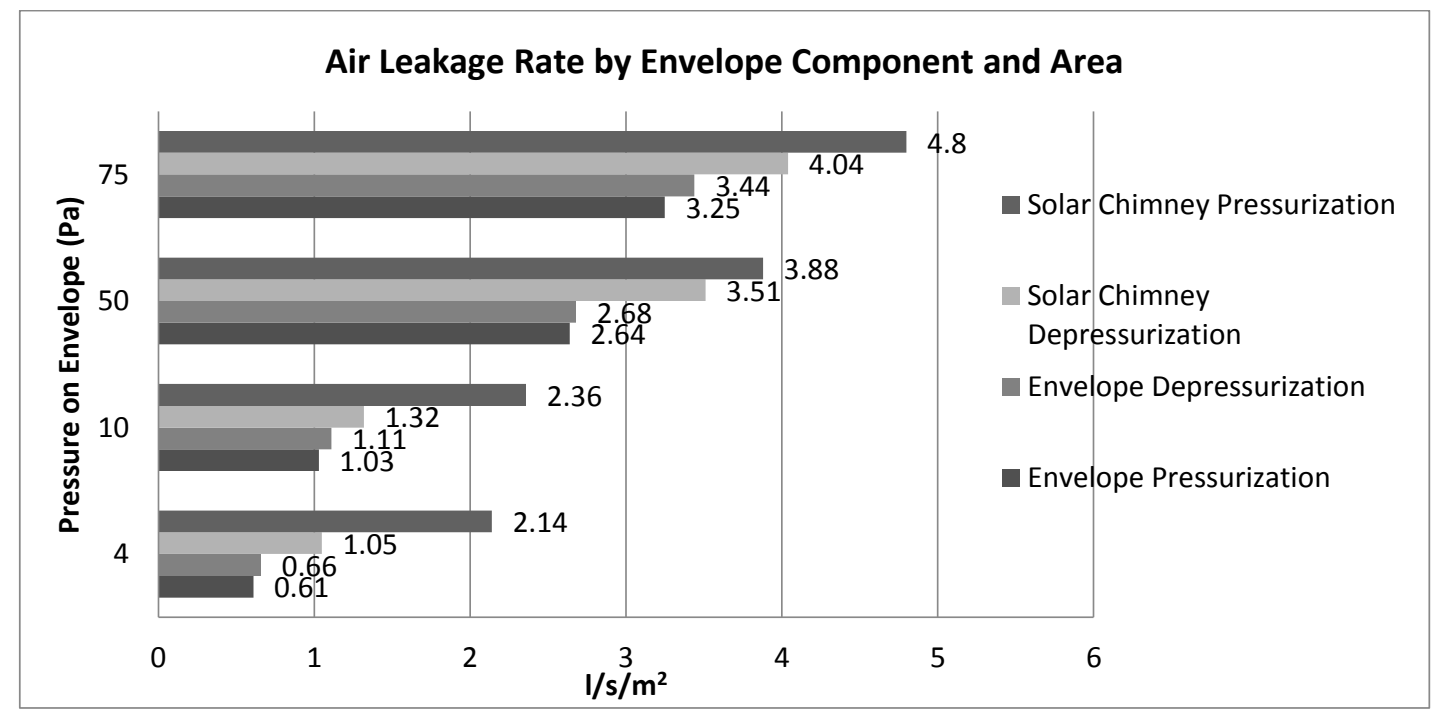

Figure 38. Comparative air leakage rates of building enclosure components normalized by surface area $\left(\mathrm{l} / \mathrm{s} / \mathrm{m}^{2}\right)$. 
The quantitative results, which indicate that the solar chimney dampers are a poorly sealed component of the enclosure, are further supported by data collected using thermography and IAQ temperature readings. Thermographic images of the damper houses, presented in the Thermography section of this report, show higher relative enclosure surface temperatures then surrounding areas. Furthermore, the images show significantly higher internal air temperatures inside the damper houses compared to the outside ambient temperatures. These figures support the above findings, indicating that the mechanical dampers may be an air leakage pathway. The building occupant survey did not indicate thermal comfort issues that could be expected to occur with a building enclosure air leakage rate this high. Building occupants may not notice drafts from air leakage due to the hydronic and perimeter radiative heat. Given the exterior and interior condition of the ground floor brick assembly, as shown in Figure 39 and Figure 40 , it is most likely that this area is the most leaky portion of the building enclosure. Diffuse air leakage through porous brick and cementitious mortar, or cracked brick and mortar could be responsible for the air leakage rate. Further investigation into ground floor air leakage could be undertaken using guarded air leakage testing and smoke pencil testing to determine the location of air leakage. Remediation of the original brick assembly to lower the air leakage rate could be accomplished with a cementitious overcoating. The predictive energy simulation originally developed for this project would not have accounted for such a high infiltration/exfiltration rate. As a result, the energy performance gap noted in the energy section of this report may be $s$ associated with the modeled rate versus the actual rate. 

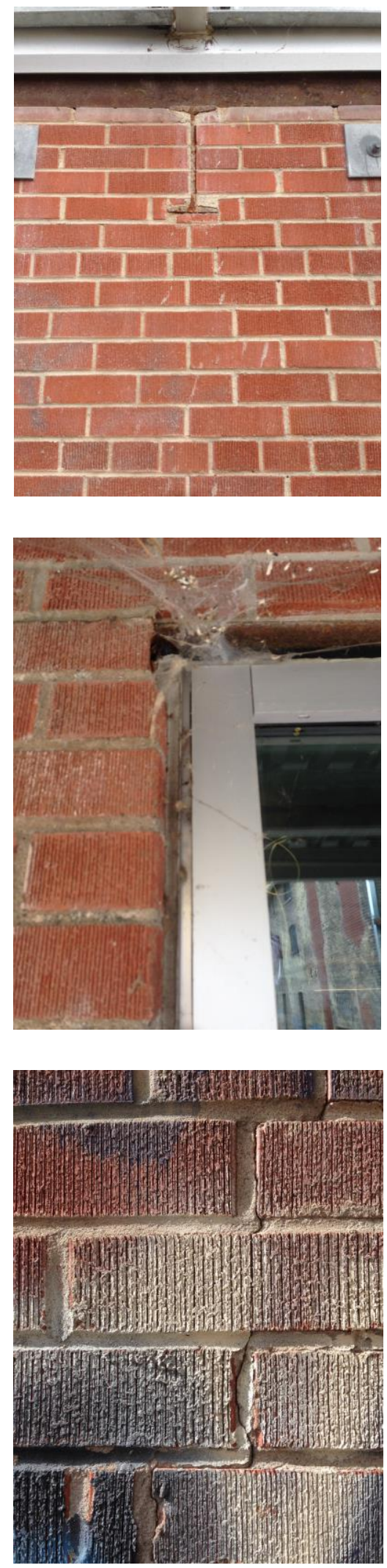
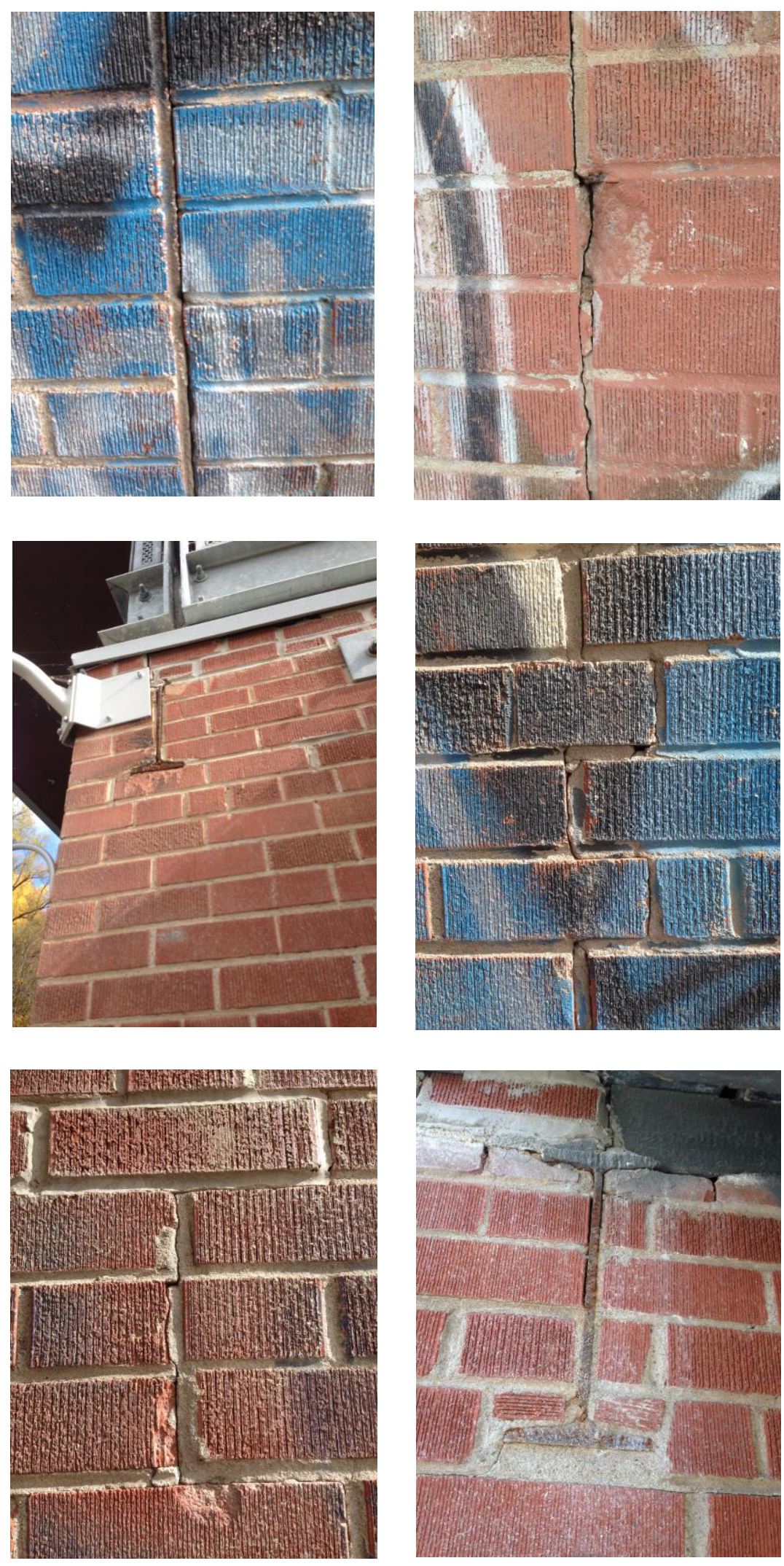

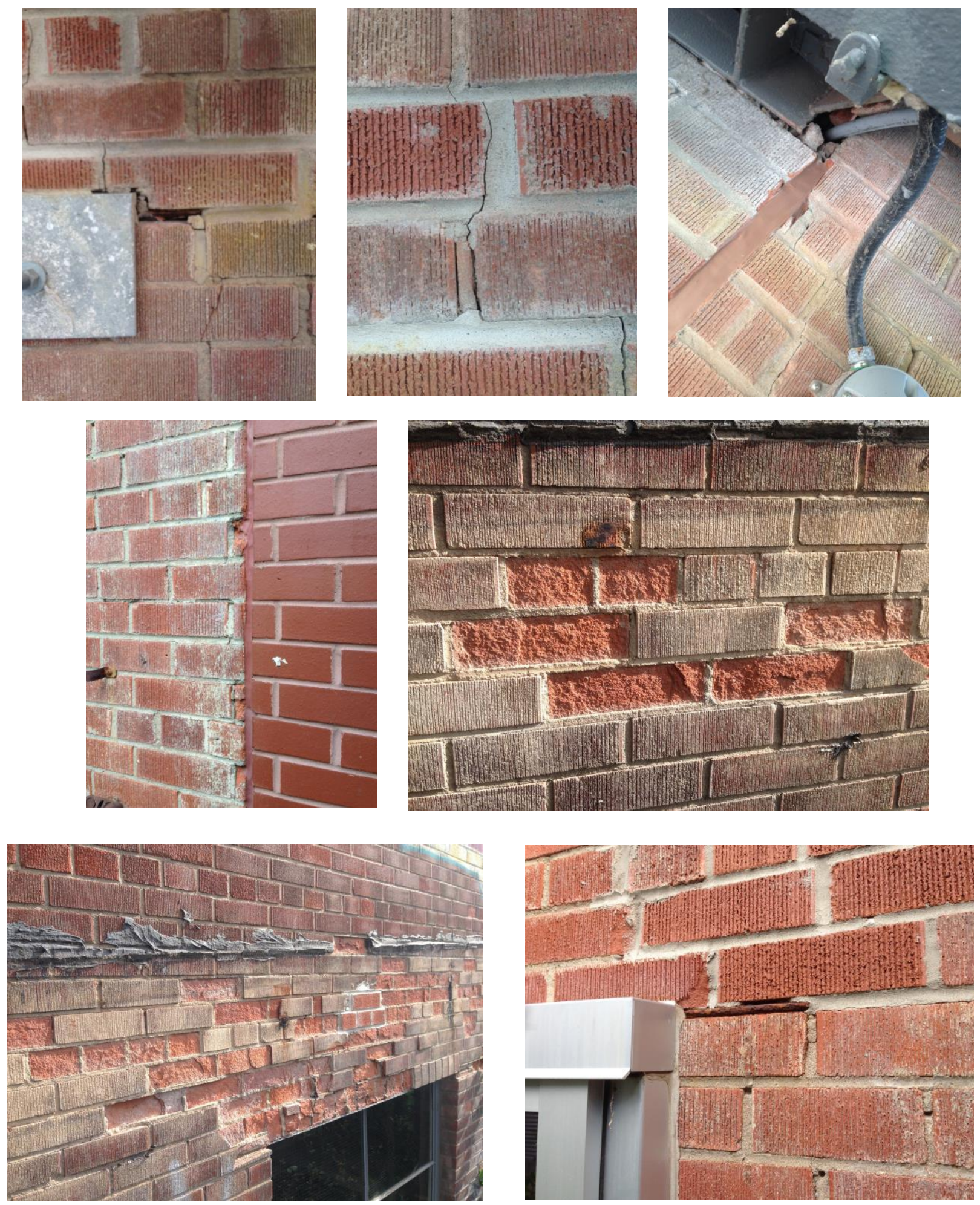

Figure 39. Images of deteriorated exterior brick indicating areas of potential air leakage. 

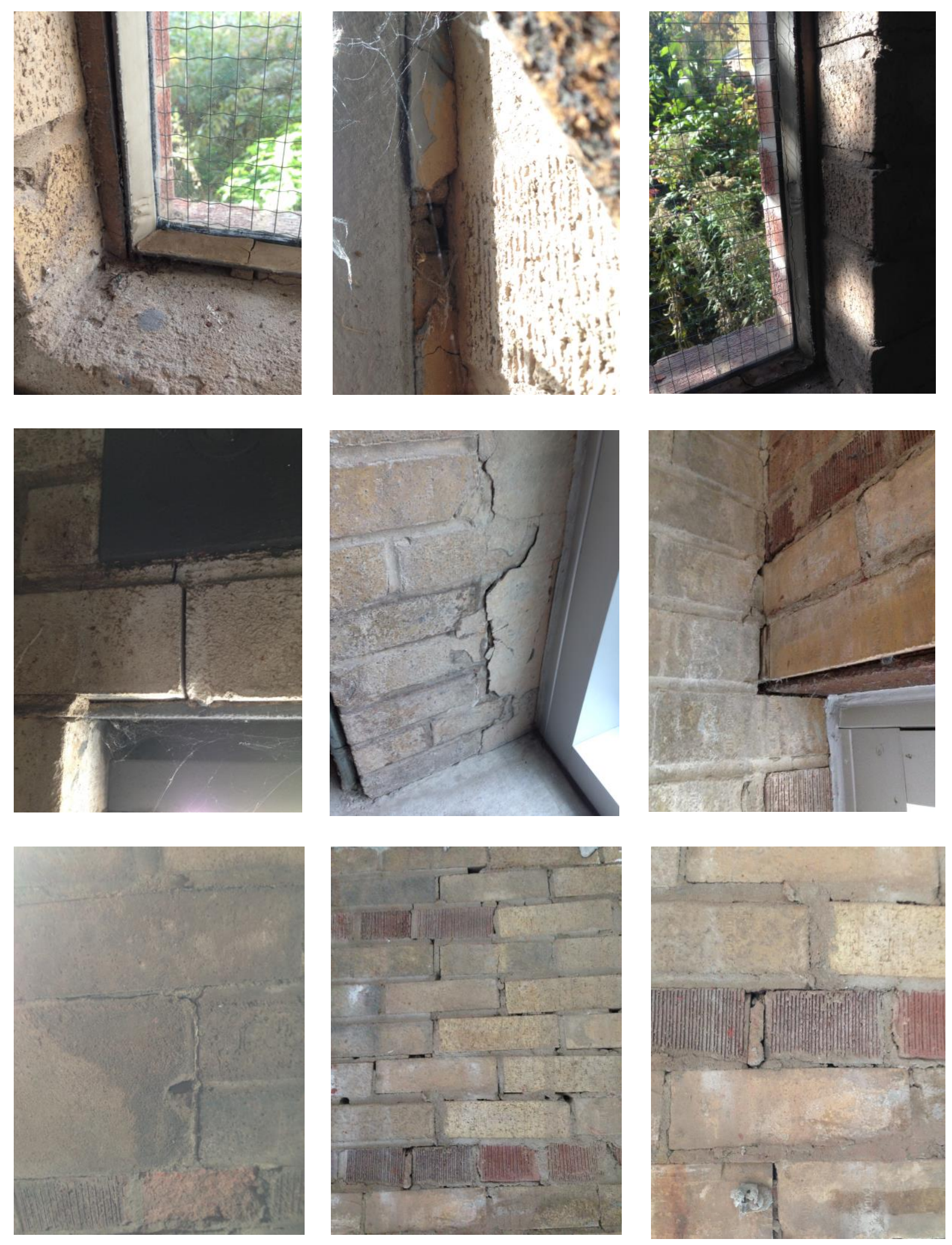

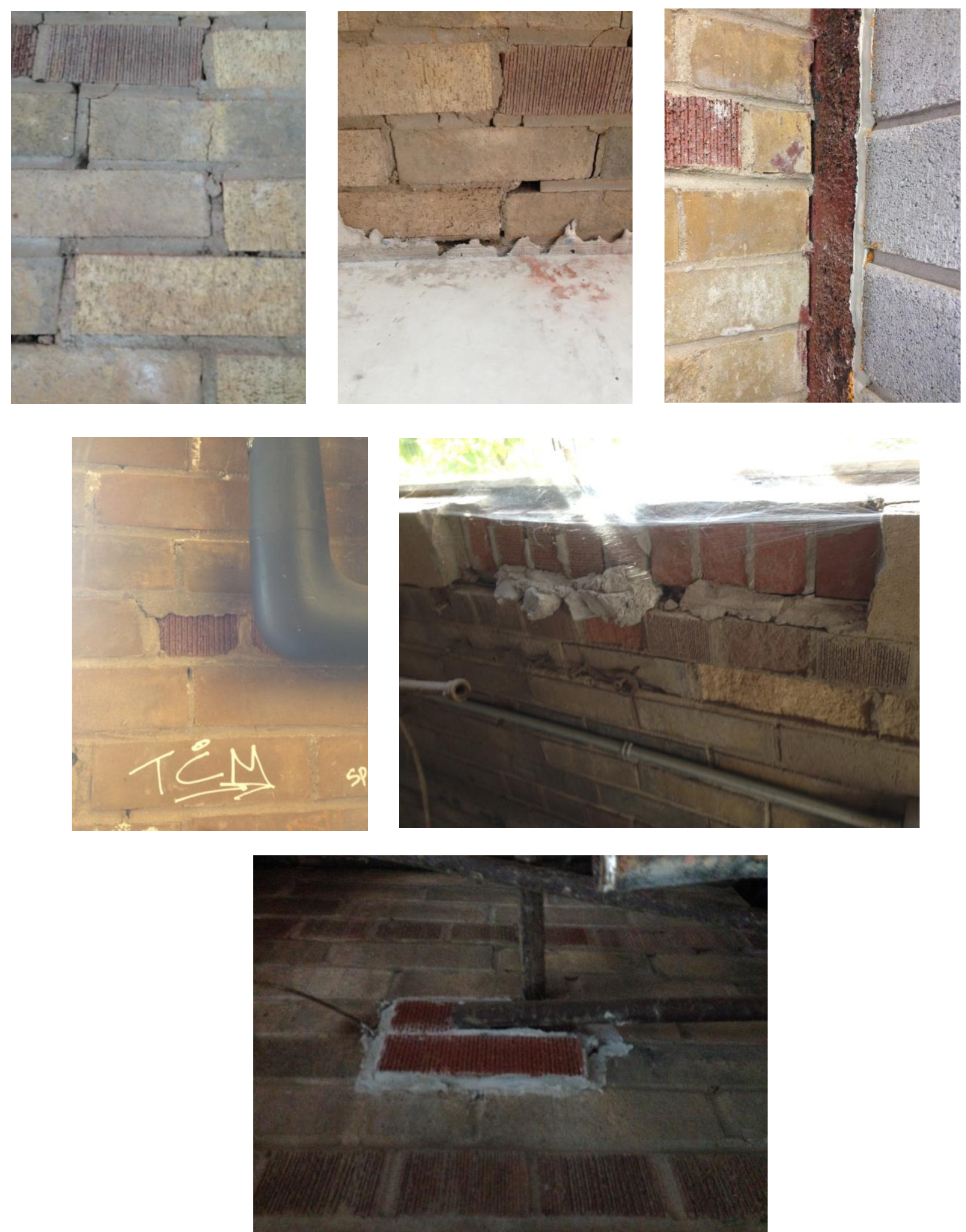

Figure 40. Images of interior brick indicating areas of potential air leakage. 


\subsection{Discussion}

The mixed-method approach to POE utilized a combination of auditing techniques, building science and social science; as a result, a comprehensive understanding of the current operational performance of EBW12 was developed. In addressing the research questions, this report has presented results defining the operational performance of EBW12, these metrics may be useful to help improve future building operation. The findings of the various data collection techniques are used to define the performance gap at EBW12, the finding of this report are summarized as follows.

EBW12 consumes $311 \%$ more energy than its original predictive energy model. Increased energy consumption over the predictive model is likely related to unrealistic modeling inputs. Based on the information gathered in this $\mathrm{POE}$, the following areas may be accountable for the relatively low simulated energy consumption, these would include: utilization of a typical office occupancy pattern only; omission of kitchen energy consumption, omission of kitchen internal gains, increased natural ventilation and cooling assumption through solar chimney operation, exclusion of linear and point thermal bridging, low assumption for the air leakage rate, inclusion of an operable shading system, and inclusion of a photovoltaic array. Based on the information from this $\mathrm{POE}$, these factors are an identifiable cause of much of the variance between predicted and actual energy consumption. The largest contributing factor related to the performance gap may be the assumed building enclosure air leakage rate and the more intensive occupancy pattern. The revised building energy simulation indicates that inclusion of these parameters results in a more realistic modeling scenario over the original energy model. The revised building energy simulation indicated an estimated annual energy consumption of 1,701,674 kWh/year, with an associative EUI of $356 \mathrm{kWh} / \mathrm{m}^{2} /$ year. The results appear more representative of actual annual energy consumption at EBW12.

The building enclosure is leakier than ASHRAE's "leaky building" of $3 \mathrm{~L} / \mathrm{s} / \mathrm{m}^{2}$, at $3.44 \mathrm{~L} / \mathrm{s} / \mathrm{m}^{2}$. This can be conceptualized as an ELA of $1.25 \mathrm{~m}^{2}$ or EqLA of $2.14 \mathrm{~m}^{2}$. Results of the air leakage evaluation are in part attributable to the relatively leaky solar chimney dampers, at $4.8 \mathrm{~L} / \mathrm{s} / \mathrm{m}^{2}$, as shown by the solar chimney duct leakage to outside test. These quantitative findings are congruent with the results of the rooftop qualitative thermograms showing higher surface and air temperatures in the damper houses. Infrared images taken of the ground floor interior under negative pressure gradient did not substantiate significant air leakage areas as was initially suspected. Air leakage through this masonry assembly may be diffuse in nature as a result of the porosity of the older brick. This would explain why significant leakage areas were not detectable by infrared, and the $\mathrm{ACH}$ results of the air leakage evaluation. The original 
ground floor brick is the most likely area for air leakage as it represents a considerable porous surface area, that has been subject to years of deterioration. Diffuse air leakage through this assembly may not be noticeable to building occupants due to the hydronic floor heating in the ground floor slab. Further investigation with a positive pressure gradient and exterior thermography should be undertaken to confirm this. Seals on the operable window units may also be an area of significant air leakage. With air leakage at the windows, a thermal comfort issue should be present in the building occupant survey, however this was not overwhelmingly noted by the respondents. This may be due to the fact that that the space conditioning system includes perimeter hydronic heating that would mask air leakage and possible convection at the windows. In other aspects of building performance, EBW12 is comparative to industry standards. It consumes $11 \%$ more water than the Energy Star median of $0.61 \mathrm{~m}^{3} / \mathrm{m}^{2} /$ year, at 0.69 $\mathrm{m}^{3} / \mathrm{m}^{2} /$ year. Indoor air quality parameters for temperature, $\% \mathrm{RH}, \mathrm{CO}_{2}, \mathrm{CO}, \mathrm{VOC}$ and dust all fall within the acceptable range as per ASHRAE and WHO formaldehyde guidelines. The building occupant survey did not indicate considerable issues with occupant thermal comfort in either the heating or cooling season. Furthermore, respondents of the survey indicated general satisfaction with the indoor environmental quality. There is a clear performance gap with EBW12 in relation to energy consumption; EBW12 consumes considerably more energy than the building energy simulation. However, in areas such as occupant thermal comfort, air quality, and indoor environmental quality EBW12 falls within an acceptable range of performance when compared to industry standards and the whole building energy building simulation. As such, it is not possible to define a performance gap for indoor environmental quality, indoor air quality or thermal comfort.

The focus of the discussion on the performance gap is therefore on evaluating the discrepancies between the operational energy consumption and the simulated energy consumption. However, it is important to consider other factors of building performance. EBW12 serves a variety of purposes for a large mixed occupancy. The building occupant survey, whose results were qualified by other data collection techniques did not indicate major issues with occupant productivity, or thermal comfort. Furthermore, the building occupant survey, indoor air quality analyses, and the simulated building condition results did not expose issues with the indoor environmental quality of EBW12. In addition, the building is located on a remediated site subject to flooding; EBW12 has endured several episodes of flooding without considerable failure or durability issues. Given the unique site and the collective findings of all the data collection techniques it is impractical to compare the operational performance of EBW12 against only simulated energy consumption. The operational performance of EBW12 will fall amongst four overlapping parameters of energy consumption, building durability, occupant comfort \& productivity, and 
indoor environmental quality, as per Figure 41. Improvements and commissioning to EBW12 will draw the operational performance of EBW12 closer to the center of this diagram, increasing the overlap between the four parameters and acting to close the performance gap.

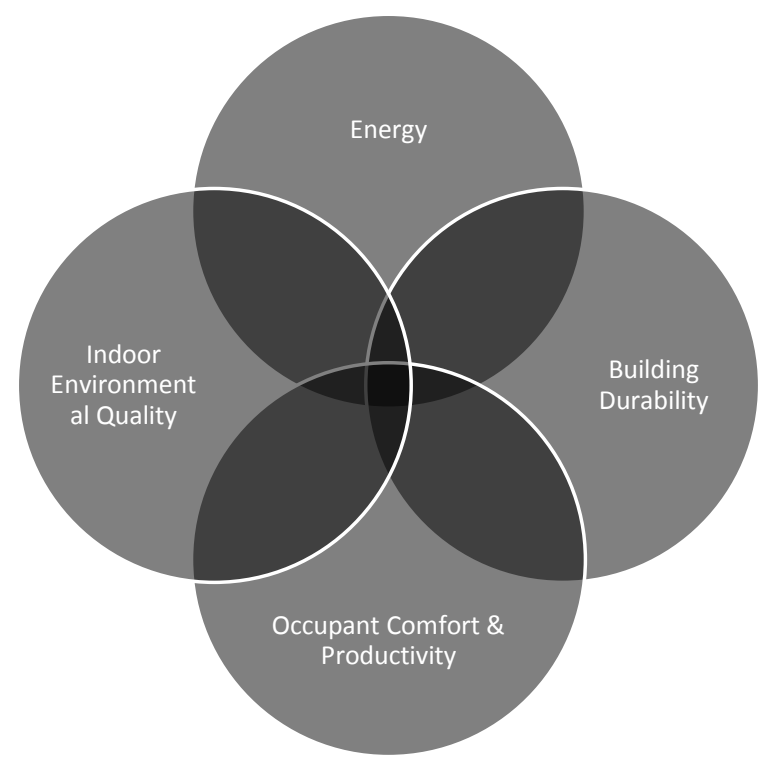

Figure 41. Conceptual understanding of the EBW12 operational performance.

Information gathered using mixed-method data collection tends to inform a greater understanding of the performance gap. While one data collection technique provides limited information, combinations of multiple data collection techniques provide compounding value as information is built, and the totality of the results are analyzed. Each data collection technique had a different time and cost investment, and provided variable information return. The combined data collection techniques provided a more comprehensive understanding of the performance gap as per the conceptual information gradient model described in Figure 41. This information model describes the interrelationship between POE data collection techniques that were realized in this case study. In this information model, the qualitative data collection techniques inform understanding of quantitative data analyzed, as information on operational performance is built; information accumulation is represented by the left to right gradient. It is the suggestion of this report that designer interviews and building occupant survey(s) should always be conducted in a POE as there is little to no cost associated and a limited time investment for high information return. These data collection techniques are shown as DC 1 and DC 2, in Figure 42. If further information is required, DC 1 and 2 could be combined with an energy audit (DC 3), whole building air leakage evaluation (DC 4), and infrared thermography (DC 5) to further inform the POE and the conceptual understanding of the performance gap. Energy Audits can be performed by an outside 
consultant, or by building managers with a small investment of training and time. A whole building air leakage evaluation will help qualify the results of DC 1, DC 2, and DC 3 . Whole building air leakage evaluation and duct leakage to outside testing (DC 4) will be the largest investment of time and cost in a POE. As such, it may be desirable to couple this with infrared thermography (DC 5). Indoor Air Quality analysis (DC 6) can be used to verify results from DC1, DC 2, DC 3, DC 4, and DC 5; specifically, to confirm thermal comfort issues potentially identified from the building occupant survey, air leakage evaluation, and thermographic scanning. The above description identifies the relationship between qualitative and quantitative data collection techniques from this case study; these interrelationships should be considered and may be applied to inform the structure of future POE frameworks and future POE data acquisition.

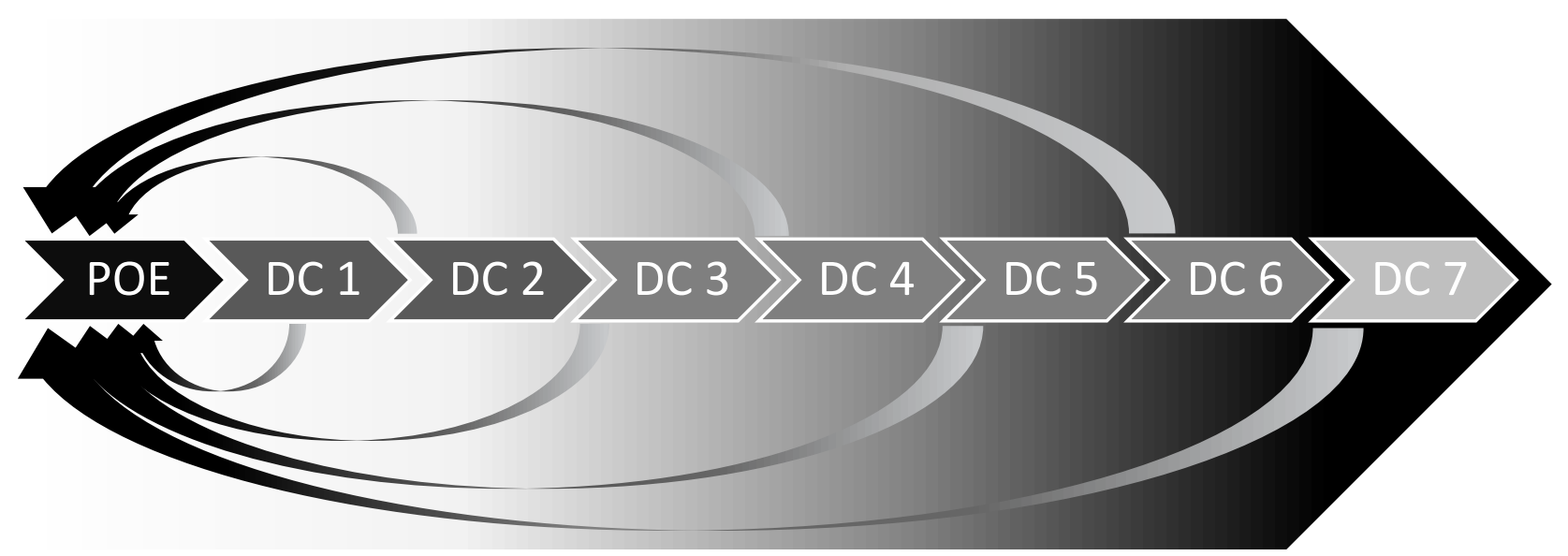

Figure 42. Conceptual understanding of POE framework used in this study, with the interalationship between Data Collection (DC) techniques. Stakeholder interviews (DC 1), building occupant survey (DC 2), energy audit (DC 3), whole building air leakage evaluation and duct leakage to outside testing (DC 4), Infrared thermography (DC 5), IAQ (DC 6), and water audit (DC 7).

In future, qualitative/quantitative data and information collected in this mixed-method POE is to be passed to project stakeholders as an information feedback to help improve building design and the current operation of EBW12. The data provided in this report can be used as a benchmark to commission EBW12 after improvements are completed. The interrelationship between data collection techniques identified in this case study on EBW12 could be used to develop and assess an idealized POE framework for use at other building sites. Further investigation into the connectivity of data collection techniques could be evaluated in multi-zone simulations calibrated with normalized weather data and information collected during POE. 


\subsection{Recommendations}

It is the recommendation of this report that further investigation and building diagnostics occur at EBW12 to develop a better understanding of the air leakage results. Specifically guarded air leakage testing could occur in an itterative process on each floor of EBW12. By process of elimination guarded testing would isolate the area(s) of the building enclosure that are most leaky. Guarded testing under positive pressure should be coupled with extensive exterior thermographic imaging. Smoke pencil testing at the ground floor brick assemblies should occur in coordination with additional air leakage testing. Smoke pencil testing could detect slight air movement and reveal smaller air leakage pathways that are a result of porous brick, degraded brick, and cracked or loose cementitious mortar. Areas of the brick eclosure that are identified as air leakage pathways could be remediated with a cementitious parging overcoat or a trowel applied air barrier product, such as StoGold TM. A deeper energy audit could be undertaken to gather data from on-site equipment. Due to the lack of electircal sub-metering non invasive magnetic current detectors could be deployed to collect data on boiler run time, cooling system run-time, kitchen equipment, lighting operation, and plug loads. By collecting data directly from building equipment and appliances, a better understanding of energy consumption by end use could be developed indicating areas for potential reductions. A multi-week intensive survey of occupancy could be devleoped to build an occupancy pattern. Additional data collected in a deeper energy audit could be fed back into the revised energy model for increased calibration. The results of further investigation and increased claibration of the revised enegy model could provide greater understanding of the performance gap. 


\section{Appendix}

Appendix A: Building Enclosure Air Leakage Results
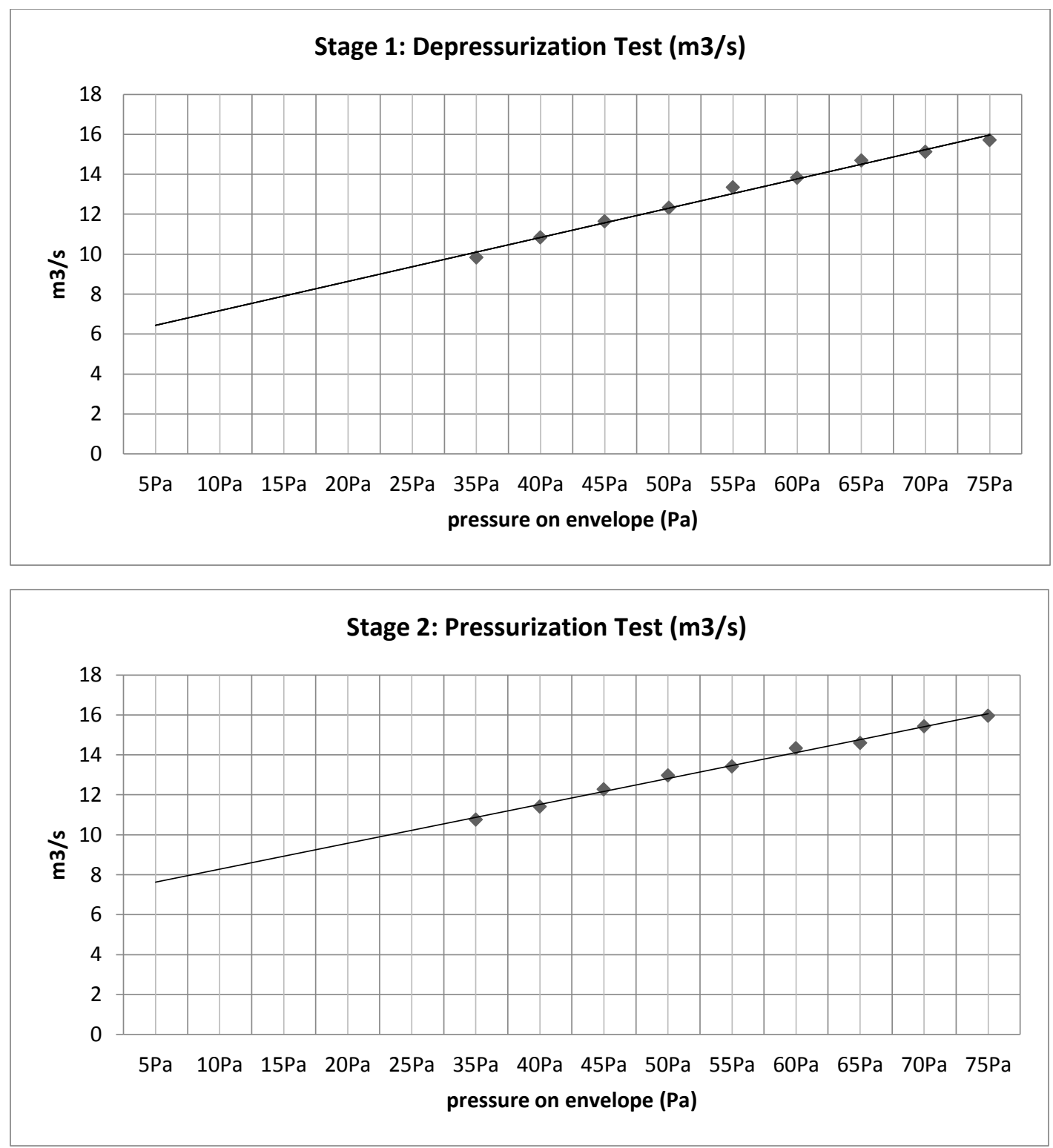

Appendix A, Figure 1. Air leakage results in $\mathrm{m}^{3} / \mathrm{s}$. 

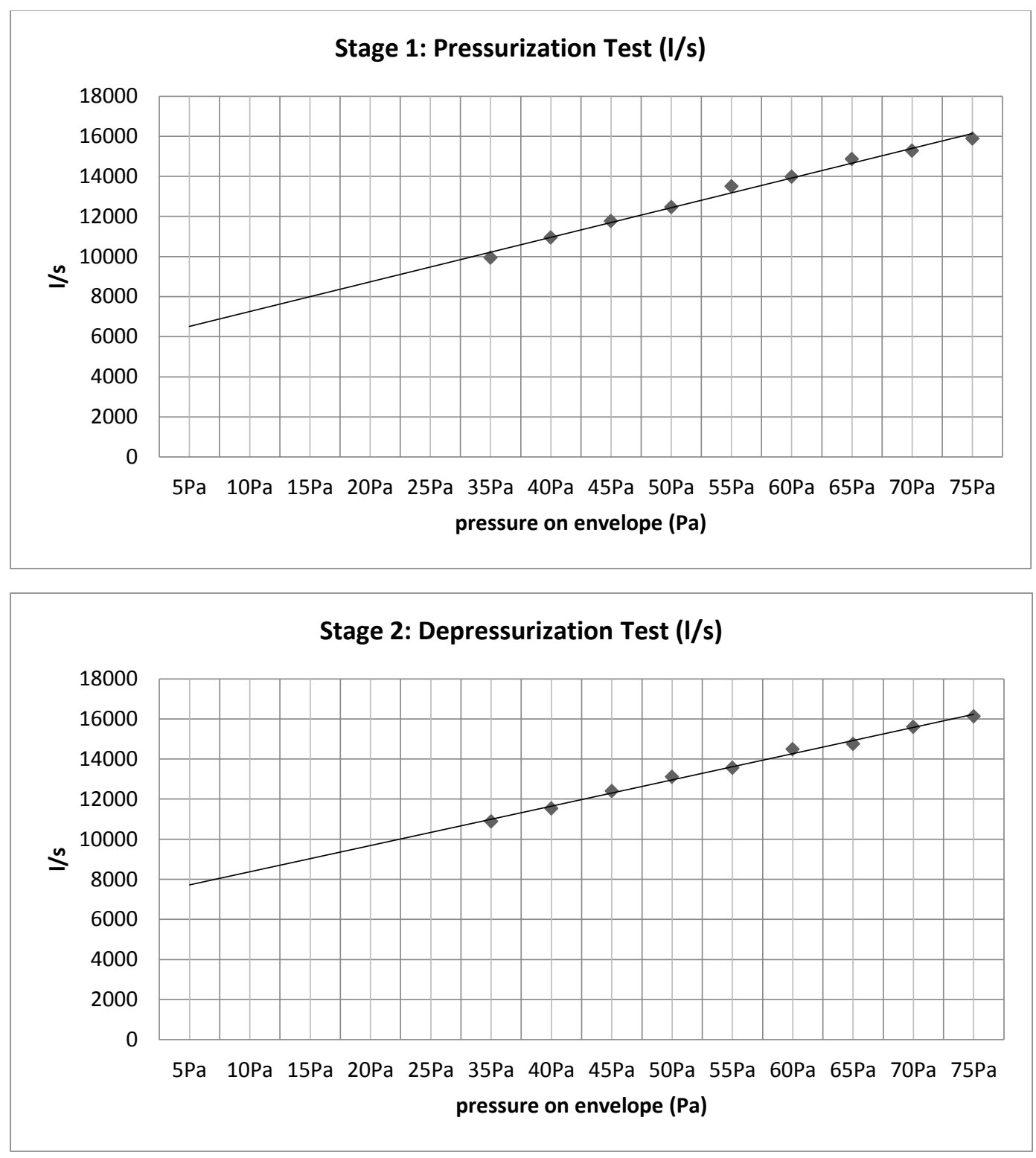

Appendix A, Figure 2. Air leakage results in I/s. 


\begin{tabular}{|l|l|l|}
\hline Alternative Units of Measurement & $\begin{array}{l}\text { Test Stage 1 } \\
\text { Depressurization }\end{array}$ & $\begin{array}{l}\text { Test Stage 2 } \\
\text { Pressurization }\end{array}$ \\
\hline Air Changes per hour at 50 Pa (ACH50) & 2.57 & 2.54 \\
\hline $\begin{array}{l}\text { Air Changes per hour at natural pressure (ACH Natural = } \\
\text { ACH50/20) }\end{array}$ & 0.13 & .12 \\
\hline Air leakage rate in cfm at 50 Pa (CFM50) & 27346 & 26962 \\
\hline Air leakage rate in cfm at 75 Pa (CFM75) & 35131 & 33168 \\
\hline $\begin{array}{l}\text { Air leakage rate/unit area of exterior enclosure at 50Pa } \\
\text { (CFM50/ft2) }\end{array}$ & 0.578 & 0.5204 \\
\hline $\begin{array}{l}\text { Air leakage rate/unit area of exterior enclosure at 50 Pa } \\
\text { (L/s/m²@50Pa) }\end{array}$ & $2.68 \mathrm{~L} / \mathrm{s} / \mathrm{m}^{2}$ & $2.64 \mathrm{~L} / \mathrm{s} / \mathrm{m}^{2}$ \\
\hline & & \\
\hline $\begin{array}{l}\text { Air leakage rate/unit area of exterior enclosure at 75 Pa } \\
\text { (L/s/m²@75Pa) }\end{array}$ & $3.44 \mathrm{~L} / \mathrm{s} / \mathrm{m}^{2}$ & $3.25 \mathrm{~L} / \mathrm{s} / \mathrm{m}^{2}$ \\
\hline Equivalent Leakage Area in in ${ }^{2}$ (EqLA@10Pa) & 3272.7 & 3193.1 \\
\hline Effective Leakage Area in in ${ }^{2}$ (ELA@4Pa) & 1895.8 & 1838.7 \\
\hline
\end{tabular}

Appendix A, Table 1. Commonly used alternative metrics. Results calculated from test stage 1 \& 2 .

Appendix B: Indoor Air Quality Results

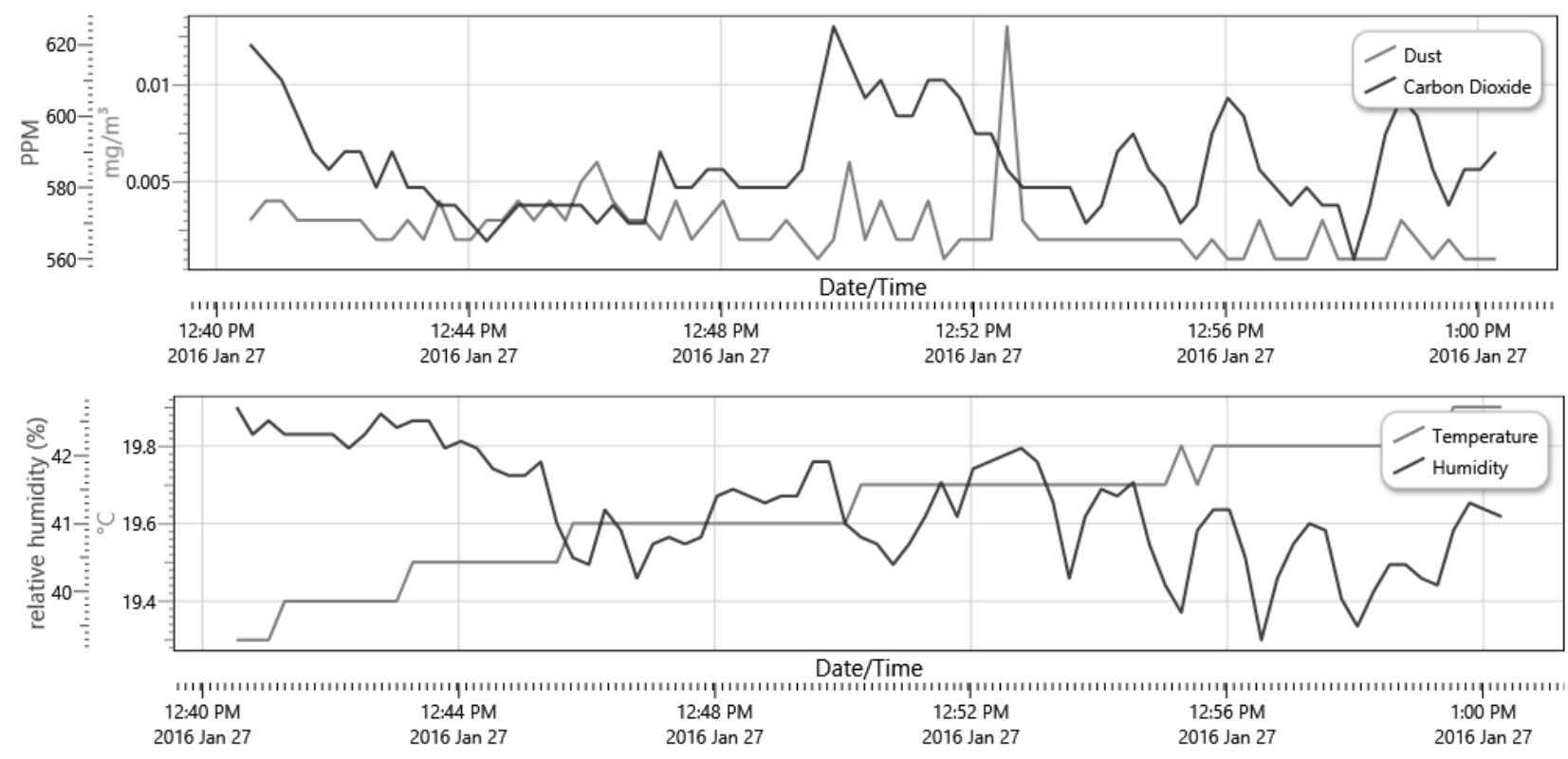

Appendix B, Figure 1. Indoor Air Quality spot measurement results taken from the Yonge Welcome center.

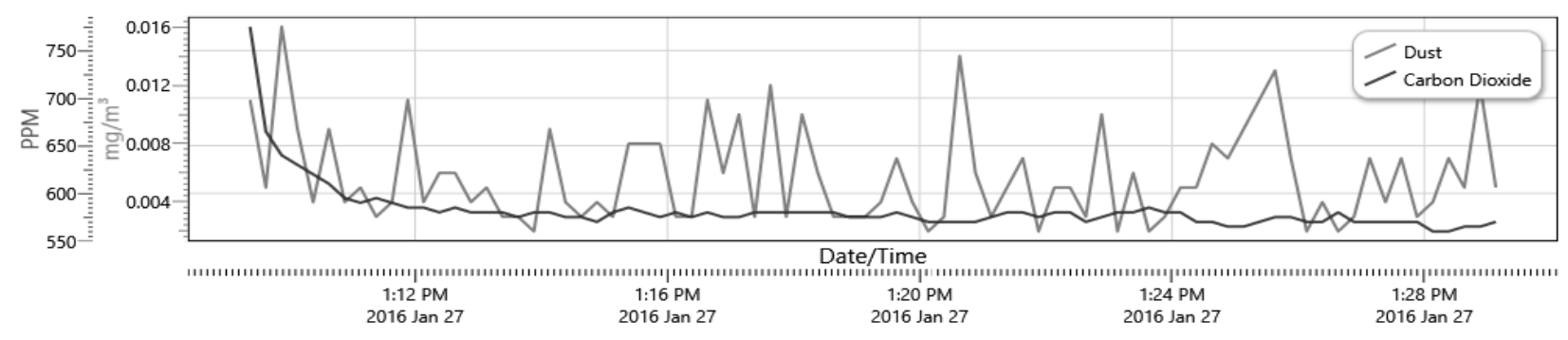




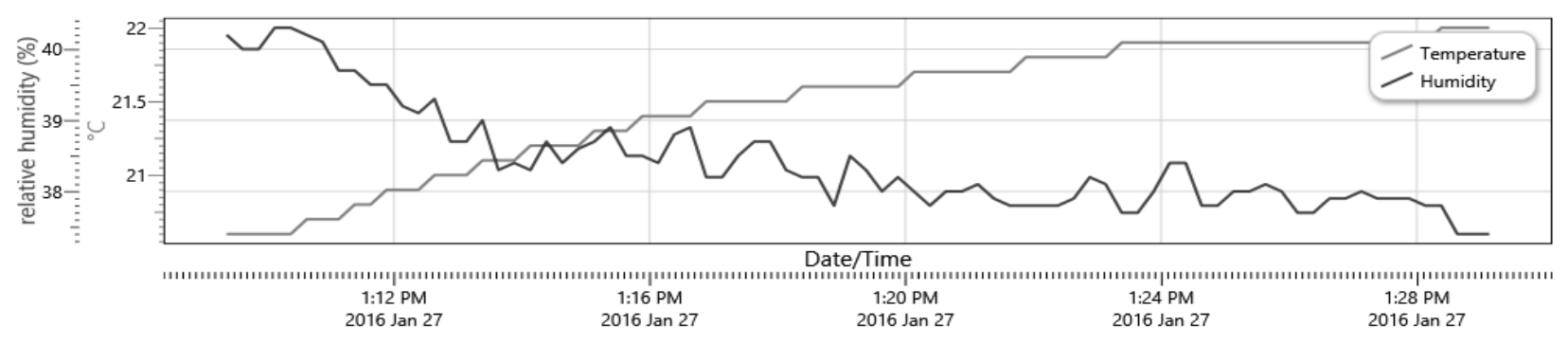

Appendix B, Figure 2. Indoor Air Quality Spot measurement results taken from the BMO Atrium.
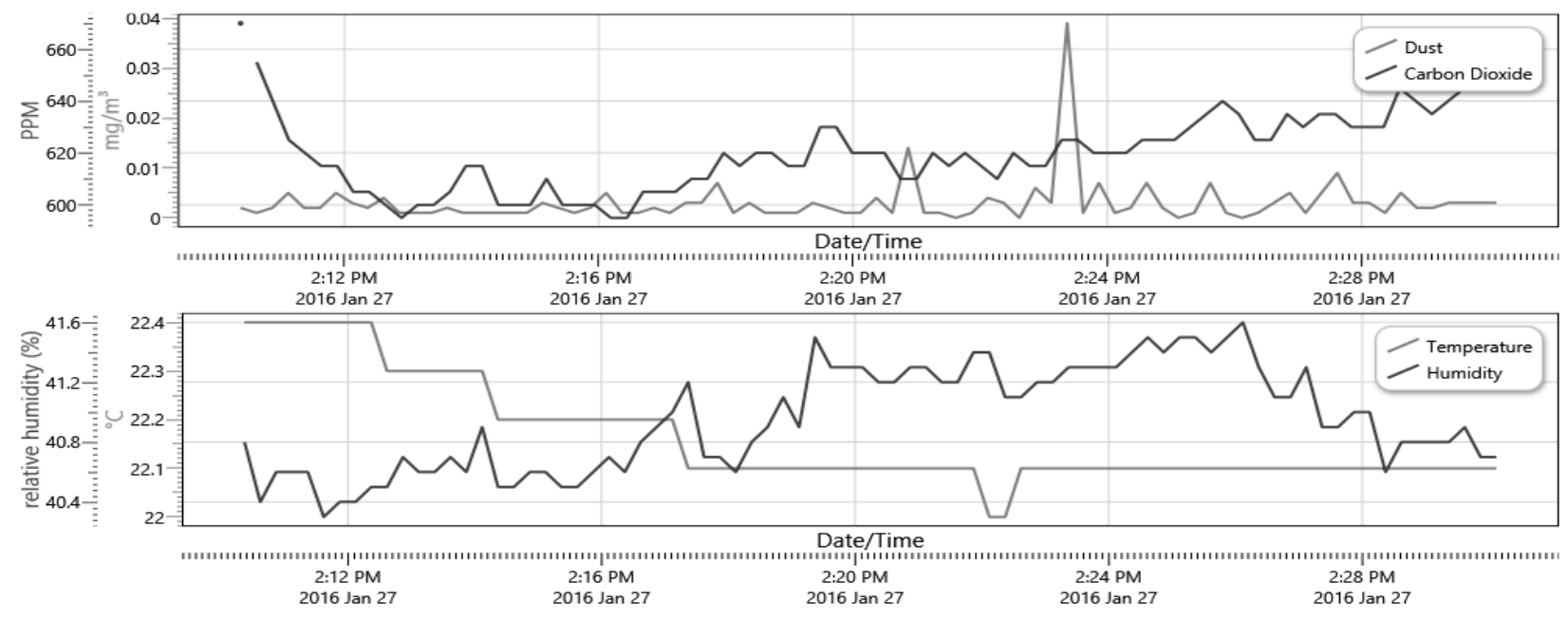

Appendix B, Figure 3. Indoor Air Quality Spot measurement results taken from the $2^{\text {"Iu }}$ floor.
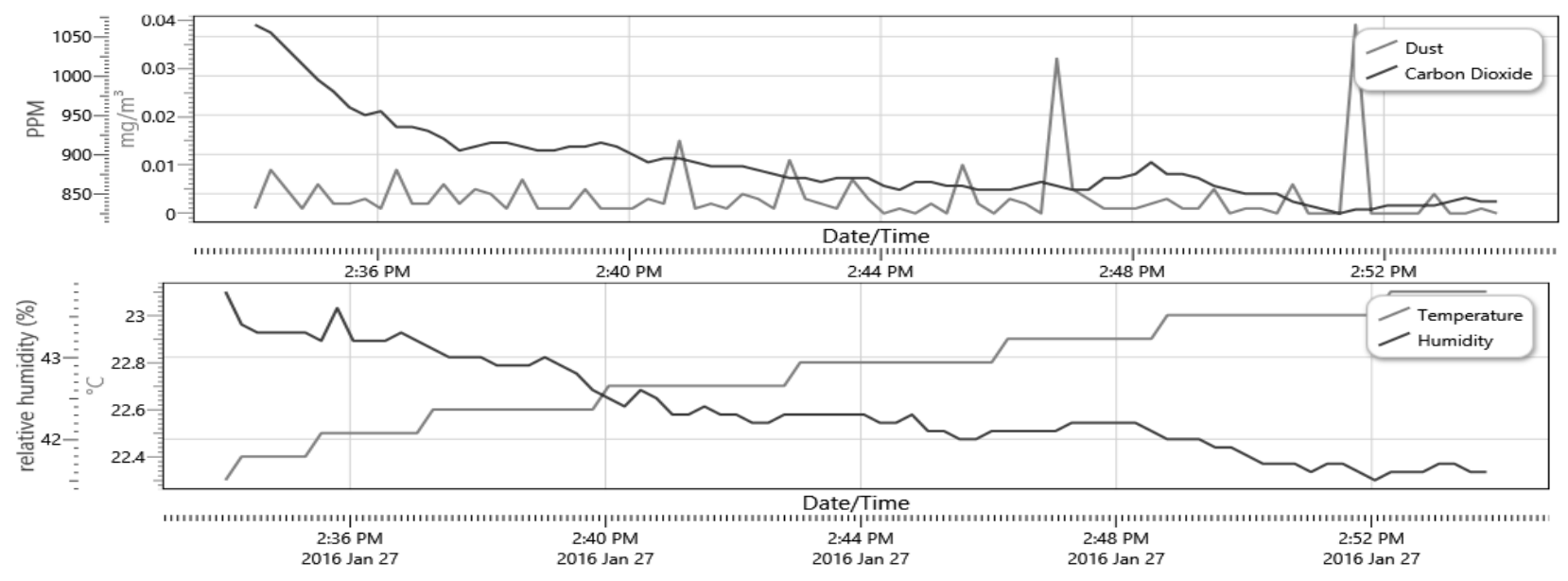


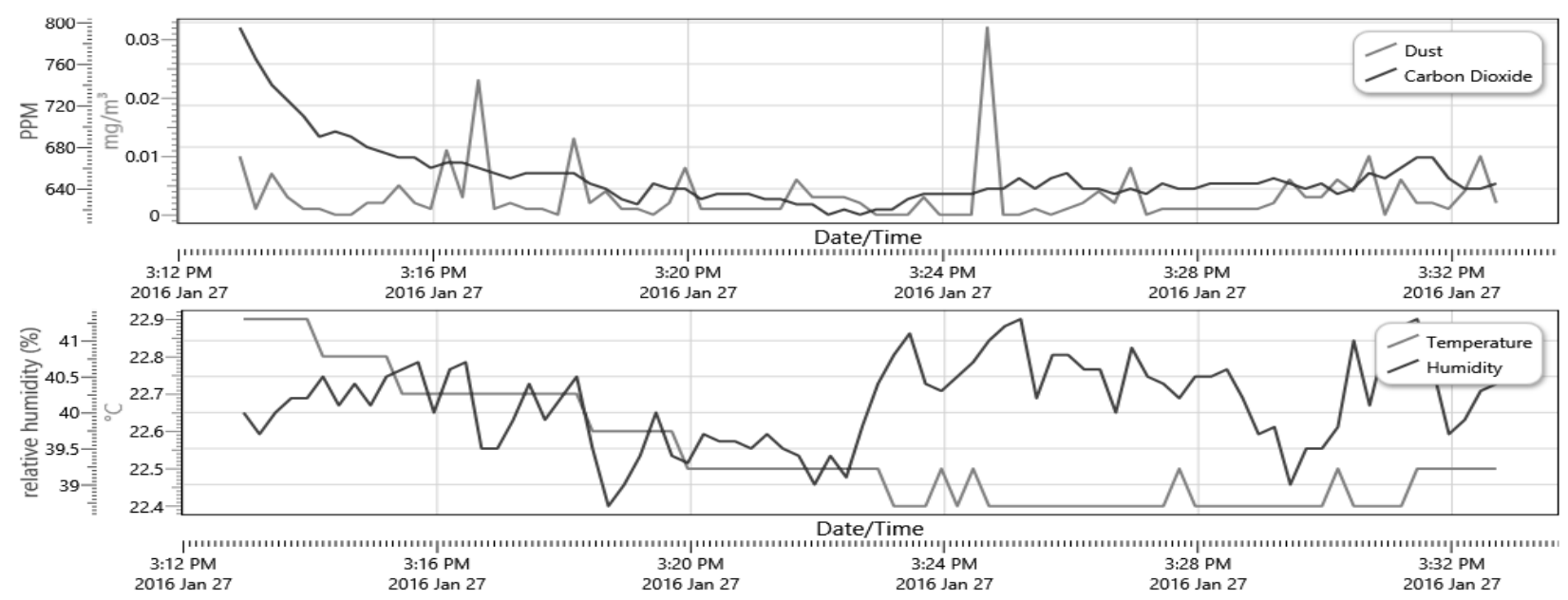

Appendix B, Figure 4. Indoor Air Quality Spot measurement results taken from the $4^{\text {th }}$ floor corridor.

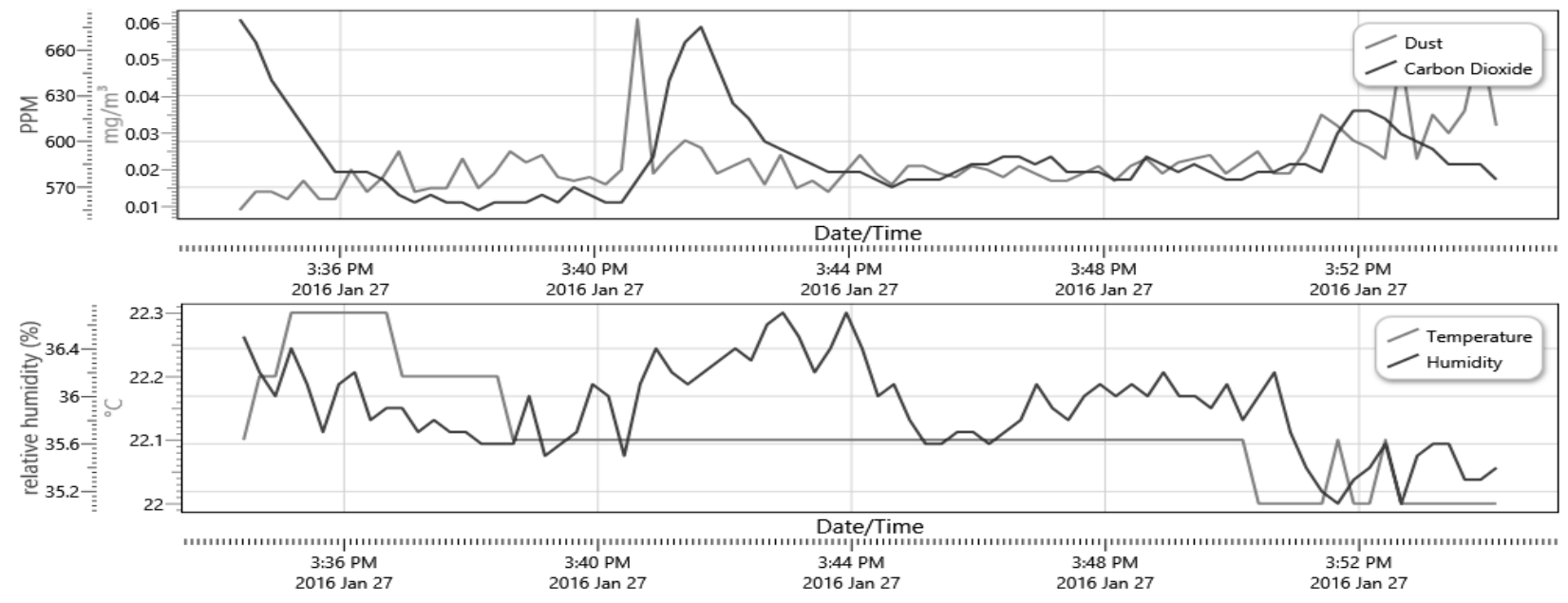

Appendix B, Figure 5. Indoor Air Quality spot measurement results taken from the $5^{\text {th }}$ floor corridor. 
Appendix C: WUFI Plus Building Energy Simulation Information
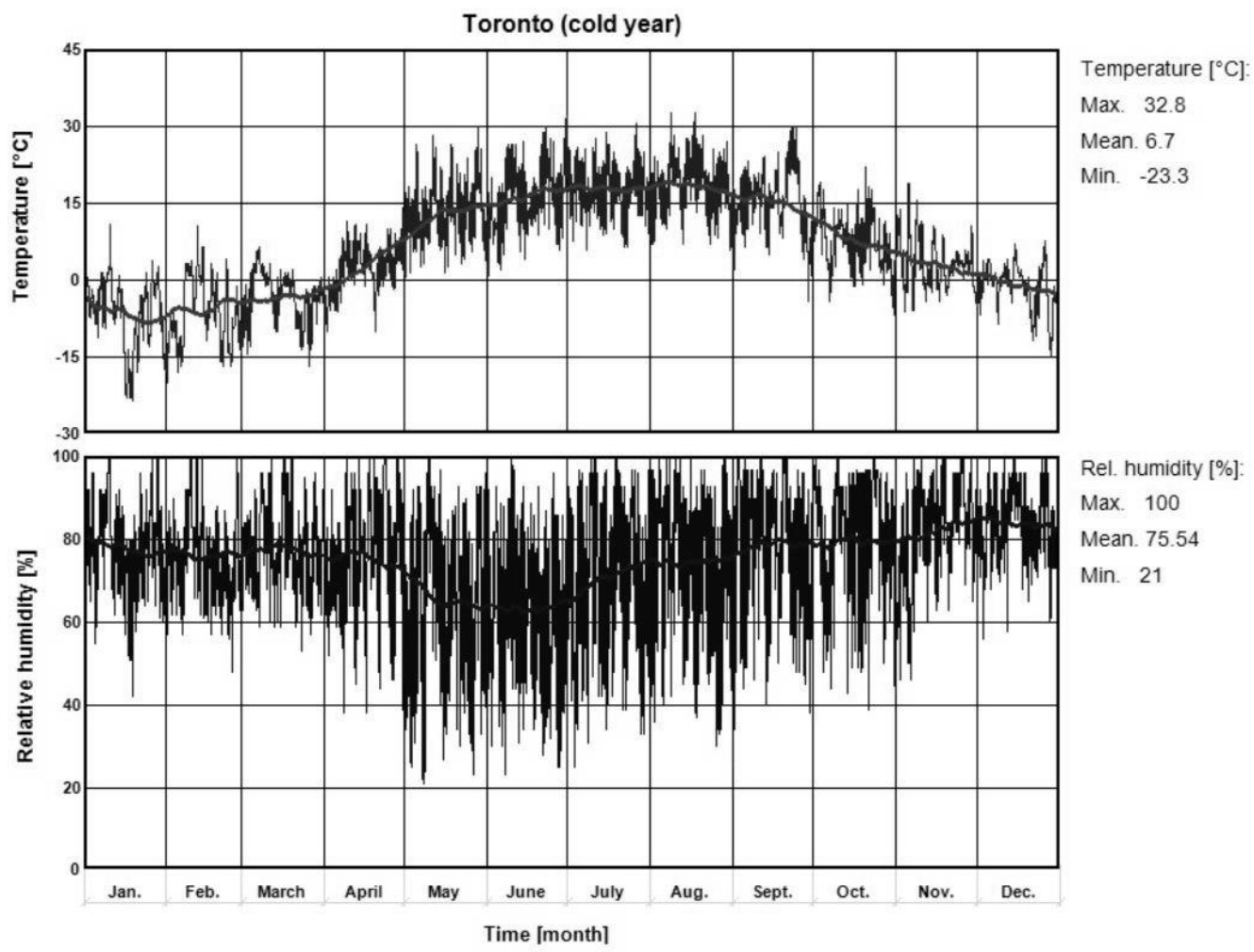

Rel. humidity [\%]

Max. 100

Mean. 75.54

Min. 21

Appendix C, Figure 1. Toronto Climate File used in WUFI Plus dynamic modeling
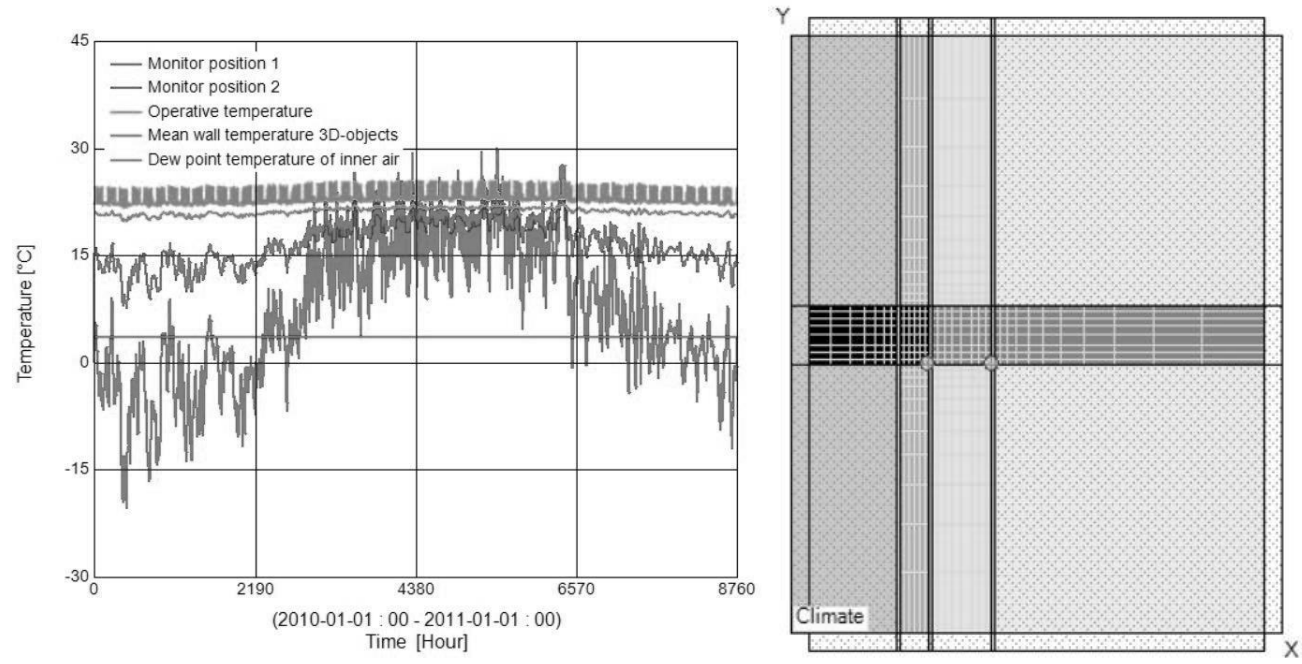

Appendix C, Figure 2. Shading substructure thermal bridge geometry with monitoring positions indicated 


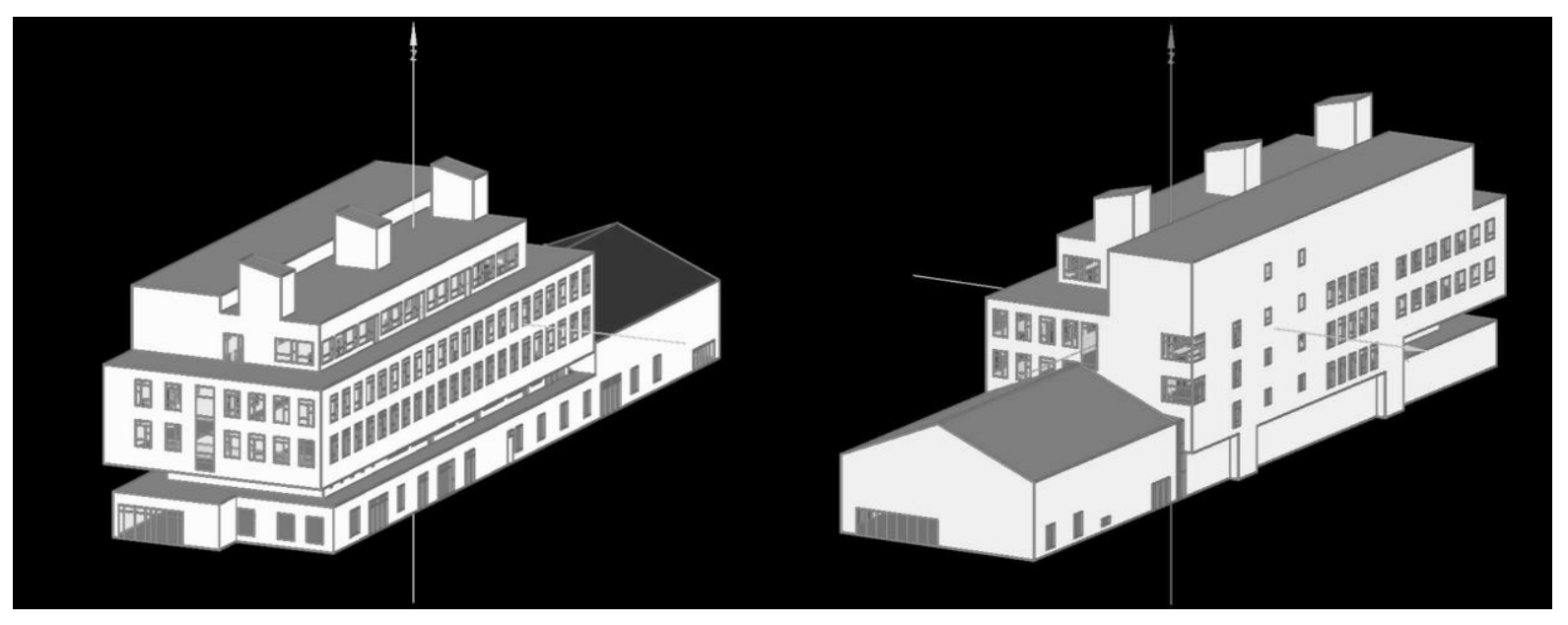

Appendix C, Figure 3. EBW12 3-dimensional input geometry for WUFI Passive. 


\section{Appendix D: Building Occupant Survey}

\section{Evergreen Brickworks Building Occupant Survey}

Q1.1 Evergreen Brickworks Building Occupant Survey Consent Form Purpose: You are invited to participate in a study that is being conducted by a team of researchers from Ryerson University's Department of Architectural Science. This research team is working in collaboration with the Evergreen Brickworks Property Management Team. If you agree to participate in this research, your participation will include the completion of a survey. The purpose of this survey is to assess and improve the indoor environmental quality of the selected building. Participation: You are being asked to participate because you work in the building that was selected for inclusion in this study. This survey will require 10 - 15 minutes to complete. The survey includes general questions about you, as well as questions about your satisfaction with various aspects of your physical workspace. In addition, objective measures of your indoor environment (e.g., acoustics, lighting thermal comfort, air quality) will be assessed in the survey.

Confidentiality: Your survey responses will not be linked to your name, address, or any other identifying information. Individual responses will not be given to your employer, or anyone else outside of our research team. Any quotes will be labelled as "anonymous." Ryerson University may use submitted data for analyses in future studies of a similar nature. Results of this study will be shared through published articles, and presented at scholarly meetings. Withdrawal from Study: Your participation in this survey must be completely voluntary. If you decide to participate, you may withdraw at any time without any consequences or explanation. If you do withdraw from the study, your data will not be used. You may withdraw by closing the survey window, or opting not to submit your answers upon completion of the survey. Contact Information: You may verify the ethical approval of this study, or raise any concerns you might have, by contacting the Ryerson University Research Ethics Board, 416979-5042. Highlights of research results or publications are available to participants upon request, after the publications have been completed. Please contact Thomas Moore if you have any questions about this study. Email: thomas.moore@ryerson.ca

Consent: By checking "yes" below you are indicating that you have read the information in this agreement and consent to participate in the survey. As mentioned, you may withdraw your consent to participate at any time, prior to the submission of your data. This consent form will not be used to identify you in any way.

O YES, I WILL PARTICIPATE (1)

O NO, I WILL NOT PARTICIPATE (2)

If NO, I WILL NOT PARTICIPATE Is Selected, Then Skip To End of Survey

Q2.1 About You - Module 2I am a...

Tenant at Evergreen Brickworks (1)

Employee of Evergreen (2) 
Q2.2 For how many years have you been working for your organization?
0 - 1 year (1)
O 1 year -2 years (2)
2 years -5 years $(3)$
5 years- 10 years (4)

Q2.3 What is your age?

O $18-29(1)$

O $30-39(2)$

O $40-49(3)$

O $50-59$ (4)

O 60 or over (5)

I choose not to answer (6)

Q2.4 What is your gender?

O Male (1)

Female (2)

I choose not to answer (3)

Q2.4 What type of position do you have?

Administrative (1)

O Managerial (2)

O Professional (3)

O Technical (4)

Q3.1 Your Workstation - Module 30n which floor of the building is your personal desk located?
Ground Floor (1)
O Second Floor (2)
Third Floor (3)
Fourth Floor (4)
Fifth Floor (5) 
Q3.2 Would you describe your personal desk to be located closest to the North, East, South or West side of the building?
O North (1)
O East (2)
South (3)
O West (4)

Q3.3 Which of the following best describes your personal workspace?

O Private office

Shared office (2 to 6 people) (2)

Open plan (more than 6 people without partitions)

(1)

Cubicles with low partitions

(4)

Cubicles with high partitions (1.5m or high)

Q3.4 For how long (years/months) have you been working at your current workstation?
0 - 1 year (1)
O 1 year -2 years (2)
O 2 years -5 years (3)
5 years or greater (4)

Q3.5 Have you moved to a new workstation in the past three months?

Yes (1)

No (2)

Q4.1 Your Work Habits - Module 4 What percentage of your time at work do you spend doing each activity in a typical week (total 100\%)?

\begin{tabular}{|c|c|}
\hline Computer and quiet work (1) & Percentage of time (1) \\
Phoning (2) & \\
Meetings, interactions in one's workstation (3) & \\
Scheduled meetings outside one's workstation (4) & \\
Informal interactions outside one's workstation (5) & \\
Taking breaks (6) & \\
Doing office chores (filing, copying, email etc.) (7) & \\
Other (8)
\end{tabular}


Q4.2 What is your favourite place for task completion (see favourite place options)?

No. Favourite place options 1 Personal Workstation 2 Public Space

3 Kitchen or Staff Lounge 4 Outside 5 Communal Team Area

6 Private Meeting Room

Favourite place (enter number from table above) (1)

Computer and quiet work (1)

Phoning (2)

Meetings, interactions in one's workstation (3)

Scheduled meetings outside one's workstation (4)

Informal interactions outside one's workstation (5)

Taking breaks (6)

Doing office chores (filing, copying, email etc.) (7)

Other (8)

Q4.3 What percentage of your working week requires you to individually concentrate, contemplate, or collaborate while working (total $100 \%$ )?

Percentage per week (1)

Concentrate (Work independently in a quiet environment) (1)

Contemplate (Work independently at task that does not require a quiet environment) (2)

Collaborate (Work with others) (3) 
Q4.4 To what extent do you agree or disagree that each statement in the table below?

\begin{tabular}{|c|c|c|c|c|c|c|c|}
\hline & $\begin{array}{c}\text { Strongly } \\
\text { Disagree } \\
\text { (1) }\end{array}$ & $\begin{array}{l}\text { Moderately } \\
\text { Disagree } \\
\text { (2) }\end{array}$ & $\begin{array}{c}\text { Slightly } \\
\text { Disagree } \\
\text { (3) }\end{array}$ & $\begin{array}{l}\text { Neither } \\
\text { Agree nor } \\
\text { Disagree } \\
\text { (4) }\end{array}$ & $\begin{array}{c}\text { Slightly } \\
\text { Agree (5) }\end{array}$ & $\begin{array}{c}\text { Moderately } \\
\text { Agree (6) }\end{array}$ & $\begin{array}{l}\text { Strongly } \\
\text { Agree (7) }\end{array}$ \\
\hline $\begin{array}{l}\text { If necessary I } \\
\text { can find a quiet } \\
\text { place to work } \\
\text { elsewhere in } \\
\text { my office (1) }\end{array}$ & O & O & 0 & O & 0 & 0 & 0 \\
\hline $\begin{array}{l}\text { I am usually } \\
\text { able to } \\
\text { concentrate on } \\
\text { my work in my } \\
\text { workstation (2) }\end{array}$ & O & 0 & 0 & $\mathrm{O}$ & $\mathrm{O}$ & 0 & 0 \\
\hline $\begin{array}{l}\text { Our office } \\
\text { stimulates the } \\
\text { delivery of high } \\
\text { quality work } \\
\text { (3) }\end{array}$ & 0 & 0 & 0 & 0 & 0 & 0 & 0 \\
\hline $\begin{array}{l}\text { Our work } \\
\text { environment } \\
\text { stimulates } \\
\text { positive } \\
\text { communication } \\
\text { pathways with } \\
\text { colleagues (4) }\end{array}$ & O & 0 & 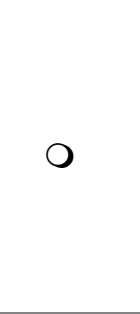 & 0 & 0 & 0 & $\mathrm{O}$ \\
\hline
\end{tabular}

Q8.1 Your Commute - Module 5What are your methods of commuting to work? (select all that apply)

- Personal Gasoline/Diesel Fuel Car (1)

C Carpool (2)

口 Public Transit (3)

Electric or Hybrid Car (4)

Bicycle, Rollerblades, Scooter, etc) (5)

Walking (6)

O Other (please specify) (7) 
Q8.2 Have you altered your primary transportation/commuting method since starting your position at Evergreen Brickworks?

Y Yes (4)

O No (5)

Only Sometimes (6) 
Q6.1 Your Health - Module 6Please think back over the past few months. For each of the symptoms listed below, please tell us how frequently you have experienced the symptoms at work and the intensity of that feeling.

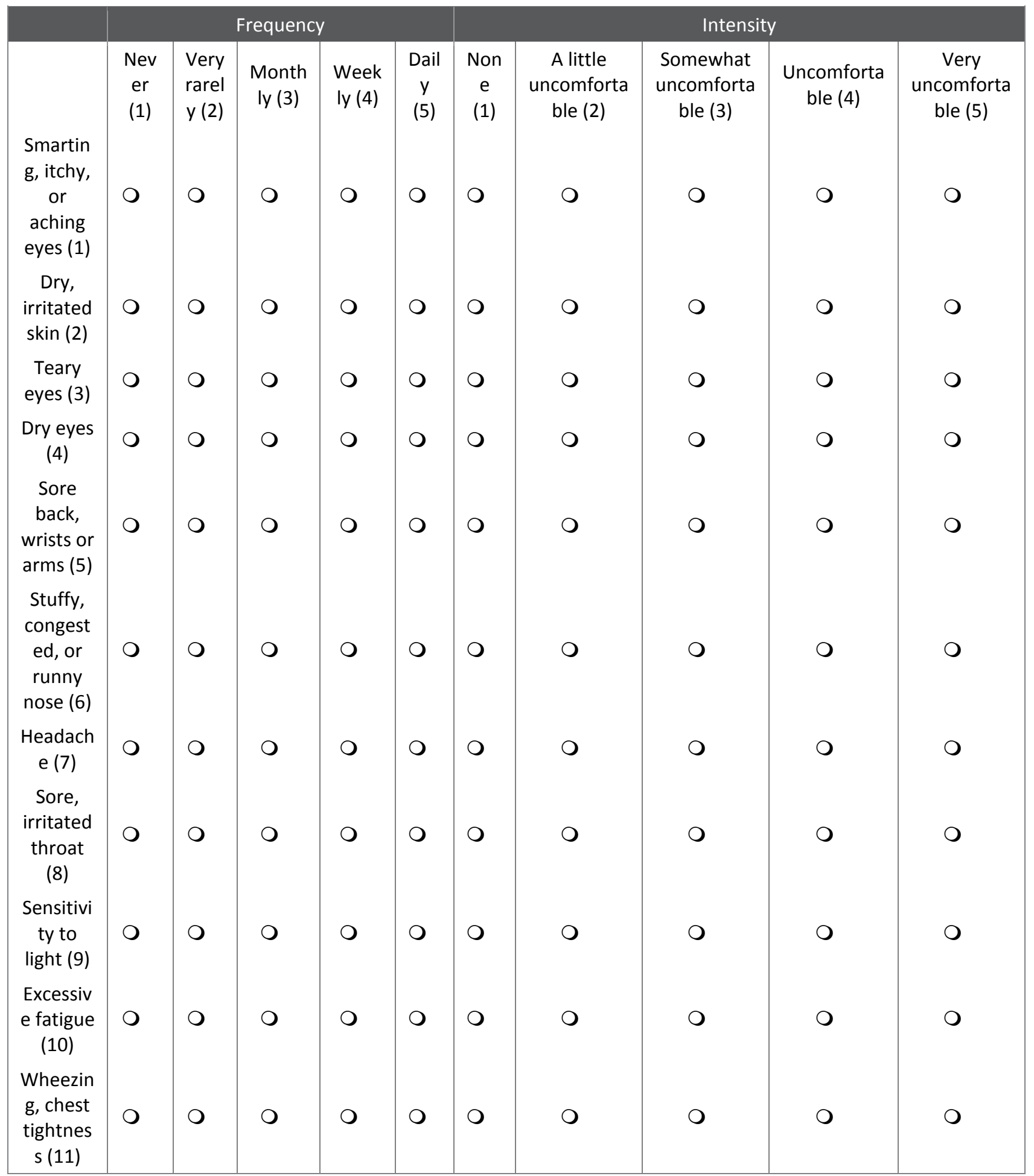


Q6.2 For each statement, please answer "true" or "false".

\begin{tabular}{|c|c|c|}
\hline & True (1) & False (2) \\
\hline I had a deep sleep last night. (1) & $\mathrm{O}$ & $\mathrm{O}$ \\
\hline $\begin{array}{l}\text { I feel that I slept poorly last night. } \\
\text { (2) }\end{array}$ & $\mathrm{O}$ & $\mathrm{O}$ \\
\hline $\begin{array}{l}\text { It took me more than half an hour } \\
\text { to fall asleep last night. (3) }\end{array}$ & $\mathrm{O}$ & $\mathrm{O}$ \\
\hline $\begin{array}{l}\text { I woke up several times last night. } \\
\text { (4) }\end{array}$ & $\mathrm{O}$ & $\mathrm{O}$ \\
\hline $\begin{array}{l}\text { I felt tired after waking up this } \\
\text { morning. (5) }\end{array}$ & O & $\mathrm{O}$ \\
\hline $\begin{array}{l}\text { I feel that I didn't get enough sleep } \\
\text { last night. (6) }\end{array}$ & $\mathrm{O}$ & $\mathrm{O}$ \\
\hline $\begin{array}{l}\text { I got up in the middle of the night. } \\
\text { (7) }\end{array}$ & $\mathrm{O}$ & $\mathrm{O}$ \\
\hline $\begin{array}{l}\text { I felt rested after waking up this } \\
\text { morning. (8) }\end{array}$ & $\mathrm{O}$ & $\mathrm{O}$ \\
\hline $\begin{array}{l}\text { I feel that I only had a couple of } \\
\text { hours' sleep last night. (9) }\end{array}$ & $\mathrm{O}$ & $\mathrm{O}$ \\
\hline I feel that I slept well last night. (10) & $\mathrm{O}$ & $\mathrm{O}$ \\
\hline I didn't sleep a wink last night. (11) & $\mathrm{O}$ & $\mathrm{O}$ \\
\hline $\begin{array}{l}\text { I didn't have trouble falling asleep } \\
\text { last night. (12) }\end{array}$ & O & $\mathrm{O}$ \\
\hline $\begin{array}{l}\text { After I woke up last night, I had } \\
\text { trouble falling asleep again. (13) }\end{array}$ & $\mathrm{O}$ & O \\
\hline $\begin{array}{l}\text { I tossed and turned all night last } \\
\text { night. (14) }\end{array}$ & $\mathrm{O}$ & $\mathrm{O}$ \\
\hline $\begin{array}{l}\text { I didn't get more than } 5 \text { hours' sleep } \\
\text { last night. (15) }\end{array}$ & $\mathrm{O}$ & $\mathrm{O}$ \\
\hline
\end{tabular}

Q7.1 Your Thermal Comfort - Module 7At the moment I feel...
Cold (1)
O Cool (2)
O Slightly Cool (3)
O Neutral (4)
O Slightly Warm (5)
O Warm (6)
O Hot (7) 
Q7.2 At the moment, I would like to be...

Cooler (1)

No Change (2)

O Warmer (3)

Q7.3 Overall, does the temperature in your workspace enhance or interfere with your ability to get your work done (i.e. reading, writing, thinking, concentration)?

Highly interferes (1)

O Moderately interferes (2)

Slightly interferes (3)

O Neutral (4)

Slightly enhances (5)

O Moderately enhances (6)

O Highly enhances (7)

Q7.4 Overall, how satisfied/dissatisfied are you with the temperature at your workstation?

Highly dissatisfied (1)

O Dissatisfied (2)

O Slightly dissatisfied (3)

O Neutral (4)

O Slightly satisfied (5)

O Satisfied (6)

O Highly satisfied (7) 
Q7.5 If your response to the question above was "Highly dissatisfied", "Dissatisfied" or "Slightly dissatisfied", which of the following could best describe your source(s) of dissatisfaction with temperature? (Check all that apply)

Humidity too high (damp) (1)

- Humidity too low (dry) (2)

Air movement too high (3)

A Air movement too low (4)

Incoming sun (5)

Hot/cold floor surfaces (6)

- Hot/cold ceiling surfaces (7)

- Hot/cold wall surfaces (8)

Hot/cold window surfaces (9)

- Heat from office equipment (10)

D Drafts from windows (11)

Drafts from vents (12)

Drafts falling from the ceiling (13)

My area is hotter than other areas (14)

My area is colder than other areas (15)

Thermostat is inaccessible (16)

Thermostat is adjusted by other people (17)

Clothing policy is not flexible (18)

Q7.6 Have you previously voiced concern about the thermal comfort at you workstation to a facility manager?

Yes (1)

No (2)

Q7.7 If your response to the previous question was yes, please provide details of your concern 
Q8.1 Air in Winter - Module 8Please select one of the following to express your level of satisfaction/dissatisfaction with the quality of air at your workspace in the wintertime (e.g. stuffy/stale air, cleanliness, odors etc.)?

Highly dissatisfied (1)

Dissatisfied (2)

Slightly dissatisfied (3)

O Neutral (4)

Slightly satisfied (5)

Satisfied (6)

Highly satisfied (7)

Q8.2 If your response to the question above was "Highly dissatisfied", "Dissatisfied" or "Slightly dissatisfied", which of the following could best describe your source(s) of dissatisfaction with temperature? (Check all that apply)

\begin{tabular}{|c|c|c|c|c|c|c|c|}
\hline & $\begin{array}{c}\text { Minor } \\
\text { problem (1) }\end{array}$ & $-(2)$ & $-(3)$ & $-(4)$ & $-(5)$ & $-(6)$ & $\begin{array}{c}\text { Major } \\
\text { problem (7) }\end{array}$ \\
\hline $\begin{array}{c}\text { Air is } \\
\text { stuffy/stale } \\
(1)\end{array}$ & 0 & 0 & 0 & 0 & 0 & 0 & 0 \\
$\begin{array}{c}\text { Air is not } \\
\text { clean (2) }\end{array}$ & 0 & 0 & 0 & 0 & 0 & 0 & 0 \\
$\begin{array}{c}\text { Air smells } \\
\text { bad (odors) } \\
\text { (3) }\end{array}$ & 0 & 0 & 0 & 0 & 0 & 0 & 0 \\
\hline
\end{tabular}

Q8.3 Heating in the Winter meets my needs:

Y Yes, Always (4)

Almost Always (5)

Almost Never (3)

O No, Never (6) 
Q8.4 Please rate your typical thermal comfort at your workstation in the winter:
Cold (1)
O Cool (2)
O Slightly Cool (3)
O Neutral (4)
O Slightly Warm (5)
O Warm (6)
$\mathrm{OHot}(7)$

Q8.5 Overall, does the air quality in your workspace in the winter enhance or interfere with your ability to accomplish work related tasks?
Highly Interferes (1)
O Moderately Interferes (2)
Slightly Interferes (3)
O Neutral (4)
O Slightly Enhances (5)
O Moderately Enhances (6)
O Highly Enhances (7)

Q8.6 Please indicate the clothing ensemble you typically wear in your office in this WINTER (or indicate the ensemble most similar to the one you typically wear in the WINTER):

Shorts or knee-length skirt, short-sleeve shirt (1)

Shorts or knee-length skirt, short-sleeve shirt, sweater or jacket (2)

O Shorts or knee-length skirt, long-sleeve top (3)

Shorts or knee-length skirt, long-sleeve shirt, long-sleeve sweater or jacket (4)

Trousers or ankle-length skirt, short-sleeve shirt (5)

Trousers or ankle-length skirt, short-sleeve shirt, sweater (6)

Trousers or ankle-length skirt, long-sleeve shirt (7)

Trousers or ankle-length skirt, long-sleeve shirt, sweater (8)

Trousers or ankle-length skirt, long-sleeve shirt, suit jacket (9)

O Trousers or ankle-length skirt, long-sleeve shirt, suit jacket, vest or T-shirt (10)

Trousers or ankle-length skirt, long-sleeve shirt, suit jacket, sweater, vest or T-shirt (11) 
Q9.1 Air in Summer - Module 9Please select one of the following to express your level of satisfaction/dissatisfaction with the quality of air at your workspace in the summertime (e.g. stuffy/stale air, cleanliness, odors etc.)?

Highly dissatisfied (1)

Dissatisfied (2)

Slightly dissatisfied (3)

O Neutral (4)

Slightly satisfied (5)

Satisfied (6)

Highly satisfied (7)

Q9.2 If your response to the question above was "Highly dissatisfied", "Dissatisfied" or "Slightly dissatisfied", which of the following could best describe your source(s) of dissatisfaction with temperature? (Check all that apply)

\begin{tabular}{|c|c|c|c|c|c|c|c|}
\hline & $\begin{array}{c}\text { Minor } \\
\text { problem (1) }\end{array}$ & $-(2)$ & $-(3)$ & $-(4)$ & $-(5)$ & $-(6)$ & $\begin{array}{c}\text { Major } \\
\text { problem (7) }\end{array}$ \\
\hline $\begin{array}{c}\text { Air is } \\
\text { stuffy/stale } \\
(1)\end{array}$ & 0 & 0 & 0 & 0 & 0 & 0 & 0 \\
$\begin{array}{c}\text { Air is not } \\
\text { clean (2) }\end{array}$ & 0 & 0 & 0 & 0 & 0 & 0 & 0 \\
$\begin{array}{c}\text { Air smells } \\
\text { bad (odors) } \\
\text { (3) }\end{array}$ & 0 & 0 & 0 & 0 & 0 & 0 & 0 \\
\hline
\end{tabular}

Q9.3 Cooling in the summer meets my needs:

Y Yes, Always (4)

Almost Always (5)

Almost Never (3)

O No, Never (6) 
Q9.4 Please rate your typical thermal comfort at your workstation in the summer:

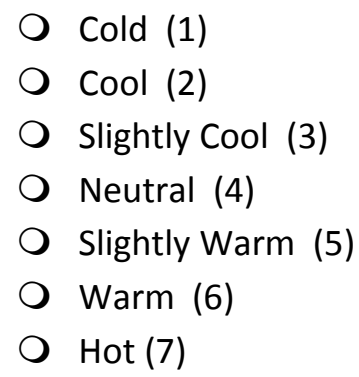

Q9.5 I appreciate that I have the option to open windows in the summer:

Y Yes, Always (1)

Almost, Always (2)

O Almost Never (3)

O No, Never (4)

Q9.6 I am concerned about allergens when the windows are open

Yes (1)

O No (2)

Q9.7 Overall, does the air quality in your workspace in the summer enhance or interfere with your ability to accomplish work related tasks?

Highly interferes (1)

O Moderately interferes (2)

Slightly interferes (3)

O Neutral (4)

Slightly enhances (5)

O Moderately enhances (6)

O Highly enhances (7) 
Q9.8 Please indicate the clothing ensemble you typically wear in your office in this SUMMER (or indicate the ensemble most similar to the one you typically wear in the SUMMER):

Shorts or knee-length skirt, short-sleeve shirt (1)

Shorts or knee-length skirt, short-sleeve shirt, sweater or jacket (2)

O Shorts or knee-length skirt, long-sleeve top (3)

Shorts or knee-length skirt, long-sleeve shirt, long-sleeve sweater or jacket (4)

Trousers or ankle-length skirt, short-sleeve shirt (5)

Trousers or ankle-length skirt, short-sleeve shirt, sweater (6)

Trousers or ankle-length skirt, long-sleeve shirt (7)

Trousers or ankle-length skirt, long-sleeve shirt, sweater (8)

Trousers or ankle-length skirt, long-sleeve shirt, suit jacket (9)

Trousers or ankle-length skirt, long-sleeve shirt, suit jacket, vest or T-shirt (10)

Trousers or ankle-length skirt, long-sleeve shirt, suit jacket, sweater, vest or T-shirt (11)

Q10.1 Interior Lighting - Module 10 Which of the following controls do you have over lighting in your workstation? (Check all that apply)

Light switch

Light dimmer

(2)

Window blinds or shades

None of these

$\square$ Other: (please specify) (5)

Q10.2 Please select one of the following to express your level of satisfaction/dissatisfaction with the quality of lighting in your workspace?

Highly dissatisfied (1)

Dissatisfied (2)

O Slightly dissatisfied (3)

O Neutral (4)

O Slightly satisfied (5)

O Satisfied (6)

Highly satisfied (7)
(1)

(3) 
Q10.3 If your response to the question above was "Highly dissatisfied", "Dissatisfied" or "Slightly dissatisfied", which of the following could best describe your source(s) of dissatisfaction with lighting? (Check all that apply)

Too dark/bright

$\square$ Daylight not enough

Electric lighting flickers

Too much daylight

(4)

$\square$ Too much electric lighting

- Not enough electric lighting

(6)

Shadows on the workspace

Reflections in the computer screen (8)

No task lighting

$\square$ Other: (please specify) (10)

Q10.4 How satisfied/dissatisfied are you with the visual comfort of the lighting (e.g., glare, reflections, contrast)?

O Highly dissatisfied (1)

Dissatisfied (2)

O Slightly dissatisfied (3)

O Neutral (4)

O Slightly satisfied (5)

O Satisfied (6)

Highly satisfied (7)

Q10.5 Overall, does the lighting quality in your workspace enhance or interfere with your ability to get your work done (i.e. reading, writing, thinking and concentration in general)?

O Highly interferes (1)

Moderately interferes (2)

O Slightly interferes (3)

O Neutral (4)

O Slightly enhances (5)

O Moderately enhances (6)

O Highly enhances (7) 
Q10.6 Do you have a window to the outside nearby?

Yes, in my office (1)

Yes, in the office next to me (2)

No, but there is a window across the corridor (3)

No, there is no window visible from my office (4)

Y Yes, there is a window visible from my office (5)

Q10.7 VIEW QUALITY Please answer the following question only if you have access to a view through a window. We would like to know your opinion of the view through the window from where you sit.

\begin{tabular}{|c|c|c|c|c|c|c|c|c|c|c|c|}
\hline & $\begin{array}{c}\text { Unattractive } \\
(1)\end{array}$ & $-(2)$ & $-(3)$ & $-(4)$ & $-(5)$ & $-(6)$ & $-(7)$ & $-(8)$ & $-(9)$ & $-(10)$ & $\begin{array}{c}\text { Attractive } \\
\text { (11) }\end{array}$ \\
\hline $\begin{array}{c}\text { Click } \\
\text { radio } \\
\text { button } \\
\text { to } \\
\text { select } \\
(1)\end{array}$ & 0 & 0 & 0 & 0 & 0 & 0 & 0 & 0 & 0 & 0 & 0 \\
\hline
\end{tabular}

Q11.1 Acoustics - Module 11 How disturbing do you find the noise (from all sources other than speech) that you hear at your workstation?

\begin{tabular}{|l|c|c|c|c|c|c|c|}
\hline & Very (1) & $-(2)$ & $-(3)$ & $\begin{array}{c}\text { Moderately } \\
(4)\end{array}$ & $-(5)$ & $-(6)$ & $\begin{array}{c}\text { Not at all } \\
\text { (7) }\end{array}$ \\
\hline $\begin{array}{c}\text { Click radio } \\
\text { button to } \\
\text { select (1) }\end{array}$ & 0 & 0 & 0 & 0 & 0 & 0 & 0 \\
\hline
\end{tabular}


Q11.2 How disturbing would you rate the following sounds at your workstation?

\begin{tabular}{|c|c|c|c|c|c|c|c|}
\hline & Very (1) & $-(2)$ & - (3) & $\begin{array}{l}\text { Moderately } \\
\text { (4) }\end{array}$ & - (5) & $-(6)$ & $\begin{array}{c}\text { Not at all } \\
\text { (7) }\end{array}$ \\
\hline $\begin{array}{l}\text { Noise from } \\
\text { heating, } \\
\text { ventilating } \\
\text { and cooling } \\
\text { systems (1) }\end{array}$ & 0 & 0 & 0 & 0 & 0 & 0 & 0 \\
\hline $\begin{array}{l}\text { Noise from } \\
\text { office } \\
\text { equipment } \\
\text { (e.g., } \\
\text { printers, } \\
\text { copiers, } \\
\text { computers, } \\
\text { telephones } \\
\text { ringing) (2) }\end{array}$ & 0 & 0 & 0 & 0 & 0 & 0 & $O$ \\
\hline $\begin{array}{l}\text { Noise from } \\
\text { washrooms } \\
\text { and other } \\
\text { plumbing } \\
\text { noises (3) }\end{array}$ & 0 & 0 & 0 & 0 & 0 & 0 & 0 \\
\hline $\begin{array}{l}\text { Noise from } \\
\text { outdoors } \\
\text { (e.g., road } \\
\text { traffic) (4) }\end{array}$ & 0 & 0 & 0 & 0 & 0 & 0 & 0 \\
\hline $\begin{array}{l}\text { Speech } \\
\text { sounds } \\
\text { from others } \\
\text { in your } \\
\text { building (5) }\end{array}$ & 0 & 0 & 0 & 0 & 0 & 0 & 0 \\
\hline $\begin{array}{c}\text { Non- } \\
\text { speech } \\
\text { sounds } \\
\text { generated } \\
\text { by others in } \\
\text { your } \\
\text { building } \\
\text { (e.g., } \\
\text { footsteps, } \\
\text { shuffling } \\
\text { papers) (6) }\end{array}$ & 0 & 0 & 0 & 0 & 0 & 0 & 0 \\
\hline
\end{tabular}


Q11.3 Please rate the privacy of your workstation (i.e., Do you feel you can have a private conversation or phone call at your workstation)?

\begin{tabular}{|l|c|c|c|c|c|c|c|}
\hline & $\begin{array}{c}\text { Not at all } \\
\text { private (1) }\end{array}$ & $-(2)$ & $-(3)$ & $\begin{array}{c}\text { Moderately } \\
\text { private (4) }\end{array}$ & $-(5)$ & $-(6)$ & $\begin{array}{c}\text { Very } \\
\text { private (7) }\end{array}$ \\
\hline $\begin{array}{c}\text { Click radio } \\
\text { button to } \\
\text { select (1) }\end{array}$ & 0 & 0 & 0 & 0 & 0 & 0 & 0 \\
\hline
\end{tabular}

Q11.4 At your workstation, how understandable are overheard conversations and phone calls from others in your building?

\begin{tabular}{|l|c|c|c|c|c|c|c|}
\hline & Very (1) & $-(2)$ & $-(3)$ & $\begin{array}{c}\text { Moderately } \\
(4)\end{array}$ & $-(5)$ & $-(6)$ & $\begin{array}{c}\text { Not at all } \\
(7)\end{array}$ \\
\hline $\begin{array}{c}\text { Click radio } \\
\text { button to } \\
\text { select (1) }\end{array}$ & 0 & 0 & 0 & 0 & 0 & 0 & 0 \\
\hline
\end{tabular}

Q11.5 How much do the following aspects of your workstation interfere with your ability to do your job?

\begin{tabular}{|c|c|c|c|c|c|c|c|}
\hline & Very (1) & $-(2)$ & $-(3)$ & $\begin{array}{c}\text { Moderately } \\
(4)\end{array}$ & $-(5)$ & $-(6)$ & $\begin{array}{c}\text { Not at all } \\
\text { (7) }\end{array}$ \\
\hline $\begin{array}{c}\text { Noise (from } \\
\text { all sources } \\
\text { other than } \\
\text { speech) } \\
\text { that you } \\
\text { hear at } \\
\text { your } \\
\text { workstation } \\
\text { (1) }\end{array}$ & 0 & 0 & 0 & 0 & 0 & 0 & 0 \\
$\begin{array}{c}\text { Overheard } \\
\text { speech } \\
\text { from others } \\
\text { in your area } \\
\text { (2) }\end{array}$ & 0 & 0 & 0 & 0 & 0 & 0 & 0 \\
\hline
\end{tabular}


Q12.1 Odours - Module 12When the air in your office smells bad (odor), which of the following would you perceive as the likely source(s)? (check all that apply)

Photocopiers/printers

(1)

a Food

(2)

Cleaning products

$\square$ Carpet or furniture

O Other people

口 Outside sources (Car exhaust) (6)

a Perfume

口 Outside sources (woodsmoke) (8)

口 Restaurant Kitchen (9)

口 Office Kitchen (10)

$\square$ Other (please specify) (11)

Q12.2 Overall, the odours and air quality at my workstation do not impact my ability to complete work related tasks?

Disagree (1)

Neither agree nor disagree (2)

O Agree (3)

Q12.3 Do you have any additional comments or concerns related to odours at your workstation? (If, so indicate yes and provide specific details in the comment field)

No (1)

Yes (please provide comment below) (2) 
Q13.1 Green Design Features - Module 13Please select the option that best expresses your agreement with the following statements...(strongly disagree, disagree, slightly disagree, neutral, slightly agree, agree, strongly agree)

\begin{tabular}{|c|c|c|c|c|c|c|c|}
\hline & $\begin{array}{c}\text { Strongly } \\
\text { Disagree } \\
\text { (1) }\end{array}$ & $\begin{array}{l}\text { Disagree } \\
\text { (2) }\end{array}$ & $\begin{array}{c}\text { Slightly } \\
\text { Disagree } \\
\text { (3) }\end{array}$ & Neutral (4) & $\begin{array}{c}\text { Slightly } \\
\text { Agree (5) }\end{array}$ & Agree (6) & $\begin{array}{c}\text { Strongly } \\
\text { Agree (7) }\end{array}$ \\
\hline $\begin{array}{l}\text { I have a good } \\
\text { understanding } \\
\text { of the green } \\
\text { features of } \\
\text { this building... } \\
\text { (1) } \\
\text { I would like to } \\
\text { learn more } \\
\text { about the } \\
\text { green } \\
\text { features of } \\
\text { this building... } \\
\text { (2) } \\
\text { I would like } \\
\text { more } \\
\text { guidance } \\
\text { about how I } \\
\text { can support } \\
\text { the green } \\
\text { initiatives of } \\
\text { this building... } \\
\text { ( } 3 \text { ) } \\
\text { I have an } \\
\text { understanding } \\
\text { of the solar } \\
\text { chimney } \\
\text { cooling } \\
\text { system, and } \\
\text { feel I know } \\
\text { when I should } \\
\text { open the } \\
\text { windows (4) }\end{array}$ & 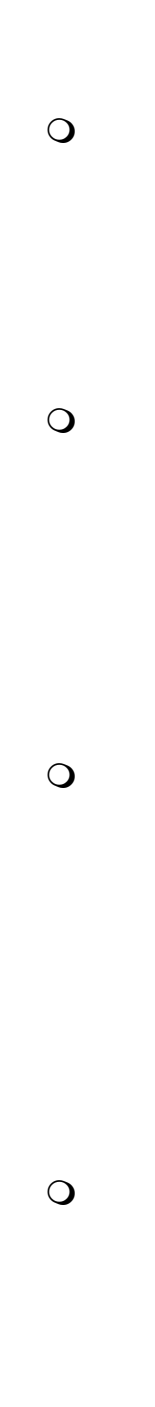 & . & . & . & . & . & 0 \\
\hline
\end{tabular}


Q14.1 Your Overall Satisfaction - Module 14 For the following questions, please select the button that best expresses your satisfaction with the...

\begin{tabular}{|c|c|c|c|c|c|c|c|}
\hline & $\begin{array}{c}\text { Very } \\
\text { Unsatisfactor } \\
\text { y (1) }\end{array}$ & $\begin{array}{c}\text { Unsatisfactor } \\
\text { y (2) }\end{array}$ & $\begin{array}{l}\text { Somewhat } \\
\text { Unsatisfactor } \\
\text { y (3) }\end{array}$ & $\begin{array}{l}\text { Neutra } \\
\text { I (4) }\end{array}$ & $\begin{array}{c}\text { Somewhat } \\
\text { Satisfactor } \\
\text { y (5) }\end{array}$ & $\begin{array}{c}\text { Satisfactor } \\
\text { y (6) }\end{array}$ & $\begin{array}{c}\text { Very } \\
\text { Satisfactor } \\
\text { y (7) }\end{array}$ \\
\hline $\begin{array}{l}\text { Amount of } \\
\text { lighting on } \\
\text { the desktop } \\
\text { (1) }\end{array}$ & 0 & 0 & 0 & 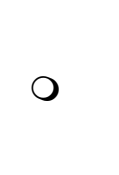 & 0 & 0 & 0 \\
\hline $\begin{array}{l}\text { Overall air } \\
\text { quality in } \\
\text { your work } \\
\text { area (2) }\end{array}$ & 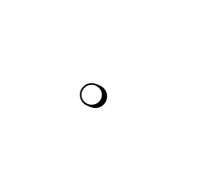 & 0 & 0 & 0 & 0 & 0 & 0 \\
\hline $\begin{array}{l}\text { Temperature } \\
\text { in your work } \\
\text { area (3) }\end{array}$ & 0 & 0 & 0 & 0 & 0 & 0 & 0 \\
\hline $\begin{array}{c}\text { Aesthetic } \\
\text { appearance } \\
\text { of your office } \\
\text { (4) }\end{array}$ & 0 & 0 & 0 & 0 & 0 & 0 & 0 \\
\hline $\begin{array}{l}\text { Level of } \\
\text { privacy for } \\
\text { conversation } \\
\text { s in your } \\
\text { office (5) }\end{array}$ & 0 & 0 & 0 & 0 & 0 & 0 & 0 \\
\hline $\begin{array}{c}\text { Level of } \\
\text { visual privacy } \\
\text { within your } \\
\text { office (6) }\end{array}$ & 0 & 0 & 0 & 0 & 0 & 0 & 0 \\
\hline $\begin{array}{l}\text { Amount of } \\
\text { noise from } \\
\text { other } \\
\text { people's } \\
\text { conversation } \\
\text { s while you } \\
\text { are at your } \\
\text { workstation } \\
\text { (7) }\end{array}$ & 0 & 0 & 0 & 0 & 0 & 0 & 0 \\
\hline $\begin{array}{l}\text { Size of your } \\
\text { personal } \\
\text { workspace to } \\
\text { accommodat } \\
\text { e your work, } \\
\text { materials, } \\
\text { and visitors } \\
\text { (8) }\end{array}$ & 0 & 0 & 0 & 0 & 0 & 0 & 0 \\
\hline $\begin{array}{l}\text { Amount of } \\
\text { background }\end{array}$ & 0 & 0 & 0 & 0 & 0 & 0 & 0 \\
\hline
\end{tabular}




\begin{tabular}{|c|c|c|c|c|c|c|c|}
\hline $\begin{array}{l}\text { noise (i.e. not } \\
\text { speech) you } \\
\text { hear at your } \\
\text { workstation } \\
\text { (9) }\end{array}$ & & & & & & & \\
\hline $\begin{array}{l}\text { Amount of } \\
\text { light for } \\
\text { computer } \\
\text { work (10) }\end{array}$ & 0 & 0 & 0 & 0 & 0 & 0 & 0 \\
\hline $\begin{array}{l}\text { Amount of } \\
\text { reflected } \\
\text { light or glare } \\
\text { on the } \\
\text { computer } \\
\text { screen (11) }\end{array}$ & 0 & O & 0 & 0 & 0 & 0 & 0 \\
\hline $\begin{array}{c}\text { Air } \\
\text { movement in } \\
\text { your work } \\
\text { area (12) }\end{array}$ & 0 & O & 0 & 0 & 0 & 0 & 0 \\
\hline $\begin{array}{l}\text { Your ability } \\
\text { to alter } \\
\text { physical } \\
\text { conditions in } \\
\text { your work } \\
\text { area (13) }\end{array}$ & 0 & O & 0 & 0 & 0 & 0 & 0 \\
\hline $\begin{array}{c}\text { Your access } \\
\text { to a view of } \\
\text { outside from } \\
\text { where you sit } \\
\text { (14) }\end{array}$ & 0 & O & 0 & 0 & 0 & 0 & 0 \\
\hline $\begin{array}{c}\text { Distance } \\
\text { between you } \\
\text { and other } \\
\text { people you } \\
\text { work with } \\
\text { (15) }\end{array}$ & 0 & 0 & 0 & 0 & 0 & 0 & 0 \\
\hline
\end{tabular}


Q14.2 Please select the button that best estimates how the PHYSICAL CONDITIONS of your workstation (e.g. desk, desk location, chair, computer screen, window location); enhance or interfere with your ability to complete tasks?

- Highly interferes (1)

Moderately interferes (2)

Slightly interferes (3)

Neutral (4)

Slightly enhances (5)

Moderately enhances (6)

- Highly enhances (7)

- Comment: If you select this response, please provide comment below indicating which aspect of your physical conditions that is most interfering... (8)

Q14.3 Considering all of the ENVIRONMENTAL CONDITIONS at your workstation (e.g. air quality, temperature, lighting, acoustics, odours); what is your degree of satisfaction with the indoor environment quality at your workstation?

Very Unsatisfactory (1)

unsatisfactory (2)

Somewhat Unsatisfactory (3)

Deutral (4)

$\square$ Somewhat Satisfactory (5)

Satisfactory (6)

Very Satisfactory (7)

Comment: If you select this response, please provide comment below indicating which aspect of the indoor environmental quality that is most unsatisfactory... (8)

Q14.4 Have we missed anything? If you would like to provide any other comments about the physical or environmental conditions of the workplace, please indicate YES and provide comment...

O NO (1)

O YES... (2)

Appendix D, Figure 1. Building Occupant Survey 


\section{References}

ABAA. (2015). Air Barrier Association of America Standard Test Method, 1-32.

Allen, E., \& lano, J. (2009). Fundamentals of building construction: Materials and methods. Wiley.

ASHRAE. (2013). ASHRAE Standard 55-2013 Acceptable Thermal Indoor Environments. American Society for Heating Refrigetation and Air Conditioning Engineers.

ASHRAE. (2013). ASHRAE Standard 62.2-2010 Ventilation for acceptable indoor air quality. American Society for Heating Refrigetation and Air Conditioning Engineers.

Berkeley Lab. (2016). Introduction to VOCS and Health. Retrieved from https://iaqscience.Ibl.gov/vocintro

Bertoldi, P., Hinge, A., Waide, P. (2006). Comparing Commercial Building Energy Use Around the World. ACEEE Panel Paper.

Birt, B., Newsham, G. (2009). Post Occupancy Evaluation of Energy and Indoor Environmental Quality in Green Buildings. National Research Council of Canada.

Building Owners and Managers Association. (2014). Experience Exchange Report. http://www.boma.org/research/pages/eer.asp. Accessed 17 ${ }^{\text {th }}$ November 2016.

Burge, P. S. (2004). Sick building syndrome. Occupational and Environmental Medicine, 61(2), 185-190. http://doi.org/10.1136/oem.2003.008813

Center for Disease Control. (1991). Building air quality: A guide for building owners and facility managers.

Chartered Institute of Builidng Service Engineers - PROBE Post Occupancy Studies. (2001). http://www.cibse.org/knowledge/probe-post-oc-occupancy-studies. Accessed $17^{\text {th }}$ August 2016.

Commercial Buildings Energy Consumption Survey (2016). http://www.eia.gov/consumption/commercial/. Accessed 20 th November 2016.

Cullen, M. R., Redlich, C. A., \& Sparer, J. (1997). Sick-building syndrome. The Lancet. http://doi.org/10.1016/S0140-6736(05)63914-1

Deuble, M. P., \& de Dear, R. J. (2012). Green occupants for green buildings: The missing link? Building and Environment, 56, 21-27. http://doi.org/10.1016/j.buildenv.2012.02.029

Energy Star, E. (2012a). DataTrends Energy Use Benchmarking.

Energy Star, E. (2012b). DataTrends Water Use Tracking.

Environment Canada. (2011). National Inventory Report: Greenhouse Gas Sources and Sinks in Canada, Part 3.

Environmental Protection Agency. (2016). GHG Equivalencies Calculator.

Fennell, H. C., \& Haehnel, J. (2005). Setting airtightness standards. ASHRAE Journal, 47(9), 26-31.

Gorgolewski, M., Brown, C., Chu, A. M., Turcato, A., Bartlett, K., Ebrahimi, G., \& Scannell, L. (2015). How 
well do our green buildings perform.

Halsall Associates. (2012). Building Enclosure Air Leakage Evaluation, Ontario Architecture Association.

Hutcheon, N. B., \& Handegord, G. O. (1995). Building science for a cold climate. National Research Council of Canada. Ottawa.

Hill-Mallory, S., Preiser, W., Watson, C. (2012) Enhancing Building Performance. John Wiley \& Sons. Oxford, U.K.

Intergovernmental Panel on Climate Change. (2007). Climate Change: The Physical Science Basis. Geneva, $\mathrm{CH}$.

Kesik, T. (2015). Vital signs: Towards meaningful building performance indicators. Green Paper.

Krigger, J. (2004). Residential energy: Cost savings and comfort for existing buildings. Saturn Resource Management, Inc.

Malory-Hill, S., Preiser, W., Watson, C. (2012) Enhancing Builidng Performance. Wiley-Blackwell.

Menezes, A. C., Cripps, A., Bouchlaghem, D., \& Buswell, R. (2012). Predicted vs. actual energy performance of non-domestic buildings: Using post-occupancy evaluation data to reduce the performance gap. Applied Energy, 97, 355-364. http://doi.org/10.1016/j.apenergy.2011.11.075

Natural Resources Canada. (2009) Survey of Commercial and Institutional Builidng Energy Use.

Newsham, G. (2009) Do LEED Buildings Save Energy, Yes, But...Energy and Buildinds, 14 (8), 897 - 905.

Newsham, G., Birt, B., Arsenault, C., Thompson, L., Veitch, J. Mancini, S., Galasiu, A., Gover, B., Macdonald, I., Burns, G. (2012). Do Green Buildings Outperform Conventional Buildings. Indoor Environment and Energy Performance in North American Offices. Natural Resources Canada.

Preiser, W., Vischer, J. (2005) Assessing Building Performance. Elsevier Publications. Burlington MA.

Red River College. (2015a). Airtightness in existing multi-unit residential buildings: Field trials of a new test protocol. Retrieved from http://blogs.rrc.ca/betac/wp-content/uploads/2016/03/CMHC-FinalReport.pdf

Red River College. (2015b). Final report: An investigation of airtightness in manitoba's commercial building sector. Retrieved from http://blogs.rrc.ca/betac/wp-content/uploads/2016/03/MB-HydroAir-Leakage.pdf

Shield, B. (2009). Review of research on office acoustics A report for the Association of Interior Specialists. Retrieved from http://thefis.org/assets/Uploads/Acoustic-Guide/Review-of-research-on-officeacoustics.pdf?utm_campaign=Office\%2BGossip\%2BWeekly\&utm_source=Office_Gossip_Weekly_6

Straube, J. (2012). High performance enclosures: Design guide for institutional, commercial, and industrial buildings in cold climates. Building Science Press.

U.S.Green Building Council (2015). The Business Case For Green Buildings. Accessed 17 October 2015, from http://www.usgbc.org/articles/business-case-green-building 
Waite, M. B., \& O'Brien, S. M. (2010). Air leakage: Difficulties in measurement, quantification, and energy simulation. New York.

Worthen, W. J. (2011). Sustainable AIA: 2031 - Why energy models don't predict actual energy use.

Retrieved 15 November 2015, from http://www.aia.org/practicing/AIAB088189\#

World Health Organization. (2010). WHO Guidelines for Indoor Air Quality. 